\title{
VI.
}

\section{Ueber die Folgen einer ausreichenden, aber eiweissarmen Nahrung. Ein Beitrag zur Lehre vom Eiweissbedarf.}

\author{
Von Immanuel Munk in Berlin.
}

Die grundlegenden Untersuchungen von Bidder und C. Schmidt, in noch höherem Grade die von Th. Bischoff und C. Voit, die weiterhin von Voit allein fortgeführt und im Verein mit v. Pettenkofer mannichfach erweitert und vertieft worden sind, haben die Bedeutung des Eiweiss als Nährstoff, die Bedingungen seines Umsatzes and Verbrauches im Körper des Hundes und des Menschen aufgedeckt. Die insbesondere aus Voit's Beobachtungen abgeleiteten Gesetze der Ernährung des Fleischfressers und des Menschen bestehen, der Hauptsache nach, noch heute, also 3 Decennien nach ihrer ersten Aufstellung, zu Recht, doch haben die von anderen Forschern seit etwa 20 Jahren durchgeführten Untersuchungen in Bezug auf eine Reihe thatsächlicher Befunde und nicht minder auf die theoretische Auffassung der Vorgänge des stofflichen Verbrauches und der Ernährung wesentliche, z. Th. grundsätzliche Modificationen der Voit-Pettenkofer'schen Lehren zur Folge gehabt. Insbesondere trifft dies für die Frage des Eiweissumsatzes und Eiweissbedarfes zu. In dieser Hinsicht hatte Voit den Satz aufgestellt, dass der Eiweissumsatz an den späteren Hungertagen (etwa vom 4. Tage ab) der niedrigste wäre, der je vorkäme, das sog. „typische Hungerminimum" und dass dieser niederste Eiweissumsatz durch jede Eiweisszufuhr, gleichviel wie gross die Menge der daneben gereichten eiweisssparenden Stoffe (Leim, Koblehydrate, Fette) sei, stets erheblich überschritten werde. Für den erwachsenen Menschen hatte endlich Voit auf Grund von Ermittelungen und Berechnungen den Eiweissbedarf für Ruhe oder leichte Arbeit bei Darreichung der nöthigen Menge N-freier Stoffe (Kohlehydrate, Fett) 
zu $118 \mathrm{~g}$ täglich angesetzt, ein Werth, unter den die Zufuhr höchstens vorübergehend sinken dürfe, wenn nicht der Körperbestand, das Wohlbefinden und die Leistungsfähigkeit leiden soll. Diese 3 Sätze Voit's sind auf Grund experimenteller Beobachtungen und statistischer Ermittelungen wiederholt wirksam angegriffen und erschüttert worden; zweifellos sind sie in der dogmatischen Form, wie sie Voit aufgestellt hat, nicht mehr aufrecht zu erhalten.

Die erste, beiläufig gemachte Beobachtung, dass bei reichlicher Aufnahme $\mathrm{N}$-freier Stoffe der Eiweissumsatz auf ein erstaunlich niedriges Maass herabgedrückt werden kann, rührt von E. Salkowski ) her: ein Hund von $20 \mathrm{~kg} \mathrm{kam}$ bei einem aus $50 \mathrm{~g}$ condensirter Milch, $50 \mathrm{~g}$ Speck und $150 \mathrm{~g}$ Brod bestehenden Futter, in dem der Berechnung nach $21 \mathrm{~g}$ Eiweiss mit $3,35 \mathrm{~g} \mathrm{~N}$ enthalten waren, nach etwa 10 Tagen auf eine N-Ausscheidung von rund $3 \mathrm{~g}$, während derselbe Hund im vollständigen Hungerzustande noch 2,6-3 g N entleerte. Bei einem kleinen Hunde Rubner's ${ }^{2}$ ) von $6,5 \mathrm{~kg}$ betrug der Harn-N bei der Inanition 2,97-1,9g und sank bei reichlicher Zuckerfütterung während einiger Tage auf 1,64-1,04g. Unter das typische Hungerminimum jst für längere Zeit der Eiweissumsatz in einer Versuchsreihe von mir ${ }^{3}$ ) gesunken. Ein Hund von $28 \mathrm{~kg}$, der durch 31 tägiges Hungern eiweissarm geworden und durch nachfolgende 12 tägige Fütterung mit je $200 \mathrm{~g}$ Fleisch unter Beigabe von $100 \mathrm{~g}$ Leim und $200 \mathrm{~g}$ Kohlehydraten im Ganzen nur $600 \mathrm{~g}$ Fleisch angesetzt hatte, konnte durch Zusatz von $500 \mathrm{~g}$ Kohlehydrate zu nur $200 \mathrm{~g}$ Fleisch (ohne Leim) im Fleischumsatz ${ }^{4}$ ) bis auf $122 \mathrm{~g}$, entsprechend einem $\mathrm{N}$-Umsatz von $4,14 \mathrm{~g}$, herabgedrückt werden, während derselbe Hund selbst in der späteren Hungerperiode (22. Tag) noch immer $160 \mathrm{~g} \mathrm{Fleisch}=5,44 \mathrm{~g} \mathrm{~N}$ zerstört hatte. Die aus den nachfolgenden Untersuchungen mitzutheilenden Beobachtungen lehren, dass bei einem weiten Nährstofiverhältniss

1) Zeitschr. f. physiol. Chem. I. S. 44. 1877.

2) Zeitschr. f. Biologie. Bd. 19. S. 326.

3) Dieses Archiv. Bd. 101. S. 112. 1885.

4) d. h. im Sinne Voit's der Zerfall eiweissreichen Gewebes, nach Art des Muskelfleisches, mit $3,4 \mathrm{pCt}$. N. 
(N-haltige $\mathrm{zu} \mathrm{N}$-freien Stoffen wie $1: 12-14$ ) und beim Ueberwiegen der Kohlehydrate in der Nahrung es gelingt, den Eiweissumsatz von derartig gefütterten $9-12 \mathrm{~kg}$ schweren Hunden Wochen lang auf $12,5 \mathrm{~g}$, entsprechend $2 \mathrm{~g} \mathrm{~N}$ täglich, zu halten. Aehnlich wie beim Hunde habe ich auch beim Menschen ${ }^{1}$ ) die bemerkenswerthe Beobachtung machen können, dass im Anschluss an eine 6tägige Hungerperiode am darauf folgenden 2. Esstage, an dem $101 \mathrm{~g}$ Eiweiss (neben $309 \mathrm{~g}$ Kohlehydrat und $139 \mathrm{~g}$ Fett) genossen wurden, nur $54 \mathrm{~g}$ Eiweiss, entsprechend $8,3 \mathrm{~g} \mathrm{~N}$, umgesetzt worden sind $d$. h. noch um $\frac{1}{6}$ weniger als am 6. Hungertage. Gelegentlich seiner Ausnützungsversuche beim Menschen hat Rubner ${ }^{2}$ ) an 3 Versuchstagen, an denen im Mittel je $3077 \mathrm{~g}$ Kartoffeln und $147 \mathrm{~g}$ Fett genossen worden sind (mit $11,45 \mathrm{~g} \mathrm{~N}$ ), die N-Ausscheidung durch den Harn auf 12,8, 7,6 und $6 \mathrm{~g} \mathrm{~N}$ heruntergehen gesehen, ohne diese Befunde hervorzuheben.

Weiter sind F. Hirschfeld ${ }^{3}$ ) und Kumagawa ${ }^{4}$ ) in Selbstversuchen zu dem Ergebniss gelangt, dass bei sehr reichlicher Ration von Kohlehydraten (354 g neben $44 \mathrm{~g}$ Eiweiss und $165 \mathrm{~g}$ Fett bezw. $570 \mathrm{~g}$ Kohlehydrat neben $55 \mathrm{~g}$ Eiweiss) für 2-8 Tage der N-Umsatz auf $6 \mathrm{~g}$, entsprechend $38 \mathrm{~g}$ Eiweiss (180 $\mathrm{g}$ Fleisch) herabgedrückt werden kann. Endlich hat F. Klemperer ${ }^{5}$ ) seine 2 Versuchsindividuen mit $406 \mathrm{~g}$ Kohlehydraten neben $262 \mathrm{~g}$ Fett, $200 \mathrm{~g}$ Alkohol und $30 \mathrm{~g}$ Eiweiss für 2-3 Tage bis auf einen Umsatz von 2,6 $\mathrm{g} \mathrm{N}$ täglich reducirt. In diesen 3 Fällen ist somit der $\mathrm{N}$-Umsatz noch unter das typische Hungerminimum heruntergegangen; zugleich ist für die angegebene Zeitdauer des niedrigen Eiweissumsatzes $\mathrm{N}$ - und Körpergleichgewicht behauptet event. sogar ein geringfügiger $\mathrm{N}$-Ansatz erzielt worden.

Somit dürfte für den Menschen als erwiesen gelten, dass bei sehr reichlicher Ration von Kohlehydraten (ohne oder mit Fett) mit einem niedrigen Eiweissquantum, $40-50 \mathrm{~g}$ für den Tag, $\mathrm{N}$ - und Körpergewicht, wenigstens für 2-8 Tage, behauptet

1) I. Munk, Med. CentralbJ. 1889. S. 835; dies Archiv Bd. 131. Suppl. S. 224.

2) Zeitschr. f. Biologie. Bd. 15. S. 147.

3) Dieses Archiv. Bd. 114. S. 350.

4) Ebenda. Bd. 116. S. 370.

5) Arch. f. (Anat. u.) Physiol. 1889. S. 361; Zeitschr. f. klin. Med. XVI, Sonderabzug S. $46 \mathrm{ff}$. 
werden kann. Ob aber auch für die Dauer, unbeschadet des Wohlbefindens und der körperlichen Leistungsfähigkeit, das Leben mit einer so kleinen Eiweissration, die nur $\frac{1}{3}-\frac{2}{5}$ von der Voit'schen Norm (118 g Eiweiss) beträgt, gefristet werden kann, das bliebe noch zu ermitteln. Da diese Frage kaum durch den Versuch am Menschen, annäherungsweise vielleicht auf dem Wege statistischer Ermittelung des Eiweissconsums bei den verschiedenen, angeblich nur wenig Eiweiss geniessenden Völkerstämmen erledigt werden kann - ich komme auf diesen Punkt im letzten Abschnitt zurück -, so schien es mir angezeigt, durch Wochen und Monate lang durchzuführende Versuche am Hunde zu ermitteln, welches die Folgen eiweissarmer, aber an Fetten und Kohlehydraten so gehaltreicher Nahrung sind, bei der durch Wochen hindurch zunächst N- und Körpergleichgewicht erzielt wird. Ich bin nunmehr in der Lage, über Versuchsreihen an 4 Hunden berichten zu können, die durch je mehrere Monate im thierphysiologischen Laboratorium der hiesigen Landwirthschaftlichen Hochschule durchgeführt worden sind, dessen Vorsteher Herrn Prof. N. Zuntz ich für sein liebenswürdiges Entgegenkommen zu aufrichtigem Dank verbunden bin. Ueber die erste Versuchsreihe habe ich vor 2 Jahren einen kurzen Bericht gegeben ${ }^{1}$ ).

Die Herabsetzung des Eiweissumsatzes beim Hunde auf einen sehr niedrigen Stand durch reichliche Beigabe von Kohlehydraten, mit oder ohne Fett, hat Voit, so zahlreich auch seine darauf bezüglichen Versuchsreihen sind, nicht erzielt, da sein grosser Hund von rund $30 \mathrm{~kg}$ selbst bei $300 \mathrm{~g}$ Stärkemehl oder Zucker immer noch $400 \mathrm{~g}$ Fleisch $=13,6 \mathrm{~g} \mathrm{~N}$ brauchte, um auf $\mathrm{N}$-Gleichgewicht zu gelangen ${ }^{2}$ ). In meiner, bereits angezogenen Versuchsreihe am Hund von rund $24 \mathrm{~kg}$ ist es mir gelungen, durch Zugabe von $500 \mathrm{~g}$ Kohlehydraten den Umsatz für längere Zeit, 2-3 Wochen, auf 170-122 g Fleisch, entsprechend 4,14 bis $5,78 \mathrm{~g} \mathrm{~N}$ herabzudrücken d. h. auf $0,16-0,24 \mathrm{~g} \mathrm{~N}$ pro Körperkg.

i) Verhandl. d. Physiol. Gesellsch. zu Berlin, Sitz. vom 18. Febr. 1891; abgedruckt im Arch. f. (Anat. u.) Physiol. 1891. S. 338.

2) Bisch off und Voit, Gesetze der Ernährung des Fleischfressers. 1860. S. 153. - Voit, Zeitschr. f. Biologie. Bd.5. S. 431. - Pettenk ofer und Voit, ebenda. Bd.9. S. 435. 
Gelegentlich auf andere Fragen gerichteter Versuche habe ich mich überzeugt, dass Mittelhunde von $10-15 \mathrm{~kg}$, deren $\mathrm{N}$ Umsatz pro Körperkg bekanntlich beträchtlicher ist als der grosser Hunde von $25-35 \mathrm{~kg}$, bei einem Futter mit dem Nährstoffverhältniss $1: 7$ längere Zeit auf einem Umsatz von 0,3 bis $0,35 \mathrm{~g} \mathrm{~N}$ und durch längere Zeit hindurch auf $\mathrm{N}$-Gleichgewicht erhalten werden können, und dass gerade solche Versuchsanordnungen, bei denen durch grössere Mengen von Kohlehydraten und mässige Fettgaben ein nur niedriger Eiweissumsatz unterhalten wird, zur Lösung von Fragen über den Einfluss der verschiedensten Agentien auf den Eiweisszerfall im Körper, grössere Ausschläge (und daher eindeutige Entscheidungen) liefern, als die von Voit zumeist bevorzugte Methode, die Prüfung, ob ein Agens den Eiweissumsatz steigert oder verringert, bei hoher Eiweisszufuhr und, dem entsprechend, hohem Eiweissumsatz, oder was z. Th. noch grössere Unsicherheiten bietet, im Hungerzustande vorzunehmen.

Unsere Frage direct anlangend, liegen in der Literatur bisher nur vereinzelte Angaben vor. In Versuchen, die Potthast ${ }^{1}$ ) unter Leitung von Zuntz angestellt hat, schien bei einem Futter mit nur mässigem Eiweissgehalt $(4,3 \mathrm{~g} \mathrm{~N}$ bei einem Hunde von $3,5 \mathrm{~kg}$ ) mit der Dauer der Fütterung die Ausnützung progressiv schlechter zu werden. In demselben Laboratorium hat Th. Rosenheim ${ }^{2}$ ) bei einem Hunde von $7,5 \mathrm{~kg}$ bei einer Tageszufuhr von $30 \mathrm{~g}$ Fleisch mit $1,3 \mathrm{~g} \mathrm{~N}$ neben $98 \mathrm{~g}$ Kohlehydrate und $42 \mathrm{~g}$ Fett letzteres zu 4,9 pCt. unbenutzt ausgestossen werden sehen, während bei Steigerung der Zufuhr auf $6,3 \mathrm{~g} \mathrm{~N}$ (neben $53 \mathrm{~g}$ Fett und $120 \mathrm{~g}$ Kohlehydrat) vom Fett nur $1,8 \mathrm{pCt}$. unbenntzt blieben. Bei einer Tagesration von $150 \mathrm{~g}$ Fett neben nur $50 \mathrm{~g}$ Fleisch $(1,7 \mathrm{~g} \mathrm{~N})$ blieben bei demselben Hund in einer 3tägigen Periode $4 \mathrm{pCt}$, in einer 6 tägigen sogar $9 \mathrm{pCt}$. Fett unresorbirt, dagegen bei Steigerung der Fleischmenge bis auf $380 \mathrm{~g}$ (mit $12,9 \mathrm{~g} \mathrm{~N}$ ) nur $2-3$ pCt. vom Fett. Aus diesen Beobachtungen geht somit hervor, dass bei eiweissarmem Futter die Ausnutzung grosser Fettgaben etwas schlechter ist als bei eiweissreichem Futter.

1) Dissert. Leipzig 1887.

2) Pflüger's Arch. Bd. 46. S. 421. 
Erste Versuchsreihe.

$\mathrm{Zu}$ dieser Reihe, die am 4. November 1890 begonnen worden ist, diente eine Hündin von $11,7 \mathrm{~kg}$. Der Harn wurde durch den Katheter, der Koth durch Knochen abgegrenzt. Die Tagesration bestand aus $130 \mathrm{~g}$ Fleisch, $35 \mathrm{~g}$ Schmalz und $90 \mathrm{~g}$ Reiss, mit $600 \mathrm{ccm}$ Wasser abgekocht. Das Futter bot $34 \mathrm{~g}$ Eiwe is (mit $5,06 \mathrm{~g} \mathrm{~N}$ ), $38 \mathrm{~g}$ Fett und $70 \mathrm{~g} \mathrm{Kohlehydrate,} \mathrm{im} \mathrm{Ganzen}$ $144 \mathrm{~g}$ Trockensubstanz; Verhältniss der N-haltigen zu den Nfreien Nährstoffen wie 1:5. Mit dieser, im Ganzen 742 Calorien oder $66 \mathrm{Cal}$. pro Körperkg bietenden Ration kam der Hund, nachdem er zunächst $400 \mathrm{~g}$ von seinem Gewicht eingebüsst hatte, schon am 7. Tage in's N-Gleichgewicht. Zur grösseren Sicherheit wurde die Fütterung noch 19 Tage fortgesetzt und während dieser 20 Tage $\mathrm{N}$ - und Körpergleichgewicht constatirt.

Im Harn und Koth wurde $\mathrm{N}$ nach Kjeldahl bestimmt. Zur Ermittelung der durch den Koth ausgestossenen Fettkörper wurde der Koth getrocknet, fein pulverisirt, ein aliquoter Theil des Pulvers im Soxhlet'schen Apparate durch mindestens 24 Stunden mit Aether extrahirt (das Aetherextract entbält Neutralfett, freie Fettsäuren, Cholesterin), dann das rückständige Pulver mit salzsaurem Alkohol angerührt, getrocknet und danach abermals mit Aether erschöpft; dies zweite, saure Aetberextract entbält im Wesentlichen die den präformirten Kothseifen entsprechenden Fettsäuren.

Ueber die Ausscheidungsverhältnisse in dieser Periode giebt folgende Tabelle Aufschluss:

\begin{tabular}{|c|c|c|c|}
\hline Nov. 10. & $\begin{array}{c}\text { Harn-N } \\
4,791\end{array}$ & Koth-N & $\underset{11,37}{\text { Gewicht } \mathrm{kg}}$ \\
\hline 11. & 4,564 & & 11,41 \\
\hline 12. & 4,71 & & 11,35 \\
\hline 13. & 4,643 & & 11,29 \\
\hline 14. & 4,586 & & 11,25 \\
\hline 15. & 4,627 & & 11,24 \\
\hline 16. & 4,46 & & 11,16 \\
\hline 17. & 4,578 & 1,00工 & 11,19 \\
\hline 18. & 4,466 & oder pro 1ag & 11,25 \\
\hline 19. & 4,322 & & 11,22 \\
\hline
\end{tabular}

1) In 4 Tagen $121,3 \mathrm{~g}$ Koth feucht $=36,2 \mathrm{~g}$ trocken, entsprechend $6,3 \mathrm{pCt}$. der Einfuhr an Trockensubstanz.

$0,931 \mathrm{~g}$ Trockenkoth geben $0,044 \mathrm{~g} \mathrm{~N}$.

$8,743 \mathrm{~g}$

- $\quad$ neutrales Aetherextract $=0,5844 \mathrm{~g}$

$\frac{\text { saures }-\frac{-3175}{\text { also an Fettkörpern }}=0,9019 \mathrm{~g}}{0 .}$




$\begin{array}{rccc} & \text { Harn-N } & \text { Koth-N } & \text { Gewicht kg } \\ \text { Nov. 20. } & 4,541 & 11,2 \\ 21 . & 4,609 & 11,24 \\ 22 . & 4,484 & 11,22 \\ 23 . & 4,46 & 11,29 \\ 24 . & 4,536 & 11,21 \\ 25 . & 4,582 & 11,19 \\ 26 . & 4,497 & 11,24 \\ 27 . & 4,528 & 11,18 \\ 28 . & 4,561 & 11,2 \\ 29 . & 4,498 & 11,21\end{array}$

Im Ganzen wurden in diesen 20 Tagen durch den Harn $90,953 \mathrm{~g} \mathrm{~N}$ oder pro Tag 4,55 g entleert, dazu $0,39 \mathrm{~g}$ durch den Koth $^{1}$ ), macht zusammen $4,94 \mathrm{~g}$ N. Das Futter bot $5,06 \mathrm{~g} \mathrm{~N}$, also bestand zum Mindesten N-Gleichgewicht. Auch das Körpergewicht hielt sich in den letzten 14 Tagen um $11,2 \mathrm{~kg}$ herum.

Nachdem so durch die Erhaltung von N- und Körpergleichgewicht die bisher gegebene Ration für den Bestand des Körpers als ausreichend erwiesen war, wurde vom 30 . November ab die e iwe is sarme Kost

eingeleitet; die Hälfte des Futtereiweiss $(17 \mathrm{~g})$ wurde fortgelassen und durch die nach Rubner isodyname Menge von Kohlehydraten (17 g Stärkemehl) ersetzt, so dass nunmehr die Nahrung $17 \mathrm{~g}$ Eiweiss (mit 2,64 g N), $38 \mathrm{~g}$ Fett und $87 \mathrm{~g} \mathrm{Kohlehydrate}$ bot, die in Form von $40 \mathrm{~g}$ Fleisch, $37 \mathrm{~g}$ Schmalz und $113 \mathrm{~g}$ Reiss, wiederum mit $600 \mathrm{ccm}$ Wasser abgekocht, gereicht wurden, so dass sich an dem calorischen Werthe der Nahrung (742 Cal.) und an dem Gehalt an Trockensubstanz (144 g) nichts änderte. Bei diesem Futter sank das Körpergewicht sofort bis auf 11,14-11,03-10,98 kg; die N-Ausscheidung durch den Harn betrug $3,52-3,47-3,61-3,55-3,49 \mathrm{~g}$, überstieg also, schon ohne

oder für den Koth von 4 Tagen im Ganzen $3,94 \mathrm{~g}$ Fett d. h. $0,98 \mathrm{~g}$ Fett pro Tag, entsprechend 2,6 pCt. der Fetteinfuhr.

1) Daraus würde sich eine Resorption des Futtereiweiss zu 92,3 pCt. berechnen, so dass 7,7 pCt. oder $\frac{1}{13}$ der N-Einfuhr unbenutzt mit dem Koth ausgestossen wurde. Indess ist bei niedrigem Betrag des Nah. rungs- $\mathrm{N}$ die Berechnung etwas zweifelhaft, weil ein relativ beträchtlicher Theil des Koth-N dem $\mathrm{N}$ der Darmsecrete, insbesondere der Galle, und dem Darmschleim entstammt. Ich komme im Text alsbald darauf zurück (S. 98). 
Berücksichtigung des Koth-N, die Einfuhr um 0,8-1 g. E musste bis auf $55 \mathrm{~g} \mathrm{Fett}$ und $116 \mathrm{~g}$ Kohlehydrat (mit 190 ; Trockensubstanz) angestiegen werden, um N- und Körpergleich gewicht zu erzielen. Am 17. Tage seit Beginn der eiweissarmer Nahrung war so die N-Ausscheidung durch den Harn bis au 2,11 g gesunken, so dass nunmehr die N-Ausfubr durch Harı und Koth $(0,45 \mathrm{~g})$ der N-Einfuhr gleichkam. Das Körpergewich hob sich wieder bis auf $11,21 \mathrm{~kg}$.

\begin{tabular}{|c|c|c|c|c|}
\hline \multirow[b]{2}{*}{ Dec. } & & Harn-N & Koth-N & Gewicht kg \\
\hline & 16. & 2,111 & & 11,21 \\
\hline & 17. & 2,114 & & 11,3 \\
\hline & 18. & 2,249 & $\left.1,348^{1}\right)$ & 11,22 \\
\hline & 19. & 2,086 & oder pro Tag & 11,15 \\
\hline & 20. & 2,23 & 0,449 & 11,14 \\
\hline
\end{tabular}

Es wurden somit in diesen 5 Tagen $10,79 \mathrm{~g} N$ oder pro Tag $2,158 \mathrm{~g}$ durch den Harn entleert, dazu $0,449 \mathrm{~g} \mathrm{~N}$ durch den Koth. macht zusammen $2,61 \mathrm{~g}$ gegenüber $2,64 \mathrm{~g} \mathrm{~N}$ der Einfuhr. Auch das Körpergewicht blieb constant zwischen 11,2 und $11,1 \mathrm{~kg}$ : also bestand bei der eiweissarmen Nahrung nunmehr $\mathrm{N}$ - und Körpergleichgewicht.

Die Ausnützung des Eiweiss anlangend, könnte dieselbe als eine nur mässige gelten, weil von $2,64 \mathrm{~g}$ Nahrungs- $\mathrm{N}$ im Koth $0,45 \mathrm{~g}=17 \mathrm{pCt}$. oder $\frac{1}{6}$ wieder erschienen sind. Hier ist in Anschlag zu bringen, dass nicht der gesammte Koth-N auf unausgenützten Nahrungs- $\mathrm{N}$ zu beziehen ist, sondern zum Theil auf N-haltige Residuen der Verdaunngssäfte (Galle, Bauchspeichel, Darmsaft), auf Darmschleim und abgestossene Darmepithelien. Je geringer der N-Gehalt der Nahrung ist, eine relativ um so grössere Quote bildet der von den Verdauungssäften gelieferte, in den Koth übergehende N-Antheil, daher im Allgemeinen die Ausnützung des Nahrungs-N um so schlechter erscheinen wird, je geringer der N-Gehalt des Futters ist ${ }^{2}$ ). Und dieser schon bei jeder Nahrung gelieferte $\mathrm{N}$-Antheil seitens der

1) In 3 Tagen $109,6 \mathrm{~g}$ feuchter Koth $=31,3 \mathrm{~g}$ trocken, entsprechend 5,5 pCt. der Einfuhr an Trockensubstanz.

$1,142 \mathrm{~g}$ Trockenkoth geben $0,04918 \mathrm{~g} \mathrm{~N}$.

2) Vgl. I. Munk und Uffelmann, Die Ernährung des gesunden und kranken Menschen. 2. Aufl. 1891. S. 189. 
Verdauungssäfte fällt um so grösser aus, je reicher an Kohlehydraten das Futter ist, hat doch Rieder ${ }^{\mathrm{x}}$ ) bei ausschliesslichem Kohlehydratfutter die Menge des mit dem Koth ausgestossenen $N$ gegenüber dem Hungerkoth bis auf das $2 \frac{1}{2}$ fache ansteigen sehen.

Bemerkenswerth ist zunächst das weite $\mathrm{Nährstoffver-}$ hältniss dieser eiweissarmen Nahrung. Reducirt man in bekannter Weise das Fett durch Multiplication mit 2,4 auf Kohlehydrate, so enthielt das Futter $248 \mathrm{~g}$ Kohlehydrate auf $17 \mathrm{~g} \mathrm{Ei-}$ weiss; also bestand ein Nährstoffverhältniss wie $1: 14,5$. Dabei bot selbst diese eiweissarme Nahrung noch $1,5 \mathrm{~g}$ Eiweiss pro Körperkilo, also 2-3 Mal so viel als in den Selbstversuchen von Hirschfeld und Kumagawa; damit war dem Erfahrungssatze, dass kleinere Organismen einen relativ, d. h. pro Körperkilo berechnet, höheren Eiweissverbrauch haben als grössere, in mehr als genügender Weise Rechnung getragen. Abgesehen davon, beweist schon die Thatsache des erzielten und, wie wir sehen werden, durch mehrere Wochen hindurch behaupteten N-Gleichgewichtes, dass die Eiweissgabe von $17 \mathrm{~g}$, neben den Kohlehydraten und dem Fett, dem Bedarf genügte.

An der gesammten, im Futter enthaltenen potentiellen Energie war hier das Eiweiss nur mit 7 pCt., die Fette und Kohlehydrate mit 93 pCt. betheiligt.

In noch höherem Grade bemerkenswerth erscheint es, dass bei eiweissarmer Kost zur Erhaltung des Körperbestandes der Gesammtinhalt an potentieller Energie in der Nahrung grösser sein muss als bei eiweissreicher Kost. Letztere, iu der 1. Periode verfütterte, lieferte 66 (S. 96), die eiweissarme 93 Cal., also volle $\frac{2}{5}$ mehr, ohne dass das Plus der eingeführten Nährstoffe zum Ansatz von Körpersubstanz geführt hätte. Da dieselbe Beobachtung auch in 3 Versuchsreihen an anderen Hunden wiederkehrt, kann die Thatsache als gesetzmässiges Verhalten angesprochen werden. Das Gleiche habe ich $^{2}$ ) schon vor 3 Jahren, so weit mir bekannt, als Erster, auch für den Menschen aus den Versuchen von Voit

1) Zeitschr. f. Biologie. Bd. 20. S. 378 .

2) I. Munk, Centralbl. f. d. med. Wiss. 1889. S. 835 . 
and Ranke einerseits, Hirschfeld, Kumagawa und Klemperer andererseits abgeleitet. Selbstversuche von $Z$ untz und Ad. Magnus-Levy lassen sich mit einiger Berechtigung gleichfalls nach dieser Richtung hin verwerthen.

Der $69,5 \mathrm{~kg}$ schwere Arbeiter von Pettenk ofer und $V_{0}$ it $^{1}$ ) verbrauchte bei $\mathrm{N}$-Gleichgewicht $137 \mathrm{~g}$ Eiweiss, $65 \mathrm{~g}$ Fett und $352 \mathrm{~g}$ Kohlehydrate; der Wärmewerth dieser Nahrung beträgt 2491 Cal. oder pro Körperkilo 35 Cal. J. Ranke ${ }^{2}$ ), rund $70 \mathrm{~kg}$ schwer, blieb bei $100 \mathrm{~g}$ Eiweiss, $100 \mathrm{~g}$ Fett und $240 \mathrm{~g}$ Kohlehydrate 7 Tage hindurch in N- und C-Gleichgewicht; seine Kost lieferte 2230 Cal. oder pro Körperkilo 32 Cal. Nach den Ermittelungen von Playfair, Voit, Forster o. A. ${ }^{3}$ ) erweist sich als mittleres ausreichendes Kostmaass für den mässig arbeitenden Menschen von rund $70 \mathrm{~kg}: 116 \mathrm{~g}$ Eiweiss, $62 \mathrm{~g}$ Fett und $404 \mathrm{~g}$ Kohlehydrate; diese Tagesration liefert, nach Abzug des mit dem Koth unbenutzt austretenden Antheiles, 2630 Cal. oder pro Körperkilo $37 \mathrm{Cal}$. Danach reicht für den erwachsenen "mittleren Arbeiter" bei eiweissreicher Nahrung (100 bis $137 \mathrm{~g}$ Eiweiss) eine Tagesration aus, die pro Körperkilo 32-37 Cal. liefert.

Anders verhält es sich bei eiweissarmer Nahrung. Hirschfeld ${ }^{4}$ ), $73 \mathrm{~kg}$ schwer, kam bei einem Eiweissumsatz von nur $44 \mathrm{~g}$ neben $165 \mathrm{~g}$ Fett und $354 \mathrm{~g}$ Kohlehydraten allmählich in's N-Gleichgewicht, verlor aber dabei noch täglich $50 \mathrm{~g}$ von seinem Körper; diese Nahrung lieferte 3140 Cal. oder pro Körperkilo 43 Cal. Kumagawa ${ }^{4}$ ), allerdings nur $48 \mathrm{~kg}$ schwer, setzte $38 \mathrm{~g}$ Eiweiss und $570 \mathrm{~g}$ Kohlehydrate um und erreichte dabei für 7 Tage nur N- und Körpergleichgewicht; diese Ration konnte 2493 Cal. bilden oder pro Körperkilo 52 Cal. Die Versuchsmänner von Klemperer ${ }^{4}$ ) setzten sich mit $30 \mathrm{~g}$ Eiweiss, $262 \mathrm{~g}$ Fett, $406 \mathrm{~g}$ Kohlehydrate und $199 \mathrm{~g}$ Alkohol allmählich in's $\mathrm{N}$-Gleichgewicht; verrechnet man den Alkohol selbst nur zu dem calorischen Werth der Kohlehydrate [4,1 an-

1) Zeitschr. f. Biologie. Bd. 2. S. 488.

2) Arch. f. Anat. u. Physiol. 1862. S. 311.

3) Vergl. meine Zusammenstellung in Munk und Uffelmann, Ernährung. 2. Aufl. 1891. S. 204.

4) a. a. 0 . 
statt $\left.7^{1}\right)$ ], so konnten aus der Nahrung 4900 verwerthbare Cal. entstehen oder mindestens pro Körperkilo 75 Cal.; dabei war das Endgewicht der Versuchspersonen noch um $250 \mathrm{~g}$ kleiner als das Anfangsgewicht. Zuntz $\left.{ }^{2}\right), 65 \mathrm{~kg}$ schwer, kam mit einer eiweissarmen Nahrung, von der $44 \mathrm{~g}$ Eiweiss, $96 \mathrm{~g}$ Fett, $364 \mathrm{~g}$ Kohlehydrat und $20 \mathrm{~g}$ Alkohol resorbirt wurden, innerhalb 3 'Tagen nicht in $\mathrm{N}$-Gleichgewicht; er büsste über $2 \mathrm{~kg}$ an Gewicht ein und verlor noch am 3. Tage 2,3 g N vom Körper. Dabei betrug der calorische Werth der resorbirten Nahrung fast 2700 Cal. oder pro Körperkilo 42 Cal. Ad. Magnus-Levy ${ }^{2}$ ), der bei denselben Nahrungsmitteln, von denen er jedoch mehr aufnahm, pro Tag $56 \mathrm{~g}$ Eiweiss, $118 \mathrm{~g}$ Fett, $490 \mathrm{~g}$ Kohlehydrat und $58 \mathrm{~g}$ Alkohol resorbirte, kam, nachdem er an den ersten 3 Tagen im Ganzen $8,65 \mathrm{~g} \mathrm{~N}$ vom Körper verloren hatte, am 4. Tage annähernd in's N-Gleichgewicht; dabei war der Gewichtsverlust noch etwas grösser, als dem Eiweiss- oder Fleischverlust entsprach, obwohl die resorbirte Nahrung 3730 Cal. oder, entsprechend dem Körpergewicht von $67,5 \mathrm{~kg}, 55,3$ Cal. pro Körperkilo lieferte. Endlich hat Breisacher ${ }^{3}$ ), nur $52 \mathrm{~kg}$ schwer, bei $68 \mathrm{~g}$ Eiweiss $494 \mathrm{~g}$ Kohlehydrat und $60 \mathrm{~g}$ Fett gebraucht, um auf N- und Körpergleichgewicht zu bleiben; die Nahrung lieferte 54 Cal. pro Körperkilo. Also erfordert eine eiweissarme Kost für einen Menschen, sogar bei leichter Arbeit, soviel potentielle Energie, dass für das Körperkilo mindestens 43 , zumeist $52-55$ Cal. (unter besonderen Umständen sogar 75 Cal.) zur Verfügung stehen müssen. 'Wie der erheblich grössere Bedarf an $\mathrm{N}$-freien Stoffen bei geringer Eiweisszufuhr zu deuten ist, lässt sich vor der Hand noch nicht mit Sicherheit sagen. Möglich, dass für so eiweissarme Kost Rubner's Isodynamie der Nährstoffe, der zu Folge $10 \mathrm{~g}$ Eiweiss durch $10 \mathrm{~g}$ Kohlehydrate oder $4,2 \mathrm{~g}$ Fett vertreten werden können, nicht mehr zutrifit. Es ist dies um so eher möglich, als, streng genommen, die Isodynamie nicht für den Ersatz von Eiweiss bezw. für die Verhütung des Eiweissverlustes, sondern nur für die Fähigkeit gilt, den Fettverlust vom

1) Nach Maassgabe der unter Anmerk. 2 citirten Arbeit entwickelt $1 \mathrm{~g}$ Alkohol im Körper sogar 6,4 Cal.

2) Zuntz und A. Magnus-Levy, Pflüger's Arehiv, Bd, 49. S, 438.

$\left.{ }^{3}\right)$ Deutsch. med. Wochenschr. 1891. No. 48. 
Körper zu verhüten. Zum Theil mag dieser höhere Bedarf an Nährstoffen sich aus dem von Zuntz und Ad. Magnus-Lery ${ }^{3}$ ) erhobenen interessanten Befunde erklären, wonach die Steigerung des Sauerstoffverbrauches durch die Verdauungsarbeit, welche eine an N-freien Stoffen so reiche voluminöse Nahrung (Nährstoffverhältniss 1:11-12) bedingt, volle 10 pCt. des gesammten O-Bedarfes bei Ruhe beträgt.

Endlich soll gleich hier darauf hingewiesen werden, was durch den gleich zu schildernden weiteren Ablauf des Versuches auch für einen Zeitraum von mehreren Wochen durchgängig bestätigt werden konnte, nehmlich dass durch eine Nahrung mit so weitem Nährstoffverhältniss der N-Umsatz für die Dauer auf einen so geringen Werth herabgedrückt werden kann, nehmlich $2,1 \mathrm{~g}$ pro Tag, der noch weit unter dem "typischen Hungerminimum" gelegen ist. Ich verfüge über einen noch nicht veröffentlichten Hungerversuch an einem Hunde von einem, allerdings $\frac{1}{2}$ Mal grösseren Körpergewicht $(16,9 \mathrm{~kg})$, bei dem selbst in der späteren Inanitionszeit, am 9. und 10. Hungertage, als das Körpergewicht auf 14,5 bezw. $14,3 \mathrm{~kg}$ gesunken war, die N-Ausscheidung durch den Harn noch 3,7-3,6 g betrug. Der von F. A. Falck ${ }^{2}$ ) beobachtete Hund von $8,9 \mathrm{~kg}$ schied als "typisches Hungerminimum" am 9 . und 10. Tage noch 5,4 bezw. $4,8 \mathrm{~g} \mathrm{~N}$ aus. Danach steht es unzweifelhaft fest, dass ein Eiweissumsatz von $2,1 \mathrm{~g} \mathrm{~N}$ (entsprechend einem Fleischverbrauch von $62 \mathrm{~g}$ ) weit unter der niedrigsten Hungerausscheidung für einen Hund von $11,2 \mathrm{~kg}$ liegt.

$$
\text { 4. -6. Woche. }
$$

Von nun ab wurde das Fleisch durch Fleischmehl, das eine gleichmässige unveränderliche Zusammensetzung besitzt, ersetzt und täglich etwa $2 \mathrm{~g}$ des künstlichen Gemisches der Fleischsalze ${ }^{3}$ )

1) a. a. 0.

2) Beiträge zur Pbysiologie, Toxikologie u. Hygiene. Stuttgart 1875. S. I ff.

3) Das künstliche Gemisch war auf Grund von E. Wolff's Zusammenstellung von Aschenanalysen (Berlin 1871-1880), der zu Folge die Fleischasche 37 pCt. Kali, 10 pCt. Natron, 2,3 pCt. Kalk, 3 pCt. Magnesia, $\frac{1}{2}$ pCt. Eisenoxyd, 41 pCt. Phosphorsäure, 5 pCt. Chlor enthält, zu 70 pCt. aus Kaliumphospbat, zu $15 \mathrm{pCt}$. aus Chlornatrium, zu $6 \mathrm{pCt}$. aus Kalkphosphat, zu 8 pCt. aus Magnesiumphosphat und zu $\frac{1}{2}$ pCt. aus Eisenoxyd zusammengesetzt. 
hinzugefügt. Das verfütterte Fleischmehl enthielt nach $\mathrm{Kjeldahl}$ 11,392 pCt. N, ferner 19,6 pCt. Rohfett (Aetherextract). Es wulden nunmehr $11 \mathrm{~g}$ Fleischmehl, $53 \mathrm{~g}$ Schmalz, $150 \mathrm{~g}$ Reiss, wiederum mit $600 \mathrm{ccm}$ Wasser abgekocht, gegeben. Das Futter enthielt $17 \mathrm{~g}$ Eiweiss (mit 2,74 $\mathrm{g} \mathrm{N}$ ), $55 \mathrm{~g}$ Fett und $116 \mathrm{~g}$ Kohlehydrate, konnte also 1070 Cal. oder pro Körperkilo 97 Cal. liefern.

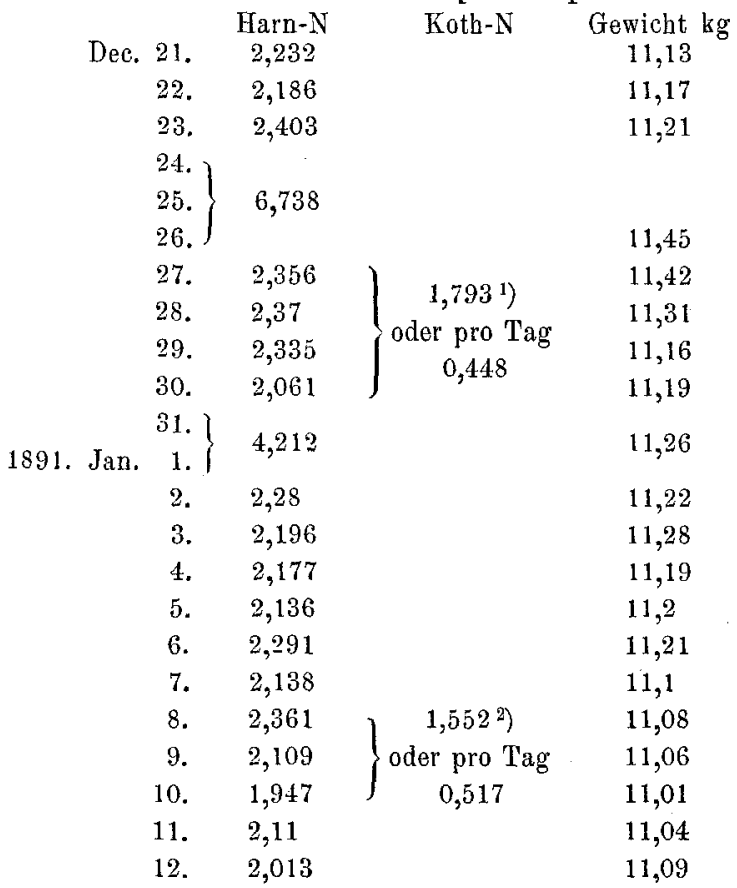

1) In 4 Tagen $101,6 \mathrm{~g}$ feuchter $\mathrm{Koth}=31,3 \mathrm{~g}$ trocken, entsprechend 4,1 pCt. der eingeführten Trockensubstanz.

$0,965 \mathrm{~g}$ Trockenkoth geben $0,0553 \mathrm{~g} \mathrm{~N}$.

$8,472 \mathrm{~g} \quad-\quad$ - neutrales Aetherextract $1,193 \mathrm{~g}$

saures

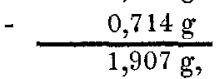

mithin im Gesammitkoth $7,044 \mathrm{~g}$ Rohfett $=3,2 \mathrm{pCt}$. der Fetteinfuhr.

2) In 3 Tagen $103,9 \mathrm{~g}$ feuchter Koth $=29,7 \mathrm{~g}$ troeken, entsprechend 5,2 pCt. der Einfubr.

$1,042 \mathrm{~g}$ Trockenkoth geben $0,0545 \mathrm{~g} \mathrm{~N}$.

$7,843 \mathrm{~g} \quad-\quad-\quad$ neutrales Aetherextract $1,936 \mathrm{~g}$

saures

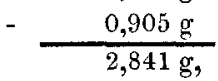

also im Gesammtkoth $10,758 \mathrm{~g}$. Fett, entsprechend 4,9 pCt. der Fetteinfubr. 
In diesen 23 Tagen verharrte der Hund, wie schon in den 5 letzten Tagen zuvor (S. 98), auf $\mathrm{N}$ - und Körpergleichgewicht. Der Eiweissumsatz war während dieser 3 Wochen auf einem ebenso niedrigen Stande, als in der Woche zuvor, also wiederum erheblich unter dem typischen Hungerminimum. Die Gesammtausfuhr durch den Harn an diesen $23 \mathrm{Ta}$ gen betrug $50,65 \mathrm{~g} \mathrm{~N}$ oder pro Tag 2,2 g, durch den Koth in der 4. Woche $0,45 \mathrm{~g}$, in der 6 . Woche $0,52 \mathrm{~g} \mathrm{~N}$, also die Gesammtausscheidung durch Harn und Koth 2,65-2,72 g N gegenüber 2,74 g N der Einfuhr.

Ende der 6. Woche der eiweissarmen Fütterung wurde die erste Veränderung beobachtet; der Koth wurde etwas reichlicher, die zuvor intensiv gelbe bis gelbbraune Farbe wurde blasser, mehr graugelb. Die N-Ausstossung durch den Koth nahm ein wenig zu, von 0,45 bis zu $0,52 \mathrm{~g}$ auf den Tag; auch die Fettausnützung, die zuvor bis auf 3 pCt. erfolgt war, stieg bis fast auf 5 pCt. an. Doch war diese Verschlechterung der $\mathbf{N}$ - und Fettausnützung immerhin noch so geringfügig, dass sie eventuell noch in die auch sonst bei Versuchsreihen am Koth auftretenden Schwankungen hineinfallen dürfte. Andererseits konnten diese, zunächst noch wenig auffälligen Veränderungen ebenso gut die Vorläufer einer im Organismus sich entwickelnden bedeutsamen Störung sein.

\section{7. - 9. Woche.}

Eingeführt wurden, wie in den letaten 3 Wochen, $17 \mathrm{~g} \mathrm{Ei-}$ weiss (mit 2,74 g N), $55 \mathrm{~g}$ Fett, $116 \mathrm{~g}$ Kohlebydrate und $600 \mathrm{ccm}$ Wasser, im Ganzen $192 \mathrm{~g}$ Trockensubstanz.

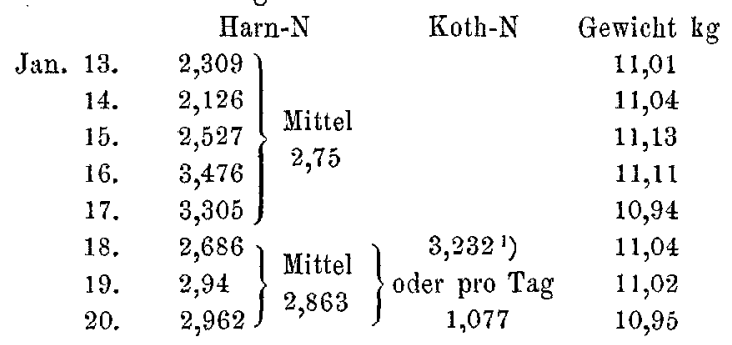

1) Koth, grauweiss, fast ohne Gallenfärbung, stark sauer reagirend, beim Trocknen intensiven Geruch nach Buttersäure entwickelnd. $325,9 \mathrm{~g}$ feucht $=93,1 \mathrm{~g}$ trocken, entsprechend $16,2 \mathrm{pCt}$. der eingeführten 


\begin{tabular}{|c|c|c|c|c|}
\hline & \multicolumn{2}{|c|}{ Harn-N } & Koth-N & Gewicht $\mathrm{kg}$ \\
\hline Jan. 21. & 2,696 & & & 10,91 \\
\hline 22 & 2,54 & & & 10,9 \\
\hline 23. & 2,952 & & & 10,92 \\
\hline 24. & 3,338 & & & 10,94 \\
\hline 25. & 2,664 & & $\left.2,968^{1}\right)$ & 11,05 \\
\hline 26. & 2,55 & Hittel & oder pro Tag & 11,01 \\
\hline 27. & $2,371 J$ & & 0,99 & 10,94 \\
\hline 28. & 2,579 & & & 11,03 \\
\hline 29. & 2,357 & & & 10,97 \\
\hline 30. & $\left.{ }^{2}\right)$ & & & 10,89 \\
\hline $\left.31 . .^{3}\right)$ & 2,562 & & & 10,99 \\
\hline ebr. 1 & 2,981 & & & 10,9 \\
\hline
\end{tabular}

Von der 7. Woche ab stieg die N-Ausfuhr durch den Harn von $2,2 \mathrm{~g}$ in den nächsten 6 Tagen im Mittel auf $2,75 \mathrm{~g}$, mit einem Minimum von 2,13 und einem Maximum von $3,48 \mathrm{~g}$. Für den Anstieg des Eiweissumsatzes um 25 pCt. lieferte die genaue Analyse des durch Knochen gut abgegrenzten Kothes einen erklärenden Gesichtspunkt. Dieser, in viel reichlicherer Menge als zuvor ausgestossen, so dass rund 3 Mal so viel feste Stoffe auf den Tag trafen, als in der 6 . Woche und rund $\frac{1}{6}$ von der

Trockensubstanz. 2,2268 g Trockenkoth geben $0,0773 \mathrm{~g} \mathrm{~N}$. 17,2924 g, mit angesäuertem Alkohol extrahirt, Filtrat giebt nach Kjeldahl $0,1054 \mathrm{~g} \mathrm{~N}$, also im ganzen Koth $0,568 \mathrm{~g}$ alkohollöslicher $\mathrm{N}$, entsprechend $17,6 \mathrm{pCt}$. des Gesammt-Koth-N. 12,5176 g Trockenkoth liefern 2,6948 $\mathrm{g}$ neutrales Aetherextract

$0,5307 \mathrm{~g}$ saures

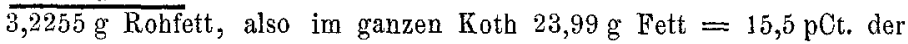
Fetteinfuhr. $1,373 \mathrm{~g}$ feinst pulverisirter Trockenkotb entbalten nach Maercker (S. 106) lösliche Koblehydrate, entsprechend 0,11 g Stärkemehl, also im Gesammtkoth 7,46 $\mathrm{g}$ Stärkemehl $=2,1 \mathrm{pCt}$. der Einfuhr.

1) Koth, grau, fast acholisch, $289,2 \mathrm{~g}$ feucht $=84,7 \mathrm{~g}$ trocken, entsprechend 14,7 pCt. der Einfubr an Trockensubstanz. 1,473 g Trockenkoth geben $0,0516 \mathrm{~g} \mathrm{~N}$. - Leider ist der gesammte übrige Koth durch einen Cnfall in Verlust gegangen, so dass die Bestimmung der Fett- und Kohlehydrat-Ausnützung feblt.

2) In der Nacht über die Hälfte des Fettes erbrocben, auch Koth in den Käfig entleert, daher es nicht sicher ist, ob nicht zugleich auch Harn entleert ist und die per Katheter gewonnenen $147 \mathrm{ccm}$ Harn der gesammten Tagesmenge entsprechen.

3) Von nun ab das Futter in 2 Portionen mit einem Intervall von 8 Stunden verabreicht. 
eingeführten Trockensubstanz einschliessend, war nur graugelblich gefärbt, fast ohne gallige Färbung, liess auf dem Durchschnitt einzelne grieskorngrosse weissliche Einsprenklungen, Residuen von Reisskörnern erkennen. Auf den Tag trafen $1,08 \mathrm{~g} \mathrm{~N}$, in der 9 . Woche $0,99 \mathrm{~g}$, also $2 \frac{1}{2} \mathrm{Mal}$ so viel als in der 3 . Woche und doppelt so viel als in der 6 . Woche, ferner $8 \mathrm{~g}$ Rohfett (Fett, Fettsäuren, Seifen, Cholesterin), entsprechend $15,5 \mathrm{pCt}$. des Nahrungsfettes, d. h. mehr denn $3 \mathrm{Mal}$ so viel als in der 6 . Woche. Endlich fanden sich auch darin $2,9 \mathrm{~g}$ lösliche Kohlehydrate, entsprechend 2 pCt. der Einfuhr. Somit hatte sich die Ausnützung aller Nährstoffe aus dem Futter beträchtlich verschlechtert, am stärksten die des Fettes, sehr erheblich die des Eiweiss, am wenigsten die der Kohlehydrate. Indem so weniger Nährstoffe als zuvor zur Resorption gelangten, konnte das bisher durch fast 4 Wochen bestandene $\mathrm{N}$-Gleichgewicht nicht länger behauptet werden; es stieg die $\mathrm{N}$-Ausscheidung durch den Harn rund um $25 \mathrm{pCt}$. an, so dass der Hund nunmehr $1,2 \mathrm{~g} \mathrm{~N}=7,6 \mathrm{~g}$ Eiweiss oder $35 \mathrm{~g}$ Körperfleisch pro Tag einbüsste. Allein ungeachtet dieser erheblichen Verschlechterung in der Resorption traten noch so viel Nährstoffe aus dem Futter in die Säfte über, dass die Zersetzung des resorbirten Antheils reichlich 85 Cal. pro Körperkilo lieferte, also eine Summe von potentieller Energie, die sonst (d. h. ausser bei eiweissarmem Futter) den Körperbestand vollständig zu wahren vermag.

Die Verschlechterung in der Ausnützung der Nährstoffe deutet auf eine Alteration der bei der Resorption activ eingreifenden Epithelzellen der Darmschleimhaut. Mit der Alteration des Darmkanals dürfte auch das Erbrechen zusammenhängen, das sich in der 9. Woche der eiweissarmen Fütterung zum ersten Mal eingestellt hat.

Die Bestimmung der löslichen Koblehgdrate im Koth sei, da dieselbe für gewöhnlich kaum geschieht, hier angeführt. Nach Maercker ${ }^{1}$ ) verfährt man so, dass man $3 \mathrm{~g}$ staubfeine Substanz mit $25 \mathrm{ccm} 1$ procentige Milchsäure und $30 \mathrm{ccm}$ Wasser in mit Deckel belegten cylindrischen Messinggefässen $2 \frac{1}{2}$ Stunden lang im Autoclar ( $P$ apin'schen Topf) bei $3 \frac{1}{2}$

1) Zeitschr. f. analyt. Chem. Bd. 24, S.617; auch Soxhlet, ebenda, S. 618 . 
Atmosphärendruck digerirt $\left.{ }^{1}\right)$. Nachdem auf 1 Atmosphäre erkalten gelassen, wird das Gemisch in einen $250 \mathrm{ccm}-\mathrm{K}_{0}$ lben gespült, mit Wasser bis zur Marke aufgefüllt, $200 \mathrm{ccm}$ davon abfiltrirt, djese mit $15 \mathrm{ccm}$ reiner Salzsäure $2 \frac{1}{2}$ Stunden lang im Wasserbade behufs Inversion ${ }^{2}$ ) gekocht, nach dem Erkalten mit Natronlauge beinahe neutralisirt, auf $500 \mathrm{ccm}$ aufgefüllt und in 25 bis $50 \mathrm{ccm}$ davon der Traubenzucker gewichtsanalytisch nach Allibn ${ }^{3}$ ) bestimmt. Je $30 \mathrm{ccm}$ Kupferlösung $(34,6 \mathrm{~g}$ krystallisirtes Kupfervitriol in $500 \mathrm{cem}$ Wasser) und alkalische Weinsäurelösung (173 g Seignettesalz, $125 \mathrm{~g}$ Kalibydrat in Wasser gelöst, auf $500 \mathrm{ccm}$ aufgefüllt) werden gemischt, zum Kochen erbitzt, $25 \mathrm{ccm}$ der (höchstens 1 procentigen) Zuckerlösung zugesetzt. Man kocht auf, filtrirt das Kupferoxydul siedend auf einem Asbestfilter $a b$, wäscht erst mit heissem Wasser, dann mit Alkohol und Aether nach, glüht das Kupferoxydul im Wasserstoffstrome und wägt das gebildete metallische Kupfer. Aus dem Gewicht des letzteren ergiebt sich der Gehalt an Traubenzucker ${ }^{4}$ ). 1 Theil Zucker entspricht 0,9 Theilen präformirten Stärkemehls.

Schon während dieser ganzen Periode und in noch höherem Grade im weiteren Verlauf des Versuches war der Koth nur wenig gelb, mehr grau gefärbt, so dass schon das Aussehen desselben für eine nur noch geringe Beimischung von Galle sprach; weiterhin sah der Koth fast gallenfarbstofffrei, wie acholisch aus, so wie ich ihn bei meinen Ausnützungsversuchen am Hunde mit permanenter Gallenfistel ${ }^{5}$ ) gesehen und genauer beschrieben habe. Indess erschien es wünschenswerth, neben diesem Merkmale im Aussehen den objectiven Nachweis zu liefern, in welchem Umfange Galle bezw. deren Residuen dem Koth beigemengt sind. Es würde dies bis zu einem gewissen Grade möglich sein durch die Bestimmung des Farbstoffgehaltes vom Koth, da der Kothfarbstoff, das Hydrobilirubin oder Urobilin (Stercobilin) ein Derivat des Gallenfarbstoffes und zwar das durch (bei der Fäulniss im Darm frei gewordenen) Wasserstoff gebildete Reductionsprodukt des Bilirubin und Biliverdin

1) Eine 0,5procentige Milchsäure führt bei höherem Druck Stärkemehl in lösliche Stärke (Amidulin), Dextrin und wenig Zucker über, ohne die Cellulose (Rohfaser) anzugreifen.

2) Umwandlung der löslichen Stärke und des Dextrins in Traubenzucker.

3) Journ. f. prakt. Chem. 2. Folge. Bd. 22, S. 55; Zeitschr, f. analyt. Chem. Bd. 22, S. 451.

4) Tabellen zur Ermittelung des Zuckergehaltes aus dem Gewicht des Kupfers s. Zeitschr. f. analyt. Chem. Bd. 22, S. 449.

5) I. Munk, Dieses Archiv Bd, 122, S. 302. 
1st. Da diese Bestimmung uur mittelst eines sehr kostspieligen Spectrophotometers auszuführen ist und andererseits von Manchem nicht als entscheidend angesehen wird, zumal ein wechseInder Antheil des im Darm gebildeten Urobilins resorbirt wird und durch den Harn austritt, so schien mir ein anderer Weg einfacher and eher noch schärfer. Die Gallenfarbstoffe bezw. das Urobilin sowie die Gallensäuren (Tauro- und Glykocholsäure) bezw. deren Spaltungsprodukt, die Cholalsäure sind N-haltig und in Alkohol löslich, dagegen sind die anderen N-haltigen Bestandtheile des Kothes: Nuclein, Mucin event. Keratin (bei Fleischnahrung auch Hämatin), welche unverdauliche bezw. unverdaute Reste der Nahrung und der Darmsecrete vorstellen, in Alkohol unlöslich. Bestimmt man daher einerseits den Gesammt-N des Kothes nach Kjeldahl, andererseits den N-Gehalt des (siedenden) Alkoholextractes aus dem pulverisirten Trockenkoth, so geben beide N-Werthe das Verhältniss des Gallen-N zu dem Gesammt-N des Kothes an. Bei normaler Ernährung mit Fleisch und Fett, odẻr Fleisch, Fett und wenig Kohlehydraten erweisen sich 50 bis 60 pCt. des Koth-N als in Alkohol löslich, beim Ueberwiegen der Kohlehydrate neben Fett und wenig Fleisch nur $35-44$ pCt. $^{1}$ ). Dagegen erwies sich von dem gesammten $\mathrm{N}$ des Kothes vom 18.-20. Januar $(3,232 \mathrm{~g})$ nur $0,568 \mathrm{~g} \mathrm{~N}$ als in Alkohol löslich $\left.{ }^{2}\right)$ d. h. nur 17,6 pCt. Es war also kaum halb so viel Galle dem Koth beigemischt, als dies bei der gleichen Fütterung in der Norm der Fall ist. Dies Verfahren, das meines Wissens bisher noch nicht angegeben ist, dürfte sich überall empfehlen, wo es sich darum handelt, die dem Koth beigemischten Gallenstoffe approximativ zu ermitteln (vergl. auch S. 116).

1) Beispiel: $0,969 \mathrm{~g}$ des pulverisirten Trockenkothes vom Futter der 1. Periode (S. 96) gab $0,0676 \mathrm{~g} \mathrm{~N}=6,976 \mathrm{pCt}$. N. $-3,524 \mathrm{~g}$ des Kothpulvers, mit Alkohol, dem 2-3 Tropfen Scbwefelsäure zugesetzt sind (ein stärkeres Ansäuern ist fehlerhaft, weil dann auch Hämatin in Lösung gehen kann), aw Rückflusskühler 8 Stunden gekocht, nach dem Erkalten auf $200 \mathrm{ccm}$ aufgefüllt. $100 \mathrm{ccm}$ Filtrat geben nach

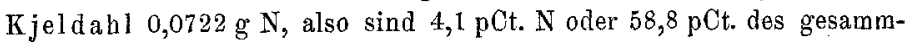
ten Koth-N in Alkohol löslich.

2) $17,2924 \mathrm{~g}$ mit kochendem Alkohol extrahirt, auf $500 \mathrm{ccm}$ aufgefïllt; $250 \mathrm{ccm}$ Filtrat geben $0,0527 \mathrm{~g} \mathrm{~N}$. 
Zur Erhärtung der Brauchbarkeit des eben geschilderten Verfahrens war es von Interesse nachzusehen, wie gross der alkobollösliche N-Antheil im acholischen Koth vom Gallenfistelhund ist. Von meinen früheren Ausnutzungsversuchen ${ }^{\text {) }}$ hatte ich noch aus den verschiedenen Perioden Trockenkoth mit genauer Bezeichnung der Fütterungsart und der Gesammtkothmenge aufbewahrt stehen. Der Koth, den mein Gallenfistelhund bei Fütterung mit $500 \mathrm{~g}$ Fleisch; $160 \mathrm{~g}$ Fett und $190 \mathrm{~g}$ Reiss entleerte, betrug pro Tag $198,6 \mathrm{~g}$ feucht $=67,5 \mathrm{~g}$ trocken. Wegen des grossen Fettgehaltes wurde eine der Tagesmenge $(67,5 \mathrm{~g})$ entsprechende Portion in toto im Soxhletschen Apparate erschöpft; ich gewann so für den Tageskotb $20,2 \mathrm{~g}$ fettfreie Trockensubstanz und $46,6 \mathrm{~g}$ Trockenrückstand von der Aetherextraction. In der fettfreien Trockensubstanz fand sich 1,186 g N. Ferner gaben $3,1537 \mathrm{~g}$ des fettfreien Kothes 0,02181 alkohollöslichen N, so dass auf den Tageskoth aus dem fettfreien Antheil $0,13 \mathrm{~g}$ alkohollöslicher $\mathrm{N}$ entfallen. Da aber der Aetherextractrückstand nocb alkohollöslichen $\mathrm{N}$ entbalten konnte, wurden $20,4 \mathrm{~g}$ davon in ein $200 \mathrm{ccm}-\mathrm{Kölbchen}$ gebracht, etwa $150 \mathrm{~g}$ Alkohol zugesetzt, in der Wärme digerirt and nach dem Erkalten auf $200 \mathrm{ccm}$ aufgefüllt; $100 \mathrm{cem}$ Filtrat in einen $\mathrm{Kjeldahl-Kolben} \mathrm{übergeführt,} \mathrm{mit} \mathrm{einigen} \mathrm{Tropfen}$ Schwefelsäure auf ein kleines Volumen eingedampft und mit Schwefelsäure bis zu klarer Lösung gekocht. So fanden sich $3,35 \mathrm{mg}$ alkohollöslicher $\mathrm{N}$, also auf die Tagesmenge des Aetherextractrückstandes berechnet: $15,6 \mathrm{mg}$ alkohollöslicher $\mathrm{N}$. Mithin treffen auf $1,186 \mathrm{~g}$ Gesammt- $\mathrm{N}:(0,13+0,0156 \Rightarrow$ $0,146 \mathrm{~g}$ alkohollöslicher $\mathrm{N}, \mathrm{d} . \mathrm{h}$. im gallenfreien Koth sind nur $12,3 \mathrm{pCt}$. oder nur $\frac{1}{8}$ des Gesammt-N alkohollöslich.

Eine zweite Bestimmung am acholischen Koth bei sonst derselben Fütterungsart, aber einer Fettgabe von nur $150 \mathrm{~g}$, ergab 15,4 pCt. oder mebr als $\frac{1}{7}$ des Gesammt-N alkobollöslich. Auch diese Befunde sprechen zweifellos dafür, dass der grösste Antheil des in Alkohol löslichen Koth-N von den Residuen der Galle berrährt, insofern bei Gallenzutritt zum Darm 35-60 pCt., beim Ansschluss der Galle vom Darm nur 12-15 pCt. des Koth-N sich in Alkohol lösen.

Es mag schliesslich noch hervorgehoben werden, dass ungeachtet dieses fast acholischen Kothes niemals Gallenfarbstoff im Harn oder eine Spur von Icterus am Körper (Bindehaut und Lederhaut des Auges) zu beobachten war, ebenso wenig eine reichliche Beimengung von Schleim zum Koth, die auf einen Darmkatarrh hingedeutet hätte.

10. bis 11. Woche.

Harn-N Koth-N Gewicht kg

Febr. 2. 3,271

10,81

3. 2,547

10,88

1) Dieses Archiv, Bd. 122. S. 302. 


\begin{tabular}{|c|c|c|c|c|}
\hline \multirow{2}{*}{ Febr. } & & \multirow{2}{*}{$\begin{array}{c}\text { Harn -N } \\
2,42\end{array}$} & \multirow[t]{2}{*}{ Koth-N } & \multirow{2}{*}{$\begin{array}{c}\text { Gewicht } \mathrm{kg} \\
10,8\end{array}$} \\
\hline & 4. & & & \\
\hline & 5. & 2,249 & \multirow{6}{*}{$\begin{array}{c}4,047 \\
\text { oder pro Tag } \\
1,012\end{array}$} & 10,94 \\
\hline & 6. & 3,252 & & 10,79 \\
\hline & 7. & 2,743 & & 10,81 \\
\hline & 8. & 2,806 & & 10,75 \\
\hline & 9. & 2,53 & & 10,67 \\
\hline & 10. & 2,507 & & 10,76 \\
\hline & 11. & 2,752 & & 10,62 \\
\hline
\end{tabular}

An diesen 10 Tagen wurden durch den Harn insgesammt $27,077 \mathrm{~g}$ oder pro Tag 2,71 g N entleert. Somit nahm die N-Ausfuhr durch den Harn nicht mehr zu. Dagegen war der, Ende der 10. und Anfangs der 11. Woche abgesetzte graue, keine Spur von gelber Farbe zeigende Koth noch reichlicher, als in der 8. und 9. Woche; auf 4 Tage trafen $409,7 \mathrm{~g}$ feucht $=129,1 \mathrm{~g}$ trocken, entsprechend $16,8 \mathrm{pCt}$. der verfütterten Trockensubstanz. Dabei war der getrocknete Koth so fettreich und schmierig, dass er sich nicht pulverisiren liess. Erst nachdem er in toto in mehreren Soxhlet'schen Extractoren durch 24 Stunden mit Aether erschöpft worden war, hinterblieb ein gut pulverisirbarer, fast farbloser Rückstand im Gewicht von $75,7 \mathrm{~g}$. Die vereinigten Aetherextracte wurden in einen Literkolben gebracht, bis zur Marke mit Aether aufgefüllt und nach dem Durchschütteln in $25 \mathrm{ccm}$ der feste Rückstand za 1,1162 g bestimmt; daraus ergab sich der Gesammtrückstand für $1000 \mathrm{ccm}$ zu 44,65 g (Fett, Fettsäuren, Cholesterin). Dann wurden ebenfalls $25 \mathrm{ccm}$ der Aetherlösung unter Zusatz von Phenolphtalein mit alkoholischer Normalkalilauge bis zum Eintritt von Rosafärbung titrirt; es ergaben sich so freie Fettsäuren, entsprechend $0,519 \mathrm{~g}$ Oelsäure, so dass auf das gesammte Aetherextract $20,76 \mathrm{~g}$ freie Oelsäure trafen. Ferner wurde zur Gewinnung des Restfettes in dem, 75,7 $\mathrm{g}$ betragenden, von der Hauptmenge des Fettes befreiten Trockenkoth 4,8407 $\mathrm{g}$ des letzteren abermals im Soxhlet'schen Apparate mit Aether erschöpft; dies Aetherextract hinterliess 0,4004 g Rückstand (Fett, Fettsäure), von dem gemäss der Titrirung mit alkoholischer Lange $0,33 \mathrm{~g}$ freie Oelsäure waren. Mithin enthielt das gesammte Trockenpulver noch $6,26 \mathrm{~g}$, von denen $5,16 \mathrm{~g}$ auf Oelsäure, $1,1 \mathrm{~g}$ auf Neutralfett + Cholesterin zu beziehen waren. Was bei diesem Erschöpfen des Trockenpulvers mit Aether als 
unlöslich hinterblieben war, wurde mit salzsäurehaltigem Alkohol durchgerührt, getrocknet und die durch den sauren Alkohol aus den präformirten Kothseifen frei gemachten Fettsäuren durch abermaliges Extrahiren im Soxhlet in den Aether übergeführt. Nach Verdunsten des Aethers und Trocknen wurden so noch $0,599 \mathrm{~g}$ Fettsäuren aus Seifen gewonnen, so dass auf den gesammten Trockenkoth $9,37 \mathrm{~g}$ Seifen, als Fettsäuren gewogen, entfallen. Somit enthielt der Koth im Ganzen $(44,65+6,26=) 51,91 \mathrm{~g}$ neutrales Aetherextract (Fett, Fettsäuren und Cholesterin) und darunter $\left(20,76+5,16 \Rightarrow 25,92 \mathrm{~g}\right.$ an freien Fettsäuren $\left.{ }^{1}\right)$, endlich $8,37 \mathrm{~g}$ an präformirten Seifen, insgesammt $61,28 \mathrm{~g}$ an Fettstoffen oder $15,32 \mathrm{~g}$ Kothfett pro Tag auf $55 \mathrm{~g}$ Nahrungsfett, so dass $27,9 \mathrm{pCt}$. des verfütterten Fettes unbenützt durch den Koth ausgestossen worden sind, d. h. fast doppelt so viel als in der 7 . und 9 . Woche $(15,5$ pCt.).

Zur Feststellung der N-Ausscheidung durch den Koth wurde zunächst $0,9554 \mathrm{~g}$ des (einmal mit Aether extrahirten) Trockenpulvers nach Kjeldahl behandelt und darin $0,0436 \mathrm{~g} \mathrm{~N}$ gefunden, so dass auf den gesammten Trockenkoth $3,802 \mathrm{~g} \mathrm{~N}$ entfallen. Da ferner das erste Aetherextract des gesammten Kothes, das auf 1 Liter aufgefüllt war, $\mathrm{N}$ enthalten konnte, wurde in $100 \mathrm{ccm}$ von diesem nach Verdunsten des Aethers gleichfalls $\mathrm{N}$ nach Kjeldahl zu $0,0245 \mathrm{~g}$ bestimmt, so dass im ganzen Aetherextract $0,245 \mathrm{~g} \mathrm{~N}$ waren. Mithin beträgt die Gesammtmenge des Koth-N $(3,802+0,245 \Rightarrow) 4,047 \mathrm{~g} \mathrm{~N}$ d. h. $1,012 \mathrm{~g} \mathrm{~N}$ pro $\mathrm{Tag}$, etwa ebenso viel als in den letzten 3 Wochen.

Von den mit dem Futter gegebenen verdaulichen Kohlehydraten wurden nicht mehr als in den letzten 3 Wochen, etwa 2,1 pCt. der Einfuhr unbenutzt ausgestossen.

$1,39 \mathrm{~g}$ des fettfreien Trockenkothes, fein pulverisirt, gaben nach Maercker $32 \mathrm{mg}$ Kupfer $=17 \mathrm{mg}$ Traubenzucker $=15,3 \mathrm{mg}$ Stärkemebl; folglich enthält der ganze 75,7 $\mathrm{g}$ wägende Trockenkoth $9,833 \mathrm{~g}$ Stärkemehl, entsprechend 2,1 pCt. der in 4 Tagen $464 \mathrm{~g}$ Kohlehydrate betragenden Einfuhr.

Endlich liess sich objectiv nachweisen, dass der Antheil der beigemischten Galle zum Koth, obwohl, absolut ge-

1) Mithin waren $(51,91-25,92 \Rightarrow 25,99 \mathrm{~g}$ Rohfett ungespalten, (25,92+ $9,37 \Longrightarrow 35,29 \mathrm{~g}$ gespalten (freie Fettsäuren, Seifen); somit verhält sich im Koth das nicht gespaltene Fett zum gespaltenen wie 1:1,4. 
nommen, nicht mehr $\mathrm{N}$ ausgestossen wurde, als in den Vorwochen, doch noch geringer war. Der aus dem Koth durch siedenden Alkohol extrahirbare $\mathrm{N}$ betrug im Ganzen nur $0,614 \mathrm{~g}$, also auf den Tag $0,154 \mathrm{~g}$ gegenüber $1,012 \mathrm{~g}$ Gesammt-N d. h. vom Koth- $\mathrm{N}$ ist fast nur $\frac{1}{7}$ auf Beimengung von Gallenstoffen $\mathrm{zu}$ beziehen, mithin noch weniger als in der 7. und 9 . Woche $\left(\frac{1}{5}-\frac{1}{6}\right)$ und etwa nur ebenso viel als sich nach den oben angeführten Bestimmungen im acholischen Koth findet, so dass von beigemischter Galle jedenfalls nur wenig vorhanden war (S. 116).

$6,8092 \mathrm{~g}$ des (entfetteten) Trockenpulvers, mit Alkohol am Rückflusskübler gekocht, gaben im Alkoholauszuge $0,0497 \mathrm{~g} \mathrm{~N}$, also treffen auf den ganzen Trockenkoth $0,556 \mathrm{~g}$ alkohollöslicher $\mathrm{N}$. Da auch das erste Aetherextract $\mathrm{N}$-haltige Gallenstoffe enthalten konnte, wurden aus $200 \mathrm{ccm}$ des auf 1 Liter gebrachten Aetherextractes der Aether verdunstet und der Rückstand mit Alkobol erschöpft; das alkoholische Filtrat und die Waschwässer gaben nach Verjagen des Alkohols beim Kochen mit Schwefelsäure $0,0116 \mathrm{~g} \mathrm{~N}$, also waren im gesammten Aetherextract $0,058 \mathrm{~g}$ alkohollöslicher $\mathrm{N}$.

Während in der 7.-9. Woche noch das Allgemeinbefinden kaum verändert erschien, trat im Verlaufe der 9. Woche und noch deutlicher in der 10. Woche eine Umwälzung im ganzen Verhalten des Hundes ein: seine Lebhaftigkeit nahm ab, er warde sichtlich matter und matter, sein vorher lautes Bellen wurde rauh und heiser (vox rauca). Unter diesen Umständen und da sein Körpergewicht um $500 \mathrm{~g}$ abgenommen hatte (Ende der 6 . Woche $11,1 \mathrm{~kg}$, Mitte der 11 . Woche $10,62 \mathrm{~kg}$ ), wurde der Versuch abgebrochen und zu einem eiweissreicheren Futter übergegangen. $\mathrm{Da}$ in den letzten 4 Wochen (13. Januar bis 11. Februar) der Hund rund $\left.30 \mathrm{~g} \mathrm{~N}^{1}\right)=880 \mathrm{~g}$ Körperfleisch eingebüsst hatte und doch nur um $500 \mathrm{~g}$ leichter geworden war, so mussten $380 \mathrm{~g}$ wohl in Form von Wasser und vielleicht etwas Fett zum Ansatz gelangt sein.

1) Durch den Harn scbied der Hund an diesen 30 Tagen aus $80,61 \mathrm{~g} \mathrm{~N}$, durch den Koth rund $31 \mathrm{~g} \mathrm{~N}$, im Ganzen also $116,6 \mathrm{~g} \mathrm{~N}$, denen eine Einfuhr von $(30 \times 2,74 \Rightarrow 82,2 \mathrm{~g} \mathrm{~N}$ gegenübersteht. Somit übersteigt die $\mathrm{N}$-Ausscheidung um $29,4 \mathrm{~g}$ die $\mathrm{N}$-Einnabmen. - Uebrigens ist in dem vorläufigen kurzen Bericht über diesen Versuch [Arch. f. (Anat. u.) Physiol. 1891. S. 346] in Folge unrichtiger Berechnung der Verlust zu $33 \mathrm{~g} \mathrm{~N}=1000 \mathrm{~g}$ Körperfleisch angegeben worden. 
Eiweissreichere Nachperiode.

Es wurden nun $23 \mathrm{~g}$ Kohlehydrate abgezogen und dafür $23 \mathrm{~g}$ Eiweiss hinzugefügt, so dass das Futter jetzt aus $40,4 \mathrm{~g}$ Eiweiss (mit $6,41 \mathrm{~g} \mathrm{~N}$ ), $55 \mathrm{~g}$ Fett, $93 \mathrm{~g}$ Kohlehydrate bestand (46 g Fleischmehl, $46 \mathrm{~g}$ Schmalz, $119 \mathrm{~g}$ Reiss) und das Nährstoffverhältniss nunmehr ein engeres $=1: 5,4$ wurde.

$\begin{array}{rll}\text { Febr. } 12 . & 3,168 \mathrm{~g} \mathrm{~N} \text { im Harn } & 10,83 \mathrm{~kg} \\ 13 . & 3,554 & 10,87 \\ 14 . & 4,168 & 10,9 \\ 15 . & 4,635 & 11,07 \\ 16 . & 3,925 & 11,26\end{array}$

Es stieg somit innerhalb 5 Tagen das Gewicht von 10,62 auf $11,26 \mathrm{~kg}$, um $640 \mathrm{~g}$ an, und obwohl offenbar Eiweiss ans dem Futter angesetzt wurde ${ }^{1}$ ), besserte sich das Allgemeinbefinden nicht, die Mattigkeit nahm eher zu und am 17. Februar machte der Hund den Eindruck eines Schwerkranken, auch verschmähte er das Futter. Da zu vermuthen war, dass frisches Fleisch, anstatt des Fleischmehls gereicht, mehr den Appetit reizen möchte, wurde ein Futter von gleicher Nährstoffmischung aus $160 \mathrm{~g}$ frischem Fleisch, $50 \mathrm{~g}$ Schmalz und $119 \mathrm{~g}$ Reiss mit $500 \mathrm{ccm}$ Wasser abgekocht; davon verzehrte er sofort etwa den 3. Theil, am Abend noch ein Theil und über Nacht den Rest. Allein am nächsten Morgen erbricht er einen, zumeist aus Reisskörnern bestebenden Brei, zugleich liess er Harn und dünnen Koth in den Käfig. Das Allgemeinbefinden erschien noch schlechter, der Kräftezustand noch elender als Tags zuvor; der Hund steht unsicher und knickt bald hinten, bald vorn um, sein Bellen war kraft- und tonlos. Unter diesen Umständen wurde der Reiss fortgelassen und nur $500 \mathrm{~g}$ Fleisch, $25 \mathrm{~g}$ Fleischmehl und $10 \mathrm{~g}$ Fett, mit $300 \mathrm{ccm}$ Wasser abgekocht, gegeben. Das Futter enthielt nur 712 Cal., oder pro Körperkg 63 Cal., ähnlich dem als ausreichend erprobten Futter der eiweissreicheren Vorperiode (S. 96). Nach Aufnahme dieses Futters scheint er sichtlich erholt; er bleibt dauernd ausserhalb des Käfigs. Am 19. Februar war das Befinden wieder schlecht, die Hinterbeine erschienen

1) Durch den Harn sind an diesen 5 Tagen ausgeschieden worden $19,45 \mathrm{~g} \mathrm{~N}$ und durch den Koth, boch gerecbnet, $5 \mathrm{~g} \mathrm{~N}$, also $24,45 \mathrm{~g} \mathrm{~N}$ gegenüber einer Einfuhr von $(5 \times 6,41 \Rightarrow 32,05 \mathrm{~g} \mathrm{~N}$, so dass $7,6 \mathrm{~g} \mathrm{~N}=224 \mathrm{~g}$ Fleisch im Körper zurückbehalten worden sind.

A rehir f. pathol. Anat. Bd. 192. Hft. 1. 


\section{4}

ganz paretisch. Er erhält nun ein noch eiweissreicheres Futter: $500 \mathrm{~g}$ Fleisch, $30 \mathrm{~g}$ Fett, mit $400 \mathrm{~g}$ Wasser abgekocht. Nach Verzehren dieses Futters erscheint er wieder erholt; er kann besser auf den Beinen stehen. Am Abend erhält er noch $150 \mathrm{~g}$ Fleisch, $25 \mathrm{~g}$ Fleischmehl und $20 \mathrm{~g}$ Fett, mit $200 \mathrm{~g}$ Wasser abgekocht; auch diese Ration verzehrt er gierig. Im Ganzen hat er an diesem Tage $147 \mathrm{~g}$ Eiweiss und $67 \mathrm{~g}$ Fett gefressen. Am nächsten Vormittag befindet er sich erheblich besser, steht gut auf allen Vieren, bewegt sich ziemlich lebhaft und bellt, zwar heiser, aber ziemlich laut. Er frisst mit Gier in 2 Rationen im Ganzen $550 \mathrm{~g}$ Fleisch, $50 \mathrm{~g}$ Fleischmehl und $45 \mathrm{~g}$ Schmalz, mit $400 \mathrm{~g}$ Wasser abgekocht. An den beiden letzten Tagen hat er je $147 \mathrm{~g}$ Eiweiss und $69 \mathrm{~g}$ Fett bekommen, deren Wärmewerth 1230 Cal. beträgt. Da er sich danernd ausserhalb des Käfigs befand und in Folge seines Schwächezustandes den Harn nicht gehalten hat, können für diese 3 Tage der fleisch- und fettreichen Ernährung Angaben über die N-Ausscheidung durch den Harn nicht gemacht worden. Da er nunmehr wieder ganz munter war, schwarzen Fleischkoth, wie ein gesunder Hund, absetzte, wurde wieder zum gemischten, aus Fleisch, Reiss und Fett bestehenden Futter übergegangen. Von nun an erhielt er — er wog jetzt sogar $11,61 \mathrm{~kg}-200 \mathrm{~g}$ Fleisch, $45 \mathrm{~g}$ Schmalz und $100 \mathrm{~g}$ Reiss, mit $500 \mathrm{~g}$ Wasser abgekocht; darin waren $47 \mathrm{~g}$ Eiweiss (mit 7,6 g N), $50 \mathrm{~g}$ Fett, $77 \mathrm{~g}$ Kohlehydrate, im Ganzen $147 \mathrm{~g}$ Trockensubstanz (Nührstoffverhältniss $=1: 4.2$ ) mit einem Wärmewerth von 942 Cal. oder pro Körperkg $78 \mathrm{Cal}$. Bei diesem eiweissreicheren Futter stieg sein Gewicht noch etwas an; zugleich warden beträchtliche Mengen vom Nahrungseiweiss im Körper zurückbehalten, wie aus nachfolgender tabellarischer Aufstellung hervorgeht.

\begin{tabular}{|c|c|c|c|}
\hline & Harn-N & Kotb-N & Gewicht \\
\hline Febr. 21. & 5,224 & & 11,77 \\
\hline 22 . & 4,344 & & 11,88 \\
\hline 23. & 5,011 & & 11,95 \\
\hline 24. & 4,768 & & 11,96 \\
\hline 25. & 4,123 & $\left.1,5764^{1}\right)$ & 11,88 \\
\hline 26 . & 3,264 & oder pro Tag & 11,79 \\
\hline 27. & 3,621 & 0,526 & 11,71 \\
\hline
\end{tabular}

1) Koth, schwarzbraun, geformt. In 3 Tagen $150,4 \mathrm{~g}$ feucht $=46,2 \mathrm{~g}$ trocken. 1,0484 g Trockenkoth geben $0,0358 \mathrm{~g} \mathrm{~N}$. - Vom Trockenkoth 


\begin{tabular}{|c|c|c|c|c|}
\hline \multirow{2}{*}{\multicolumn{2}{|c|}{ Febr. 28.}} & Harn-N & Koth-N & Gewicht $\mathrm{kg}$ \\
\hline & & 5,301 & & 11,75 \\
\hline \multirow[t]{3}{*}{ März } & 1. & 5,605 & & 11,78 \\
\hline & 2. & 5,369 & & 11,71 \\
\hline & 3. & 5,394 & & 11,79 \\
\hline
\end{tabular}

Der schwarzbraun gefärbte Koth betrug für 3 Tage (25. bis 27. Februar) nur noch $150 \mathrm{~g}$ feucht $=46,2 \mathrm{~g}$ trocken; es gingen also nur 8,8 pCt. der aufgenommenen Trockensubstanz unbenützt mit dem Koth heraus. Die N-Ausscheidung durch den Koth betrug, obwohl mehr denn 3 mal so viel $\mathrm{N}$ eingeführt wurde, als in den 11 Wochen der eiweissarmen Fütterung, nur noch halb so viel als während der letzten Wochen. Die Fettresorption besserte sich so sehr, dass nur noch im Tag 1,13 g Rohfett mit dem Koth austraten, d. h. von dem Nahrungsfett nur noch 2,3 pCt., wie dies auch in der Norm der Fall ist, während bei der eiweissarmen Fütterung von derselben Menge Nahrungsfett in der 7. Woche 15 pCt., in der 10. Woche sogar 28 pCt. mit dem Koth ausgestossen worden sind. Von eingesprenkelten Reisskörnern war nichts im Koth za erkennen. Somit durfte zweifellos die Resorption der Nährstoffe im Darm nunmehr als der Norm entsprechend angesehen werden. In diesen 11 Tagen traten mit dem Harn $52,02 \mathrm{~g} \mathrm{~N}$, mit dem Koth $(11 \times 0,526=5,79 \mathrm{~g} \mathrm{~N}$, im Ganzen $57,81 \mathrm{~g} \mathrm{~N}$ heraus, während mit der Nahrung $(11 \times 7,6 \Rightarrow) 83,6 \mathrm{~g} \mathrm{~N}$ eingeführt worden sind, so dass $25,8 \mathrm{~g} \mathrm{~N}$ oder rund $760 \mathrm{~g}$ Körperfleisch zum Ansatz gelangt sind. Da am Ende dieser 11 tägigen Periode das Körpergewicht nur ebenso hoch war, als am 1. Tage, muss, neben dem Eiweissansatz, Verlust von Wasser, vielleicht auch von etwas Fett erfolgt sein. Hauptsächlich wird wohl Wasser fortgegangen sein, ist doch genügend bekannt, dass bei lange fortgesetzter unzureichender Nahrung oder bei Eiweissverlusten in Folge protrahirten Hungers die Gewebe wasserreicher werden und bei darauf folgender Zufuhr von reichlichem Eiweiss das Wasser in

geben $12,18 \mathrm{~g} 0,688 \mathrm{~g}$ neutrales Aetherextract

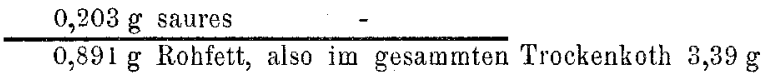
(davon $1,29 \mathrm{~g}$ freie Fettsäuren). - 3,17 $\mathrm{g}$ Trockenkoth, mit siedendem Alkohol erschöpft; alkoholisches Filtrat giebt $0,040 \mathrm{~g} \mathrm{~N}$, also it Gesammtkoth $0,291 \mathrm{~g}$ alkohollöslicher $\mathrm{N}=55$ pCt. des Gesammt-N. 
Strömen mit dem Harn den Körper verlässt ${ }^{1}$ ). In der That betrug die Harnmenge an diesen Tagen $232-576 \mathrm{ccm}$, während sie bei der eiweissarmen Nahrung nur zwischen den Grenzen von 132 und $243 \mathrm{ccm}$ geschwankt hatten.

Dass endlich nunmehr auch wieder eine reichlichere Gallensecretion erfolgte, geht aus der sehr viel stärkeren Gallenbeimengung zum Koth hervor, wofür einmal die dunkle schwarzbraune Färbung des Kothes spricht, sodann die sehr viel grössere Menge des, in der Hauptsache von Gallenstoffen herrührenden alkohollöslichen Antheiles von Koth-N. Während bei der eiweissarmen Nahrung in der 7 . Woche nur $\frac{1}{5}-\frac{1}{6}$ und in der 10. Woche sogar nur $\frac{1}{7}$ des Koth-N sich in Alkohol löste, ging nunmehr über die Hälfte, 55 pCt. ${ }^{2}$ ) des Koth-N in Alkohol über. Noch sicherer geht dies aus der absoluten Menge des auf den Tageskoth entfallenden alkohollöslichen N. Während in der 7. Woche ungeachtet der grossen Kothmenge (31 g Trockensubstanz pro Tag) nur $0,189 \mathrm{~g}$, in der 10 . Woche (bei $33 \mathrm{~g}$ Trockensubstanz) sogar nur $0,154 \mathrm{~g}$ in Alkohol löslicher $\mathrm{N}$ pro Tag im Koth erschien, betrug jetzt (bei nur 15,4 g Trockensubstanz) die Tagesmenge des alkohollöslichen N 0,291 g, also doppelt so viel als in der letzten Periode der eiweissarmen Fütterung und etwa ebenso viel als in der gleichfalls eiweissreicheren Vorperiode (vergl. Fussnote 1, S. 108).

Aus dieser durch 19 Wochen durchgefühiten Beobachtung geht hervor, dass eine sonst dem Bedarf genügende, eiweissarme Nahrung nach einer Reihe von Wochen (6-7) zur Beeinträchtigung der Verdauung und Verschlechterung der Ausnützung führt, die am stärksten das Nahrungsfett trifft, auch wenn nul mässige Mengen davon ( $5 \mathrm{~g}$ pro Körperkg) verabreicht werden, in schwächerem Grade das Nahrungseiweiss, am wenigsten die Kohlehydrate, dass ferner in Folge davon das vorher behauptete $\mathrm{N}$ - und Körpergleichgewicht gestört und weiterhin auch der Appetit und der Kräftezustand hochgradig geschädigt wird.

Aus der in den späteren Wochen der eiweissarmen Fütterung kaum noch galligen Färbung des Kothes war schon zu

1) Bischoff und Voit, Die Gesetze der Ernährung des Fleischfressers. 1860. S. 210.

3) Vergl. die analytischen Ergebnisse unter Anmerkung S. 115. 
schliessen, und dieser Schluss wird durch den Nachweis des auffällig niedrigen Betrages an (von Residuen der Galle herrührenden) alkohollöslichem Stickstoff im Koth objectiv gestützt, dass die Galle und vermuthlich auch die anderen Verdauungssäfte spärlicher als in der Norm abgeschieden werden. Bei der Herstellung der Secrete ist, wie zuerst Heidenhain erwiesen hat, das Protoplasma der Drüsenzellen in erster Reihe betheiligt und geht zum Theil dabei zu Grunde (Speicheldrüsen, Milchdrüsen u. A.). Die eiweissarme Kost dürfte - dieser Schluss liegt wohl nahe - nicht genügend Eiweissmaterial für die Regeneration des Protoplasmas der Verdauungsdrüsen erübrigen lassen, daher allmählich die Secretionsgrösse der Verdauungssäfte absinkt.

Schon in meinem ersten kurzen Bericht habe ich es als erforderlich bezeichnet, weitere Versuche anzustellen, um so Aufschluss za gewinnen, ob die, wie es scheint, durch eiweissarme Kost hervorgerufene geringere Widerstandsfähigkeit des Organismus nicht auch gelegentlich sich durch andere Störungen äussert als durch Verschlechterung der Ausnützung der Nährstoffe und deren Folgen. Diese Versuche habe ich ausgeführt und bin nunmehr in der Lage, von 3 weiteren, durch längere Zeit fortgeführten Reihen, in denen ebenfalls ein sonst ausreichendes, aber eiweissarmes Futter gegeben wurde, Mittheilung machen zu können.

Von den mancherlei Möglichkeiten anderweitiger, durch eiweissarme Nahrung hervorgerufener Störungen abgesehen, lag zu einer Fortsetzung der Untersuchungen um so mehr Anlass vor, als Rosenheim ${ }^{\mathbf{1}}$ ) zu gleicher Zeit eine Beobachtung über den "gesundheitsschädigenden Einfluss eiweissarmer Ernährung“ veröffentlicht hat. Ein $11 \mathrm{~kg}$ schwerer Hund kam mit einer kohlehydratreichen Nahrung, die bei $16 \mathrm{~g}$ Eiweiss fast $100 \mathrm{Cal}$. pro Körperkg bot, in N-Gleichgewicht und nahm innerhalb 4 Wochen noch $1,5 \mathrm{~kg}$ an Körpergewicht $z \mathrm{u}$; dabei wurden die Nährstoffe vorzüglich ausgenützt. In der 5 . Woche traten Störungen des Appetits and des Allgemeinbefindens, sowie leichter

1) Arch. f. (Anat. u.) Physiol. 1891. S. 341. 
Icterus auf, das Gewicht sank um $1,2 \mathrm{~kg}$. Von der 6. Woche ab besserte sich der Appetit wieder bei regelmässiger Einfuhr einer Nahrung, die, bei gleichem Calorienwerth wie in den ersten 5 Wochen, neben $16 \mathrm{~g}$ Eiweiss $105 \mathrm{~g}$ Fett bot. Nun trat wieder N-Gleichgewicht ein, nur 4 pCt. des Fettes gingen mit dem Koth heraus. In der 7. Woche wurde das Befinden wieder schlechter: die Nahrung wurde verweigert, nur kleine Fleischportionen aufgenommen, das Gewicht sank um $0,85 \mathrm{~kg}$. Ohne Fieber ging am Ende der 7. Woche der Hund zu Grunde; der respiratorische Gaswechsel (O-Aufnahme, $\mathrm{CO}_{2}$-Ausscheidung) bot an einem der letaten Tage vor dem Tode keine Abweichung dar. Die Section ergab hochgradige fettige Entartung der Epithelien in der Magenund Dünndarmschleimhaut und vergrösserte Fettleber. Die Degenerationen am Darm und Leber erachtet Rosenheim als durch die unzweckmässige, eiweissarme Ernährung hervorgerufen.

$\mathrm{Zuntz}{ }^{1}$ ) berichtet neuerdings eine gleichfalls hierher gehörige Erfahrung. Ein Hund von $7 \mathrm{~kg}$ erhielt ein Jahr lang in $50 \mathrm{~g}$ Fleisch und $150 \mathrm{~g}$ Reiss pro Tag $19 \mathrm{~g}$ Eiweiss, $2 \mathrm{~g}$ Fett, $116 \mathrm{~g}$ Kohlehydrate (Verhältniss $1: 6,5$ ), also $2 \frac{1}{2} \mathrm{~g}$ Eiweiss pro $\mathrm{kg}$. Nachdem dies Futter länger als ein Jahr ohne Schaden genommen war, wurde durch Verminderung des Fleisches auf $25 \mathrm{~g}$, des Reiss auf $120 \mathrm{~g}$ and Zugabe von $25 \mathrm{~g}$. Schmaly die Riweissgabe auf knapp $13 \mathrm{~g}$, entsprechend $1,8 \mathrm{~g}$ Eiweiss pro kg, herabgesetzt (Nährstoffverhältniss $=1: 12,7$ ). Hierbei hielt sich der Hund noch 8 Wochen lang vollkommen normal; in der 9. Woche aber traten Verdaungsstörungen auf, die erst nach Erhöhung der Fleischgabe wieder schwanden.

\section{Zweite Versuchsreihe.}

$\mathrm{Zu}$ dieser, am 6. Mar 1891 begonnenen Untersuchung diente ein $10,4 \mathrm{~kg}$ schwerer schwarzer Pudel, der zuerst durch ein gemischtes Futter mit nur mässigem Eiweissgehalt in $\mathrm{N}$ - und Körpergleichgewicht gebracht werden sollte. Er erhielt $85 \mathrm{~g}$ Reiss, $29 \mathrm{~g}$ Schmalz und $30 \mathrm{~g}$ Fleischmehl ${ }^{2}$ ), mit $600 \mathrm{~g}$ Wasser abgekocht, im Ganzen $131 \mathrm{~g}$ Trockensubstanz; darin waren $30,3 \mathrm{~g}$

1) Zuntz u. Ad. Magnus-Levy, Pflüger's Arcb. Bd. 49. 1891. S. 440.

2) Das Fleischmehl enthielt 13,237 pCt. N. und 6,221 pCt. Rohfett (Aetherextract). 
Eiweiss (mit 4,81 $\mathrm{g} \mathrm{N}$ ), $31 \mathrm{~g}$ Fett, $66 \mathrm{~g}$ Kohlehydrate und dazu noch $2 \mathrm{~g}$ des künstlichen Gemisches der Fleischsalze (S. 102). Die verwerthbare potentielle Energie dieses Futters mit dem Nährstoffverhältniss 1:4,6 berechnet sich zu 663 Cal. oder pro $\mathrm{kg} 63 \mathrm{Cal}$; in der Regel reicht ein Hund vom angegebenen Gewicht damit aus.

Vom 12. Mai ab wurde der Harn gesammelt und die Tagesmenge durch den Katheter abgegrenzt. Weiterhin wurde jede oder jede zweite Woche der auf 3-4 Tage treffende Koth bestimmt, indem vorher und nachher Knochen verabreicht wurden; es fand sich dann der auf die Versuchszeit entfallende Koth zwischen den Knochenkoth eingeschaltet.

\begin{tabular}{|c|c|c|c|}
\hline & $\operatorname{Harn}-\mathrm{N}$ & Koth-N & Gewicht lig \\
\hline Mai 12. & 3,18 & & 10,38 \\
\hline 13. & 3,205 & & 10,29 \\
\hline 14. & 3,44 & & 10,8 \\
\hline 15. & 3,567 & & 10,28 \\
\hline 16. & 3,472 & & 10,19 \\
\hline 17. & 3,615 & & 10,15 \\
\hline 18. & 3,596 & & 10,1 \\
\hline 19. & 3,735 & & 10,06 \\
\hline 20. & 3,998 & & 10,08 \\
\hline 21. & 4,219 & & 10,07 \\
\hline 22. & 4,278 & & 10,01 \\
\hline 23. & 4,183 & ader pro Tag & 10,0 \\
\hline 24. & 3,865 & ouer pro lag & 9,94 \\
\hline 25. & 4,025 & & 9,96 \\
\hline 26. & 4,37 & & 9,97 \\
\hline 27. & 3,828 & & 9,96 \\
\hline 28. & 4,318 & & 9,99 \\
\hline
\end{tabular}

Vom 18. Mai ab bestand annähernd Körpergleichgewicht. Für die 4 Tage (22.-25. Mai) berechnet sich die $\mathrm{N}$-Ausscheidung

1) Koth von 4 Tagen $112,4 \mathrm{~g}$ feucht $=34,1 \mathrm{~g}$ trocken, entsprechend 6,5 pCt. der eingeführten festen Stoffe.

$1,459 \mathrm{~g}$ Trockenkoth geben $0,05844 \mathrm{~g}$ N.

$12,224 \mathrm{~g}$

- $1,101 \mathrm{~g}$ neutrales Aetherextract

$\frac{0,149 \mathrm{~g} \text { saures }}{1,25 \mathrm{~g} \text { Rohfett, }}$

mithin im ganzen Koth $3,486 \mathrm{~g}$ Fettkörper (davon Neutralfett + Cholesterin $0,758 \mathrm{~g}$, freie Fettsäuren $2,313 \mathrm{~g}$, Fettsäuren aus Seifen $0,415 \mathrm{~g}$ ), entsprechend $2,8 \mathrm{pCt}$. der Fetteinfuhr. 
durch den Harn zu 16,35 g, durch den Koth zu 1,366 g, macht zusammen $17,72 \mathrm{~g} \mathrm{~N}$. Dem gegenüber betrug die $\mathrm{N}$-Einfuhr $(4 \times 4,81 \Rightarrow 19,24 \mathrm{~g} \mathrm{~N}$, so dass noch etwas $\mathrm{N}$, pro Tag $0,38 \mathrm{~g}=$ 2,4 g Eiweiss ( $11 \mathrm{~g}$ Fleisch), am Körper zum Ansatz gelangten. Die Ausnützung war eine sehr gute, insofern nur 6,5 pCt. der Trockensubstanz und 2,8 pCt. des Fettes vom Futter unbenützt mit dem Koth austraten. $V$ on dem Nahrungs- $N$ wurden scheinbar 10,6 pCt. mit dem Koth ausgestossen, allein diese Berechnung ist, wie schon oben (S. 98) erörtert, deshalb nicht zutreffend, weil, je geringer der N-Gehalt der Nahrung, eine relativ desto grössere Quote der von den Verdanungssäften gelieferte, mit dem Koth ausgestossene Antheil N-haltiger Stoffe (Gallensäuren, Gallenfarbstoff, Mucin, Darmschleim, Darmepithelien) bildet.

Eiweissarme Nahrung.

Vom 29. Mai ab wurden $15 \mathrm{~g}$ Eiweiss fortgelassen und durch $15 \mathrm{~g}$ Kohlehydrat ersetzt, so dass nunmehr die gleichfalls 64 CaI. pro Körperkg bietende Nahrung aus $15,3 \mathrm{~g}$ Eiweiss (mit $2,42 \mathrm{~g} \mathrm{~N}$ ), $31 \mathrm{~g} \mathrm{Fett,} 81 \mathrm{~g}$ Kohlehydraten bestand, und zwar wurde diese Ration in $10,4 \mathrm{~g}$ Fleischmehl (später zur Anregung des Appetits in $41 \mathrm{~g}$ Schabefleisch), $30 \mathrm{~g}$ Schmalz und $105 \mathrm{~g}$ Reiss gereicht, die mit $500 \mathrm{~g}$ Wasser unter Zusatz von je $2 \mathrm{~g}$ des Gemisches der Fleischsaize abgekocht wurden. Nunmehr gestaltete sich die $\mathrm{N}$-Ausscheidung so:

$\begin{array}{rrll}\text { Mai } & 29 . & 4,336 \mathrm{~g} \mathrm{~N} \text { im Harn } & 9,98 \mathrm{~kg} \\ 30 . & 2,432 & 9,87 \\ 31 . & 2,665 & 9,82 \\ \text { Juni } & 1 . & 2,395 & 9,77 \\ & 2 . & 2,308 & 9,76 \\ & 3 . & 2,41 & 9,77 \\ \text { (2. Woche) } & 4 . & 2,57 & 9,7 \\ & 5 . & 2,338 & 9,75 \\ & 6 . & 3,058 & 9,74 \\ & 7 . & 3,31 & 9,82\end{array}$

Da schon im Harn allein so viel $N$ war, als mit dem Futter zur Einfuhr gelangt ist, und an den beiden letzten Tagen die $\mathrm{N}$-Ausscheidung durch den Harn stark in die Höhe ging, um 27-38 pCt. gegen das Mittel der voraufgegangenen 5 Tage, so war damit bewiesen, dass die Nahrung weit davon entfernt war, zu N-Gleichgewicht zu führen. 
Es wurde deshalb bei gleichbleibender Eiweissmenge $(2,46 \mathrm{~g}$ N) auf $32 \mathrm{~g}$ Fett und $89 \mathrm{~g}$ Kohlehydrate, mit $137 \mathrm{~g}$ Trockensubstanz, angestiegen, so dass das Futter nunmehr 794 verwerthbare Cal. oder pro Körperkg 72 Cal. bot.

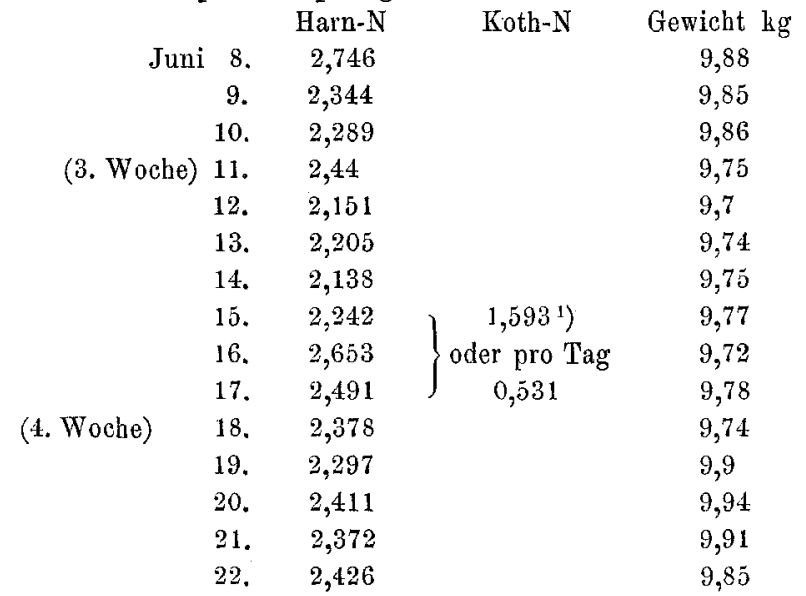

Die gewährte Zulage an N-freien Stoffen hat den N-Umsatz zwar herabgesetzt, aber noch kein N-Gleichgewicht, wohl aber Körpergleichgewicht bewirkt; denn der Harn-N liegt nur um $0,1 \mathrm{~g}$ unter dem Futter- $\mathrm{N}$; dabei wurden noch $0,53 \mathrm{~g} \mathrm{~N}$ pro Tag mit dem Koth ausgestossen, so dass $0,4 \mathrm{~g}$ N vom Körper täglich zu Verlust gegangen sind. Deshalb wurde abermals an $\mathrm{N}$-freien Stoffen zugelegt, so dass die Ration jetzt aus $15,5 \mathrm{~g}$ Eiweiss (mit 2,46 $\mathrm{g} \mathrm{N}$ ), $37 \mathrm{~g}$ Fett und $96 \mathrm{~g}$ Kohlehydraten mit $149 \mathrm{~g}$ Trockensubstanz bestand und 780 verwerthbare Cal. oder pro Körperkg 78 Cal. bot. Diese Ration mit einem Nährstoffverhältniss $1: 12$, wie es sonst nur im Futter der grossen Planzenfresser vorkommt, wurde in $37 \mathrm{~g}$ Schabefleisch, $36 \mathrm{~g}$ Schmalz und $125 \mathrm{~g}$ Reiss, mit $600 \mathrm{ccm}$ Wasser abgekocht, gereicht.

$\begin{array}{rcccc} & & \text { Harn-N } & \text { Koth-N } & \text { Gewicht kg } \\ \text { Juni 23. } & 2,338 & & 9,94 \\ \text { 24. } & 2,186 & & 9,98 \\ \text { (5. Woche) 25. } & 2,026 & & 9,93 \\ 26 . & 2,126 & & 10,01\end{array}$

1) Koth ron 3 Tagen, $98,3 \mathrm{~g}$ feucht $=29,6 \mathrm{~g}$ trocken, entsprechend 7,2 pCt. der Futtertrockensubstanz. $1,164 \mathrm{~g}$ geben $0,06264 \mathrm{~g} \mathrm{~N}$. 


\begin{tabular}{|c|c|c|c|c|}
\hline & & Harn-N & Koth-N & Gewicht $\mathrm{kg}$ \\
\hline Juni & 27. & 1,973 & & 10,06 \\
\hline & 28. & 1,998 & & 10,05 \\
\hline & 29. & 2,099 & & 10,08 \\
\hline & 30. & 2,063 & & 10,11 \\
\hline Juli & 1. & 1,996 & $\left.1,672^{1}\right)$ & 10,23 \\
\hline (6. Woche) & 2. & 1,72 & oder pro Tag & 10,27 \\
\hline & 3. & 1,932 & 0,557 & 10,18 \\
\hline & 4. & 1,754 & & 10,21 \\
\hline & 5. & 1,807 & & 10,14 \\
\hline
\end{tabular}

Somit war jetzt N-Gleichgewicht erreicht. An 3 Tagen (1.-3. Juli) betrug die $\mathrm{N}$-Ausscheidang durch den Harn $5,648 \mathrm{~g}$, durch den Koth 1,672 g, zusammen 7,32 g oder pro Tag 2,44 g N gegenüber $2,46 \mathrm{~g} \mathrm{~N}$ in der Einfuhr. Die Nahrung genügte nicht nur den Körperbestand $\mathrm{zu}$ wahren, vielmehr fand innerhalb 13 Tagen noch eine Gewichtszunahme um $200 \mathrm{~g}$, im Tagesmittel um $15 \mathrm{~g}$ statt. Gleichzeitig war die Ausnützung dieses eiweissarmen, kohlehydratreichen Futters eine vorzügliche, insofern von der Trockensubstanz nur $6 \mathrm{pCt}$. und vom Fett knapp 2 pCt. unbenützt mit dem Koth ausgestossen wurden.

Bemerkenswerther Weise ist, gleichwie in der ersten Versuchsreihe hervorzuheben, dass, während bei einer Kost mit mässigem Eiweissgehalt ( $30 \mathrm{~g}$ Eiweiss) eine Ration, die 63 verwerthbare Cal. pro Körperkg. einschloss, nicht nur $\mathrm{N}$ - und Körpergleichgewicht herbeigeführt, sondern schon einen geringfügigen N-Ansatz am Körper bewirkt hat (S. 120), eine Kost von gleichem Inhalt an potentieller Energie, aber mit nur halb so viel Eiweiss beträchtlichen $\mathrm{N}$ - und Gewichtsverlust vom Körper zur Folge hatte und dass durch Zulage an $\mathrm{N}$-freien Stoffen der Wärmewerth der Nahrung bis auf 78 Cal. pro $\mathrm{kg}$ Thier, also um 25 pCt gesteigert werden musste, um N-Gleichgewicht

1) Koth von 3 Tagen $96,4 \mathrm{~g}$ feucht $=27,1 \mathrm{~g}$ trocken, entsprechend 6,1 CCt. der eingeführten Trockensubstanz.

$1,1534 \mathrm{~g}$ Trockenkoth geben $0,0712 \mathrm{~g} \mathrm{~N}$.

$7,879 \mathrm{~g}$. $\quad$ - $\quad$ - $0,3614 \mathrm{~g}$ neutrales Aetherextract $\frac{0,2218 \mathrm{~g} \text { saures }}{0,5832 \mathrm{~g} \text {, mithin im gesammten Koth }}$ $2,007 \mathrm{~g}$ Fettkörper (davon Neutralfett + Cholesterin $0,562 \mathrm{~g}$, freie Fettsäuren $0,681 \mathrm{~g}$, Fettsäuren aus Seifen $0,764 \mathrm{~g}$ ), entsprechend $1,8 \mathrm{pCt}$. des Nahrungsfettes. 
zu erzielen. Also erhellt auch aus dieser Beobachtung wieder, dass bei eiweissarmer Kost der Brennwerth der Nahrung viel grösser sein muss, wenn damit, verglichen mit eiweissreicherer Kost, der Körperbestand gewahrt werden soll.

Des Hinweises werth erscheint es, dass bei dieser eiweissarmen und kohlehydratreichen Kost mit dem woiten Nährstoffverhältniss $1: 12$ der Eiweissumsatz ausserordentlich tief herabgedrückt worden ist, zuletzt bis zu $1,72 \mathrm{~g} \mathrm{~N}$ pro Tag oder bis auf $0,18 \mathrm{~g} \mathrm{~N}$ pro Körperkg d. i. bis zu einem, unter dem der späteren Hungertage gelegenen Werth, ohne dass sich zunächst irgend welche Störungen der Körperfunctionen bemerkbar machten.

Von Interesse ist endlich noch die Berechnung des bis zur Erreichung des N-Gleichgewichtes stattgefundenen N-Verlustes vom Körper. In den ersten 33 Tagen der eiweissarmen Kost (29. Mai bis 30. Juni) sind durch den Harn $80,21 \mathrm{~g} \mathrm{~N}$ entleert worden, durch den Koth, zu $0,53 \mathrm{~g}$ pro Tag angesetzt, 17,49 $\mathrm{g} \mathrm{N}$, so dass die gesammte Ausscheidung $97,7 \mathrm{~g} \mathrm{~N}$ beträgt. Die $\mathrm{N}$-Einfuhr berechnet sich zu $(33 \times 2,45 \Rightarrow) 80,85 \mathrm{~g}$, folglich sind vom Körper rund $17 \mathrm{~g} \mathrm{~N}=500 \mathrm{~g}$ Fleisch eingebüsst worden. Da ungeachtet dieses Fleischverlustes der Hund sogar noch um $130 \mathrm{~g}$ schwerer geworden ist, müssen $(500+130=)$ $630 \mathrm{~g}$ in Form von Wasser und vielleicht auch von Fett am Körper abgelagert worden sein.

Mit der als ausreichend erprobten Ration von 15,5 g Eiweiss (mit 2,46 $\mathrm{g} \mathrm{N}$ ), $37 \mathrm{~g}$ Fett und $96 \mathrm{~g}$ Kohlehydrate wurde der Versuch weitergeführt.

$\begin{array}{rcccc}\text { Juli } & & \text { Harn-N } & \text { Koth-N } & \text { Gewicht kg } \\ & 1,611 & & 10,2 \\ \text { 7. } & 1,913 & & 10,29 \\ 8 . & 1,902 & & 10,27 \\ \text { (7. Woche) } & 9 . & 1,761 & & 10,32 \\ 10 . & 1,909 & 1) & 10,19 \\ 11 . & 1,822 & & 10,27 \\ 12 . & 1,896 & & 10,29 \\ 13 . & 1,803 & & 10,31 \\ 14 . & 1,941 & 10,26 \\ 15 . & 1,843 & & 10,31 \\ 16 . & 1,769 & 10,41\end{array}$

1) Koth weniger gelb gefärbt. Abgrenzung des Kothes nicht sicher gelungen, 


\begin{tabular}{|c|c|c|c|c|}
\hline (8. Woche) & Juli 17. & $\begin{array}{c}\text { Harn-N } \\
1,788\end{array}$ & \multirow[t]{2}{*}{ Kotb-N } & $\underset{10,42}{\text { Gewicht } \mathrm{kg}}$ \\
\hline \multirow{13}{*}{ (9. Wocbe) } & 18 & $-1)$ & & 10,38 \\
\hline & $\left.19 .{ }^{2}\right)$ & 1,863 & \multirow{12}{*}{$\begin{array}{c}\left.3,906^{3}\right) \\
\text { oder pro Tag } \\
0,976\end{array}$} & 10,45 \\
\hline & 20. & 2,762 & & 10,41 \\
\hline & 21. & 1,753 & & 10,49 \\
\hline & 22. & 1,946 & & 10,39 \\
\hline & 23. & 1,958 & & 10,37 \\
\hline & 24. & 2,198 & & 10,31 \\
\hline & 25. & 2,237 & & 10,26 \\
\hline & 26. & 1,968 & & 10,25 \\
\hline & 27. & 2,068 & & 10,34 \\
\hline & 28. & 1,966 & & 10,26 \\
\hline & 29. & 2,065 & & 10,24 \\
\hline & 30. & 2,005 & & 10,31 \\
\hline
\end{tabular}

Die 7. Woche ging noch ohne auffällige Veränderungen vorüber, doch erschien die geringe Färbung des Kothes auch Anderen, denen der Koth gezeigt wurde, deutlich. Sodann lenkte der Umstand die Aufmerksamkeit auf sich, dass, während bisher die Ration stets mit Gier und in weniger als 10 Minuten aufgefressen wurde, nunmehr ein von Tag zu Tag grösserer Theil des Futters zunächst stehen gelassen und erst im Laufe des Tages verzehrt wurde, weshalb vom 19 . Juli ab (8. Woche) das Futter in zwei Portionen: Vormittags und Abends verabreicht wurde. Auch diese nur halben Rationen wurden mit sichtlich geringerem Appetit, aber schliesslich immer noch vollständig verzehrt. Da die am Ende der 7. und Anfang der 8. Woche versuchte Kothabgrenzung nicht befriedigend ausfiel, wurde im Laufe der 8. Woche abermals der auf 4 Tage treffende Koth abzugrenzen gesucht, diesmal mit Erfolg. Der Koth war

1) Harn zum Theil verloren gegangen.

2) Frisst nicht mehr die Ration auf einmal auf; deshalb von nun an in 2 Portionen verabreicht.

3) Koth, graugelb, in 4 Tagen $191,3 \mathrm{~g}$ feucht $=64,2 \mathrm{~g}$ trocken, entsprechend $11 \mathrm{pCt}$. der eingeführten Trockensubstanz.

$1,4284 \mathrm{~g}$ Trockenkoth geben $0,087 \mathrm{~g} \mathrm{~N}$.

$9,941 \mathrm{~g} \quad$ - $\quad$ - $1,297 \mathrm{~g}$ neutrales Aetherextract $\frac{0,641 \mathrm{~g} \text { satres }}{1,938 \mathrm{~g} \text { Robfett, also im ganzen Koth }}$ $12,52 \mathrm{~g}$ Rohfett (davon Neutralfett + Cholesterin 4,99, freie Fettsänren 4,29, Fettsäuren aus Seifen $3,24 \mathrm{~g}$ ) oder pro Tag 3,13 g Kothfett, entsprechend $8,5 \mathrm{pCt}$. der Fetteinfuhr. 
entschieden massiger als früher ( $38 \mathrm{~g}$ feucht pro Tag) und auffallend wenig gefärbt; auf den Tag trafen $16 \mathrm{~g}$ Trockensubstanz (gegen $8-9 \mathrm{~g}$ der Vorwochen), und während zuvor nur $6 \mathrm{pCt}$. der eingeführten Trockensubstanz ausgestossen wurden, waren es jetzt 11 pCt. In sehr reichlichem Maasse enthielt der Koth $\mathrm{N}$, pro Tag $0,98 \mathrm{~g}$ (gegen $0,56 \mathrm{~g} \mathrm{~N}$ der Vorwochen), so dass die $\mathrm{N}$ Ausscheidung durch den Koth rund halb so gross war als durch den Harn. Auch die Resorption des Nabrungsfettes, die in den Vorwochen, ebenso wie die der Trockensubstanz, vorzüglich gewesen war, hat sich verschlechtert, insofern nunmehr $8,5 \mathrm{pCt}$. vom Fett, also fast $5 \mathrm{mal}$ so viel als zuvor $(1,8 \mathrm{pCt}$. Fett) unbenützt mit dem Koth ausgestossen wurden. Immerhin ist selbst unter diesen Umständen die Fettresorption, absolut genommen, noch nicht als schlecht zu erachten. Von einer Einsprenkelung von Reiskörnern in den Koth war nichts wahrzunehmen, und so hat denn auch die Prüfung des Kothes auf lösliche Kohlehydrate nach Maercker's Verfahren (S. 106) keinen nennenswerthen Betrag davon im Koth ergeben. Indem so weniger Fette und weniger $\mathrm{N}$, als in den Vorwochen, zur Resorption gelangten, konnte das bisher bestandene $\mathrm{N}$-Gleichgewicht nicht mehr behauptet werden, die N-Ausscheidung durch den Harn stieg an und erreichte mit 2,237 $\mathrm{g}$ ihr Maximum, welch' letzteres das tägliche Mittel der Vorwochen, $1,8 \mathrm{~g} \mathrm{~N}$, um 24 pCt. überstieg. Doch gelangten selbst bei dieser ungünstigeren Ausnützung noch so viel Nährstofie zur Verwerthung, dass der resorbirte Antheil der Nahrung ( $9,3 \mathrm{~g}$ Eiweiss [mit 1,48 $\mathrm{g} \mathrm{N}$ ], $34 \mathrm{~g}$ Fett und $95 \mathrm{~g}$ Kohlehydrate) 734 Cal. oder pro Körperkg $72 \mathrm{Cal}$. lieferte, ein Betrag, der bei gewöhnlicher Kost mit mittlerem Eiweissgehalt erfahrungsgemäss den materiellen Bestand eines Hundes von $10 \mathrm{~kg}$ nicht nur zu wahren vermag, sondern in der Regel zum Stoffansatz führt.

Um über die Menge der Gallenbestandtheile im Koth eine objective Unterlage zu gewinnen, wurde der Trockenkoth nach dem oben geschilderten Verfahren (S. 108) mit siedendem Alkohol extrahirt und in der alkoholischen Lösung, nach Verjagen des Alkohols, der $\mathrm{N}$ nach Kjeldahl bestimmt. Es fand sich so ${ }^{1}$ ), dass von der pro Tag 0,976 $\mathrm{g} \mathrm{N}$ betragenden Aus-

1) 5,356 g pulverisirter Trockenkoth, 8 Stunden lang mit siedender Alkohol am Rückflusskübler extrahirt, das Gemisch auf $200 \mathrm{ccm}$ aufgetüllt; 
scheidung durch den Koth nur $0,22 \mathrm{~g}=22,5 \mathrm{pCt}$. alkohollöslich waren, während sonst selbst bei eiweissarmer und kohlehydratreicher Nahrung 35-44 pCt. des Koth-N sich in Alkohol lösten. Daraus erhellt, dass höchstens $\frac{2}{3}$ bis $\frac{1}{2}$ der N-haltigen Residuen von Gallenstoffen im Koth waren, als sonst in der Norm, höchst wahrscheinlich war auch die Bildung von Galle auf $\frac{2}{3}$ bis $\frac{1}{2}$ der normalen Grösse heruntergegangen.

Mit dem Beginn der 10. Woche der eiweissarmen Kost nahm der schon in letzter Zeit nur schwache Appetit noch mehr ab; auch trat wiederholtes Erbrechen auf. Am 31. Juli verzehrte der Hund seine Morgenration, erbrach etwa nach $\frac{1}{4}$ Stunde den grösseren Theil, frass aber das Erbrochene alsbald quantitativ genau wieder auf; die Abendration wurde ohne Weiteres verzehrt. Die N-Ausscheidung durch den Harn an diesem Tage betrug 2,076 g. Arn 1. August liess er, nachdem er schon zum Verzehren des Morgenfutters mehrere Stunden gebraucht hatte, von der Abendration reichlich die Hälfte stehen. In der Nacht erbrach er schmutzig grünliche Massen, welche sich mit dem bei den Brechbewegungen entleerten Harn vermischten. Am Morgen des 2. August wog er nur $10,11 \mathrm{~kg}$. Im Laufe des Vormittags erbrach er wiederholt eine dünne grüne Flüssigkeit und verschmähte nicht nur sein Fleischreissfutter, sondern sogar ein nur aus $200 \mathrm{~g}$ Fleisch und $20 \mathrm{~g}$ Fett hergestelltes Futter. Dabei sank sein Gewicht auf $9,83 \mathrm{~kg}$; die N-Ausscheidung durch den Harn an diesem Hungertag betrug $1,85 \mathrm{~g}$. Auch in den nächstfolgenden 24 Stunden war der Hund nicht dazu zu bringen, ein nur aus einer Fleischabkochung bestehendes Futter zu sich zu nehmen; sein Gewicht betrug nunmelır nur $9,74 \mathrm{~kg}$, die $\mathrm{N}$-A usscheidung dieses Hungertages $1,491 \mathrm{~g}$.

Unter ausschliesslicher Fütterung mit $250 \mathrm{~g}$ Fleisch und $50 \mathrm{~g}$ Fett stellte sich wieder Appetit ein; am 8. August betrug sein Gewicht wieder $10,11 \mathrm{~kg}$. Und als er weiterhin $150 \mathrm{~g}$ Fleisch, $37 \mathrm{~g}$ Fett und $100 \mathrm{~g}$ Reiss bekam (Nährstoffverhältniss $=1: 4,6$ ), wurde der Appetit wieder rege, der sehr gesunkene Kräftezustand nahm sichtlich zu, der Koth wurde wieder stärker gefärbt. Der vom 11. bis 13. August abgesetzte, gut abgegrenzte und dunkel $100 \mathrm{ccm}$ Filtrat $(=2,678 \mathrm{~g}$ Trockenkotb) liefern $0,03674 \mathrm{~g} \mathrm{~N}$, so dass auf den Koth pro Tag $(16,05 \mathrm{~g}$ trocken) $0,22 \mathrm{~g}$ alkohollöslicher $\mathrm{N}$ entfallen. 
gefärbte Koth ${ }^{1}$ ) enthielt nur $1,753 \mathrm{~g}$ oder pro Tag $0,584 \mathrm{~g} \mathrm{~N}$ (bei einer Einfuhr von $6,1 \mathrm{~g} \mathrm{~N}$ ) und 4,92 $\mathrm{g}$ Fett, also nur 1,64 $\mathrm{g}$ Kothfett täglich (bei einer Einfuhr von $40 \mathrm{~g}$ ). Da somit die Ausnutzung der Nahrung und das Allgemeinbefinden wieder normal geworden und die Folgen der eiweissarmen Kost als überwunden gelten konnten, wurde die weitere Beobachtung aufgegeben.

\section{Dritte Versuchsreihe.}

Eine Hündin von fast $10 \mathrm{~kg}$, welche bei mittlerem Eiweissgehalt mit einem Futter, das 650 Cal. oder pro Körperkilo $65 \mathrm{Ca}$. liefert, erfahrungsgemäss auskommt, erhielt auf Grund der in den beiden ersten Versuchsreihen gemachten Beobachtungen, denen zu Folge eine eiweissarme Kost einen erheblich grösseren Energieinhalt einschliessen muss, um dem Bedarf zu genügen, von vornherein eine reichlichere Nahrung, nehmlich $15 \mathrm{~g}$ Eiweiss (mit 2,36g N), $45 \mathrm{~g}$ Fett und $92 \mathrm{~g}$ Kohlehydrate in Form von $35 \mathrm{~g}$ Fleisch, $44 \mathrm{~g}$ Schmalz und $120 \mathrm{~g}$ Reiss; die Tagesration konnte 833 verwerthbare Cal. liefern oder pro Körperkilo $85 \mathrm{Cal}$. Allein selbst diese reichliche Zufuhr von Nährstoffen genügte dem Bedarf noch nicht, wie nachfolgende Tabelle lehrt.

$\begin{array}{rrll}1892 \text { April } & 3 . & 2,49 \mathrm{~g} \mathrm{~N} \text { im Harn } & 9,75 \mathrm{~kg} \\ & 4 . & 2,294 & 9,67 \\ & 5 . & 2,528 & 9,61 \\ & 6 . & 2,33 & 9,56 \\ & 7 . & 2,263 & 9,52 \\ & 8 . & 2,478 & 9,57 \\ \text { (2. Woche) } & 9 . & 2,612 & 9,5 \\ & 10 . & 2,528 & 9,52 \\ & 11 . & & \\ & 12 . \\ & 13 . & 7,497 & \\ & 14 . & 2,462 & 9,51 \\ & 15 . & 2,387 & 9,49 \\ & & \end{array}$

1) In 3 Tagen $83,7 \mathrm{~g}$ feucbter Koth $=29,8 \mathrm{~g}$ trocken, entsprechend $6 \mathrm{pCt}$. der eingeführten Trockensubstanz. $1,147 \mathrm{~g}$ Trockenkoth geben $0,06747 \mathrm{~g} \mathrm{~N}$. $6,733 \mathrm{~g} \quad-\quad-0,7931 \mathrm{~g}$ neutrales Aetherextract $0,3186 \mathrm{~g}$ saures

1,1117g Rohfett, mithin auf den Gesammtkoth 4,92 g Fett, entsprechend 4,1 pCt. der Fetteinfubr. 


$\begin{array}{ccll} & \text { April } 16 . & 2,448 \mathrm{~g} \cdot \mathrm{N} \text { im Harn } & 9,48 \mathrm{~kg} \\ \text { (3. Wocbe) } & 17 . & 2,415 & 9,44 \\ & 18 . & 2,452 & 9,49 \\ & 19 . & 2,448 & 9,42\end{array}$

Somit war in diesen 17 Tagen, ungeachtet der sehr reichlichen Nahrungszufuhr, durch den Harn allein schon mehr $\mathrm{N}$, im Mittel pro Tag $2,45 \mathrm{~g} \mathrm{~N}$, ausgeschieden worden, als mit dem Futter eingeführt $(2,36 \mathrm{~g} \mathrm{~N})$. Es wurde daher die Tagesration an $\mathrm{N}$-freien Stoffen auf $52 \mathrm{~g} \mathrm{Fett}$ und $107 \mathrm{~g}$ Kohlehydrate gesteigert, die der Hund in Form von $30 \mathrm{~g}$ Fleisch, $51 \mathrm{~g}$ Schmalz und $140 \mathrm{~g}$ Reiss erhielt (N-Gehalt der Nahrung 2,4 g). Dabei gestaltete sich der N-Umsatz, wie folgt:

$\begin{array}{rrll} & \text { April } 20 . & 2,3 \mathrm{~g} \mathrm{~N} \text { im Harn } & 9,55 \mathrm{~kg} \\ & 21 . & 2,338 & 9,51 \\ & 22 . & 2,21 & 9,58 \\ \text { (4. Woche) } & 23 . & 2,235 & 9,61 \\ & 24 . & 2,29 & 9,57 \\ & 25 . & 2,275 & 9,53\end{array}$

Da ungeachtet der Zulage N-freier Stoffe im Futter der Harn fast ebenso viel $\mathrm{N}$ entführte, als die Nahrung bot, wurde das Futtereiweiss durch Zulage von $8 \mathrm{~g}$ Fleisch auf $17 \mathrm{~g}$ (mit $2,7 \mathrm{~g} \mathrm{~N}$ ) erhöht, so dass die Nahrung 100 verwerthbare Cal. pro Körperkilo lieferte. Das Futter enthielt $168 \mathrm{~g}$ Trockensubstanz, das Nährstoffverhältniss war $1: 14,3$, also ein so weites, wie im Futter der grossen Herbivoren.

Dabei wurde nun N-Gleichgewicht, unter Ansteigen des Kör-

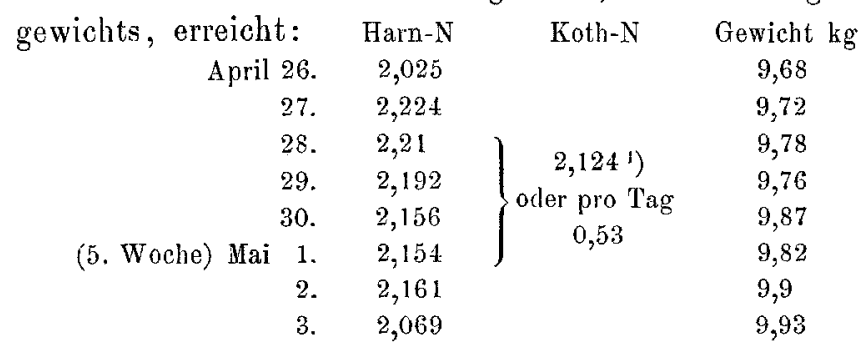

1) Koth von 4 Tagen $124,9 \mathrm{~g}$ feucht $=40,8 \mathrm{~g}$ trocken, entsprechend 6 pCt. der eingeführten Trockensubstanz. $1,1136 \mathrm{~g}$ Trockenkoth geben $0,058 \mathrm{~g} \mathrm{~N}$.

$9,7663 \mathrm{~g} \quad-\quad-0,7156 \mathrm{~g}$ neutrales Aetherextract \begin{tabular}{l}
$0,1386 \mathrm{~g}$ satires \\
\hline $0,8542 \mathrm{~g}$ Robfett, also im ganzen Trocken-
\end{tabular} koth $3,56 \mathrm{~g}$ Fettkörper $=1,7 \mathrm{pCt}$. der Fetteinfuhr. 
An diesen 8 Tagen wurden durch den Harn 17,191 $\mathrm{g}$ N oder im Tagesmittel 2,15 $\mathrm{g} \mathrm{N}$ entleert, durch den Koth $0,53 \mathrm{~g} \mathrm{~N}$, insgesammt 2,69 $\mathrm{g} \mathrm{N}$, gegenüber $2,7 \mathrm{~g} \mathrm{~N}$ in der Einfuhr. Dabei war die Ausnützung des Futters vorzüglich, insofern nur 6 pCt. der Trockensubstanz und 1,7 pCt. des Fettes durch den Koth ausgestossen worden sind. Die Berechnung der Ausnützung des Futtereiweiss beruht bei dessen geringer absoluter Grösse auf unsicheren Grundlagen (S. 98).

Unter Beibehaltung der obigen, 100 verwerthbare Cal. pro Kilo Thier bietenden Nahrung gestaltete sich der weitere Ablauf des Versuches also:

(6. Woche)

\begin{tabular}{|c|c|c|c|c|}
\hline \multirow[b]{2}{*}{ Mai } & & Harn-N & Koth-N & Gewicht $\mathrm{kg}$ \\
\hline & 4. & 2,082 & \multirow{21}{*}{$\begin{array}{c}\left.2,431^{1}\right) \\
\text { oder pro Tag } \\
0,61\end{array}$} & 9,95 \\
\hline & 5. & 2,121 & & 9,84 \\
\hline \multirow{5}{*}{ (6. Woche) } & 6. & 2,14 & & 9,91 \\
\hline & 7. & 1,838 & & 9,84 \\
\hline & s. & 2,056 & & 9,87 \\
\hline & 9. & 2,316 & & 9,76 \\
\hline & 10. & 2,257 & & 9,86 \\
\hline \multirow{9}{*}{ (7. Woche) } & 11. & 1,897 & & 9,81 \\
\hline & 12. & 2,38 & & 9,84 \\
\hline & 13. & 2,165 & & 9,78 \\
\hline & 14. & 2,334 & & 9,79 \\
\hline & 15. & 2,286 & & 9,71 \\
\hline & 16. & 2,131 & & 9,68 \\
\hline & 17. & 2,399 & & 9,72 \\
\hline & 18. & 2,105 & & 9,66 \\
\hline & 19. & 2,284 & & 9,61 \\
\hline \multirow{5}{*}{ (8. Woche) } & 20. & 2,251 & & 9,69 \\
\hline & 21. & 2,028 & & 9,74 \\
\hline & 22. & 2,195 & & 9,68 \\
\hline & 23. & 2,211 & & 9,61 \\
\hline & 24. & 2,037 & & 9,56 \\
\hline
\end{tabular}

(7. Woche)

(8. Woche)

Das Mittel dieser 21 Tage beträgt für den Harn $2,16 \mathrm{~g} \mathrm{~N}$, für den Koth $0,61 \mathrm{~g} \mathrm{~N}$ oder im Ganzen pro Tag $2,77 \mathrm{~g} \mathrm{~N}$ gegen-

1) Koth von 4 Tagen $105,3 \mathrm{~g}$ feucht $=30,9 \mathrm{~g}$ trocken, entsprechend 5 pCt. der Einfuhr an festen Stoffen.

$1,1975 \mathrm{~g}$ Trockenkoth geben $0,0944 \mathrm{~g} \mathrm{~N}$.

$4,0966 \mathrm{~g} \quad-\quad-0,4904 \mathrm{~g}$ neutrales Aetherextract $0,1916 \mathrm{~g}$ saures

$0,682 \mathrm{~g}$ Rohfett, mithin im ganzen Trok-

kenkoth $5,14 \mathrm{~g}$ Fettkörper $=3,2 \mathrm{pCt}$. der Fetteinfuhr. 
über $2,7 \mathrm{~g} \mathrm{~N}$ der Einfuhr, so dass das N-Gleichgewicht kaum noch gewahrt erscheint. Es ist eben die Ausstossung von Koth-N etwas grösser geworden $(0,61$ gegen $0,53 \mathrm{~g}$ der Vorwoche) und ebenso die Ausnützung des Nahrungsfettes, wenn auch noch absolut sehr gut (bis auf $3,2 \mathrm{pCt}$.), doch gegenüber der Vorperiode (bis auf $1,7 \mathrm{pCt}$.) verschlechtert; immerhin werden noch so viel Nährstoffè resorbirt, dass daraus 93 verwerthbare Cal. pro Körperkilo hervorgehen können. Trotzdem ging im Verlaufe dieser 3 Wochen das Körpergewicht langsam um 370 g herunter. Das, obschon zunächst nur sehr mässige Absinken des Körpergewichtes und die geringfügige Zunahme der $\mathbf{N}$ - und Fettausstossung durch den Koth, mussten nach unseren früheren Erfahrungen die Aufmerksamkeit auf eine, eben in der Entwickelung begriffene Alteration der Stoffausnutzung und -Zersetzung lenken, zumal bereits in den letzten Tagen der Koth entschieden weniger intensiv gefärbt war.

Von Interesse erscheint ferner, dass fast während der ganzen Dauer der eiweissarmen Nahrung (seit 3. April), am ausgesprochensten aber seit Mitte der 4. Woche (26. April) der Eiweissumsatz sich auf einen so niedrigen Werth einstellt, im Tagesmittel $2,13 \mathrm{~g} \mathrm{~N}$, der noch unter dem in der späteren Inanitionszeit beobachteten typischen Hungerminimum gelegen ist.

Der weitere Ablauf gestaltete sich wie folgt:

\begin{tabular}{|c|c|c|c|c|}
\hline & Mai 25. & $\begin{array}{c}\text { Harn-N } \\
2,223\end{array}$ & Kotb-N & $\begin{array}{c}\text { Gewicht } \mathrm{kg} \\
9,58\end{array}$ \\
\hline & 26. & 2,248 & & 9,54 \\
\hline & 27. & 2,196 & $\left.2,347^{1}\right)$ & 9,52 \\
\hline & 28. & 2,05 & oder pro Tag & 9,56 \\
\hline (9. Woche) & 29. & 2,448 & 0,782 & 9,48 \\
\hline & 30. & 2,368 & & 9,5 \\
\hline & 31. & 2,373 & & 9,52 \\
\hline & Juni 1. & 2,195 & & 9,47 \\
\hline
\end{tabular}

Nachdem schon in den letzten Tagen der Hund mit sichtlich geringerem Appetit das Futter verzehrt hatte und auch hier wieder zu dem Aushülfsmittel gegriffen worden war, das Futter

1) Koth nur schwach gelb gefärbt, in 3 Tagen $108,6 \mathrm{~g}$ feucht $=32,3 \mathrm{~g}$ trocken, entsprechend $6 \mathrm{pCt}$. der Einfubr an Trockensubstanz. 0,984 g Trockenkoth geben $0,07181 \mathrm{~g}$ N. Die Notizen über den Fettgehalt des Kothes sind leider zu Grunde gegangen. 


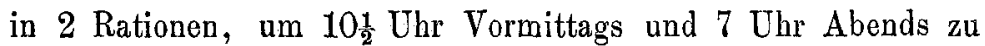
verabreichen, erbricht am 2. Juni der Hund unmittelbar nach dem Fressen und ist zur Wiederaufnahme des Erbrochenen nicht zu bewegen. Weiterhin erscheint er traurig, gegen Abend etwas erholt. Abends frisst er die 2. Portion, erbricht darauf mehrmals. Am Vormittag des 3. Juni erscheint er noch leidend, verschmäht das Futter, nimmt dagegen $80 \mathrm{~g}$ Fleisch (mit $2,7 \mathrm{~g} \mathrm{~N}$, wie in seiner bisherigen Nahrung), mit $150 \mathrm{~g}$ Wasser abgekocht. Seit der Mitte der 8. Woche (25. Mai) ist er aus dem N-Gleichgewicht ganz heraus. Im Ganzen hat er in den letzten 8 Tagen vor Eintritt des Erbrechens (25. Mai bis 1. Juni) durch den Harn $18,1 \mathrm{~g} \mathrm{~N}$ ausgeschieden, also $2,263 \mathrm{~g} \mathrm{~N}$ pro Tag, dazu $0,782 \mathrm{~g} \mathrm{~N}$ durch den Koth, macht zusammen $3,045 \mathrm{~g} \mathrm{~N}$ gegenüber einer täglichen Einfuhr von $2,7 \mathrm{~g} \mathrm{~N}$; mithin schoss er bereits $0,35 \mathrm{~g} \mathrm{~N}$ $=2,2 \mathrm{~g}$ Eiweiss $(10,3 \mathrm{~g}$ Fleisch) von seinem Körper zu. Es hat demnach gegen die 6 . und 7. Woche die N-Ausscheidung durch den Harn um 0,1 g = 5 pCt., die N-Ausstossung durch den Koth von 0,61 bis auf $0,78 \mathrm{~g}$, also um rund $25 \mathrm{pCt}$. zugenommen; entsprechend dem gesteigerten N-Umsatz war es höchst wahrscheinlich, dass auch die Ausnutzung des Nahrungsfettes heruntergegangen war, doch fehlt es leider an einem ziffermässigen Werth.

Es wurde nun, um insbesondere die Resorptions- und Ausnutzungsverhältnisse festzustellen, versucht, die frühere eiweissarme Kost, aus $17 \mathrm{~g}$ Eiweiss (mit $2,7 \mathrm{~g} \mathrm{~N}$ ), $52 \mathrm{~g}$ Fett und $107 \mathrm{~g}$ Kohlehydrate bestehend, in 2 bis 3 Portionen verabreicht, fortzuführen. So gelang es in der That, die Beobachtung noch 16 Tage fortzusetzen.

\begin{tabular}{|c|c|c|c|c|}
\hline Juni & 4. & $\begin{array}{c}\text { Harn-N } \\
2,485\end{array}$ & Koth-N & $\begin{array}{c}\text { Gewicht } \mathrm{kg} \\
\left.9,244^{1}\right)\end{array}$ \\
\hline \multirow[t]{5}{*}{ (10. Woche) } & 5. & 2,294 & & 9,29 \\
\hline & 6. & 2,311 & & 9,35 \\
\hline & 7. & 2,381 & $\left.2,855^{2}\right)$ & 9,38 \\
\hline & 8. & 2,631 & oder pro Tag & 9,44 \\
\hline & 9. & 2,497 & 0,952 & 9,42 \\
\hline
\end{tabular}

1) Das Gewicht war in Folge des Erbrechens und der geringen Nahrungsaufnahme in 3 Tagen um $230 \mathrm{~g}$ gesunken.

2) Koth von 3 Tagen, blassgelb, 139,3 $\mathrm{g}$ feucht $=48,8 \mathrm{~g}$ trocken, entsprechend $10 \mathrm{pCt}$. der Einfuhr an Trockensubstanz. Trockenkoth fühlt sich fettig an, lässt sich schlecht pulverisiren. Vom Trockenkoth 


$\begin{array}{ccccc} & & \text { Harn-N } & \text { Koth-N } & \text { Gewicht kg } \\ & \text { Juni 10. } & 2,225 & & 9,39 \\ \text { 11. Woche) } & 11 . & 2,318 & & 9,41 \\ & 12 . & 2,179 & & 9,36 \\ 13 . & 2,349 & 9,31 \\ 14 . & 2,776 & 9,34 \\ 15 . & 2,89 & 9,3 \\ 16 . & 2,368 & 9,27 \\ 17 . & 2,567 & 9,29 \\ 18 . & 2,408 & 9,24 \\ 19 . & 2,672 & 9,21\end{array}$

In diesen 16 Tagen stieg die $\mathrm{N}$-Ausfuhr durch den Harn langsam an, in maximo bis auf $2,89 \mathrm{~g}$ pro Tag, so dass schon durch den Harn allein mehr $\mathrm{N}$ austrat, als mit der Nahrung zur Einfuhr gelangt ist. Im Ganzen wurden an diesen 16 Tagen mit dem Harn 39,351 g N entleert oder 2,46 g N pro Tag, dazu $0,952 \mathrm{~g} \mathrm{~N}$ mit dem Koth, macht 3,41 $\mathrm{g} \mathrm{N}$, gegenüber $2,7 \mathrm{~g} \mathrm{~N}$ in der Einfuhr, so dass der Fehlbetrag bereits auf $0,71 \mathrm{~g} \mathrm{~N}$ pro Tag steigt, entsprechend einem Verlust von $4,47 \mathrm{~g}$ Eiweiss oder $21 \mathrm{~g}$ Körperfleisch. In dieser letzten Periode war die N-Ausnützung der Nahrung, im Verein mit reichlicher Ausstossung von Darmsecreten, Schleim u. A. so heruntergegangen, dass mit dem Koth $0,952 \mathrm{~g}$, über $\frac{1}{3}$ des mit dem Futter eingeführten $\mathrm{N}$ austrat. Es ist bemerkenswerth, dass während der eiweissarmen Fütterungsperiode noch am Ende der 4. Woche die tägliche N-Menge im Koth nur $0,53 \mathrm{~g}$ betrug, dann allmählich anstieg, in der 6 . Woche auf $0,61 \mathrm{~g}$, in der 8 . Woche auf $0,782 \mathrm{~g}$ und in der 10 . Woche (7. bis 9. Juni) bis auf $0,952 \mathrm{~g}$, so dass hier auf's deutlichste die progressive Verschlechterung in der Ausnütaung des Nahrungs-N in die Erscheinung trat, dergestalt, dass in

geben $1,1182 \mathrm{~g} 0,06544 \mathrm{~g} \mathrm{~N}$.

10,0362 $\mathrm{g}$ Trockenkoth, mit siedendem Alkohol extrahirt, geben $0,0942 \mathrm{~g} \mathrm{~N}$, also im ganzen Koth $0,458 \mathrm{~g}$ alkohollöslicher $\mathrm{N}$, d. h. knapp $\frac{1}{6}$ des gesammten Koth-N.

$4,661 \mathrm{~g}$ Trockenkoth geben $1,0442 \mathrm{~g}$ neutrales Aetherextract

$$
\frac{0,2462 \mathrm{~g} \text { saures }}{1,2904 \mathrm{~g} \text { Rohfett, also im ganzen Trocken- }}
$$

koth $13,51 \mathrm{~g}$ (davon $1,41 \mathrm{~g}$ Neutralfett + Cholesterin, $9,52 \mathrm{~g}$ freie Fettsäuren, $2,58 \mathrm{~g}$ Fettsäuren aus Seifen) oder pro Tag. 4,5 g, entsprechend 8,7 pCt. der Fetteinfuhr. 
der 10. Woche um 80 pCt. mehr $\mathrm{N}$ zur Ausstossung gelangt ist, als in der 4 . Woche.

Aehnlich verhält es sich mit der Verwerthung der Trocken. substanz und des Fettes vom Futter, welche zuvor bei diesem Hunde geradezu vorzüglich war. Während noch in der 4. und selbst in der 8 . Woche nur 6 pCt. der verfütterten Trockensubstanz unbenützt mit dem Koth austraten, erschienen in der 10. Woche $10 \mathrm{pCt}$. im Koth wieder, also eine beträchtliche relative Verschlechterung, wenn auch dieselbe, absolut genommen, noch nicht als ungünstig zu bezeichnen ist. Während endlich noch in der 4 . Woche nur $1,7 \mathrm{pCt}$. vom Nahrungsfett der Resorption entgangen sind, stieg der unverwerthete Antheil in der 6. Woche auf 3,2 pCt., in der 10 . Woche auf 8,7 pCt., so dass zuletzt die Fettausnützung $5 \mathrm{Mal}$ schlechter geworden ist, als sie früher gewesen, ohne dass aber selbst diese geringere Verwerthung, absolut betrachtet, als schlecht erachtet werden kann.

Auch hier lässt sich direct nachweisen, dass der von den Residuen der in den Darm ergossenen Galle abstammende $\mathrm{N}$-Antheil im Koth erheblich zurückgegangen ist. Es betrug die alkohollösliche Quote des Koth-N nur 16 pCt. vom gesammten Koth-N, während sonst bei eiweissarmem, kohlehydratreichen Futter 35-44 pCt. des Koth-N sich in Alkohol lösen.

Die Ausnützung der löslichen Kohlehydrate im Futter war noch eine gute geblieben; selbst in der 10. Woche zeigte der Koth weder makro- noch mikroskopisch erkennbare Stärkepartikel; auch waren nach dem Maercker'schen Verfahren nur Spuren von löslichen Kohlehydraten im Koth nachweisbar.

Das Ansteigen des Eiweissumsatzes einerseits und die $\mathrm{Ab}$ nahme des Körpergewichtes andererseits, welch letztere, gegenüber dem Anfangs der 5 . Woche beobachteten Maximum von fast $10 \mathrm{~kg}$, rund $720 \mathrm{~g}$ betrug, entsprechend einem Verlust von 8 pCt., ist um so bemerkenswerther, als aus der Nahrung immer noch mindestens $1,75 \mathrm{~g} \mathrm{~N}=11 \mathrm{~g}$ Eiweiss, $47 \mathrm{~g}$ Fett und $107 \mathrm{~g}$ Kohlehydrate resorbirt worden sind, so dass daraus 912 Cal. frei wurden oder rund $98 \mathrm{Cal}$. pro Körperkilo.

Da bis zur 8. Woche noch leidlich N-Gleichgewicht bestanden hat, rechnet der N-Verlust vom Körper erst von Mitte der 8. Woche (25. Mai) ab. In den ersten 8 Tagen wurden pro Tag 
$0,35 \mathrm{~g} \mathbf{N}$ eingebüsst (S. 131), also zusammen $2,8 \mathrm{~g} \mathrm{~N}$, an den beiden folgenden darch Erbrechen und spärliche Nahrungsaufnahme gestörten Tagen (2. und 3. Juni) ist der N-Verlust, der sich nicht direct hat bestimmen lassen, auf mindestens je $1 \mathrm{~g} \mathrm{zu}$ veranschlagen, und in der Schlussperiode von 16 Tagen beträgt er (im Tagesmittel $0,71 \mathrm{~g} \mathrm{~N}$ ) im Ganzen $11,36 \mathrm{~g} \mathrm{~N}$, so dass also überhaupt $(2,8+2+11,36=16,16 \mathrm{~g} \mathrm{~N}$ oder $102 \mathrm{~g}$ Eiweiss (475 g Körperfleisch) zu Verlust gegangen sind. Da nun innerhalb dieser Periode des N-Verlustes das Gewicht des Hundes nur um $370 \mathrm{~g}$ abgenommen hat, so müssen mindestens $100 \mathrm{~g}$ in Form von Wasser (und vielleicht etwas Fett) angesetzt worden sein. Dass bei ungenügender Ernährung, welche insbesondere den Eiweissbedarf nicht deckt, der Körper im Ganzen wasserreicher "aufgeschwemmt" wird, ist seit den Erfahrungen von Bischoff und Voit an dem ausschliesslich mit Brod gefütterten Hunde, der dabei stetig $N$ vom Körper einbüsste, bekannt (S. 116).

Nachdem somit die Folgen der durch Wochen fortgesetzten eiweissarmen und kohlehydratreichen Fütterung genügend zu Tage getreten waren, wurde zu einer Kost mit fast doppeltem Eiweissgehalt, dabei aber von demselben kalorischen Werthe übergegangen. Der Hund erhielt $32 \mathrm{~g}$ Eiweiss (mit $5,1 \mathrm{~g} \mathrm{~N}$ ) und dafür $15 \mathrm{~g}$ Kohlehydrate weniger, indem $20 \mathrm{~g}$ Reiss abgezogen und die Fleischimenge auf $115 \mathrm{~g}$ erhöht wurde. Dabei schied er an den nächsten Tagen durch den Harn aus: 2,899-$3,163-3,972-4,264-4,352-4,388-4,36 \mathrm{~g} \mathrm{~N}$ und nur $0,502 \mathrm{~g} \mathrm{~N}$ durch den Koth ${ }^{1}$ ); zugleich nahm sein Gewicht in diesen 7 Tagen um $320 \mathrm{~g}$ zu, und dies obwohl der calorische Werth des Futters derselbe geblieben war, wie in den durch $\mathrm{N}$ - und Gewichtsverlust ausgezeichneten Vorwochen, nur dass die Eiweissration fast doppelt so gross war als zuvor. Damit wurde dieser Versuch abgebrochen.

Vierte Versuchsreihe.

Der letzte Versuch stimmt mit der oben (S. 117) erwähnten Beobachtung von Rosenheim z. Th. darin überein, dass, noch ehe

1) Koth von 3 Tagen $88,4 \mathrm{~g}$ feucht $=26,3 \mathrm{~g}$ trocken, entsprechend 5,2 pCt. der Einfubr.

$0,8293 \mathrm{~g}$ Trockenkoth geben $0,06542 \mathrm{~g} \mathrm{~N}$. 
schwere Erscheinungen aufgetreten sind, der Hund unerwartet verendete. Deshalb soll der erste Theil des Versuches mit eiweissreicherer Kost, welcher im Wesentlichen sich den analogen Verhältnissen der 1. und 2. Versuchsreihe anschliesst, hier kürzer gegeben werden.

Es handelt sich um eine schwarze, etwa 3jährige, ziemlich magere Hündin, die ursprünglich $10 \mathrm{~kg}$ wog. Sie bekam zunächst $120 \mathrm{~g}$ Fleisch, $90 \mathrm{~g}$ Reiss, $30 \mathrm{~g}$ Schmalz und darin $31,1 \mathrm{~g} \mathrm{Ei-}$ weiss (mit 4,88 $\mathrm{g} \mathrm{N}$ ), $32 \mathrm{~g} \mathrm{Fett} \mathrm{und} 69 \mathrm{~g} \mathrm{Kohlehydrate,} \mathrm{im}$ Ganzen $143 \mathrm{~g}$ Trockensubstanz. Das Futter mit dem Nährstoffverhältniss $1: 4,7$ konnte 700 verwerthbare Cal. oder pro Körperkilo $70 \mathrm{Cal}$. liefern; damit kommt sonst erfahrungsgemäss ein $10 \mathrm{~kg}$ schwerer Hund reichlich aus. Mit diesem Futter wurde er 30 Tage lang, vom 17. November bis 16 . December gefüttert und kam damit ganz allmählich in's N-Gleichgewicht. Das Körpergewicht, das in den ersten 2 Wochen um $450 \mathrm{~g}$ gesunken war, hielt sich weiterhin auf gleicher Höhe. Schon hier musste es auffallen, wie lange Zeit trotz des reichlichen Futters erforderlich war, um einen einigermaassen gleichmässigen Ablauf der Zersetzungsvorgänge zu erzielen. Auch dann schwankte die NAusfuhr durch den Harn innerhalb weiterer Grenzen, als dies sonst nach längerer gleichmässiger Fütterung der Fall zu sein pflegt. Ich führe aus dieser 4 wöchentlichen Periode nur die letzte Woche an:

\begin{tabular}{|c|c|c|}
\hline & Harn-N & Koth-N \\
\hline 1891. Dec. 11. & 4,385 & \\
\hline 12 & 4,564 & \\
\hline 13. & 4,351 & \\
\hline 14. & 4,091 & $1,6651)$ \\
\hline 15. & 4,044 & \\
\hline 16. & 4,254 & \\
\hline 17. & 4,176 & \\
\hline
\end{tabular}

1) Koth von 4 Tagen $79,8 \mathrm{~g}$ feucht $=24 \mathrm{~g}$ trocken, entsprechend $4,2 \mathrm{pCt}$. der Einfubr. $1,0422 \mathrm{~g}$ Troekenkoth geben $0,07224 \mathrm{~g}$ N.

7,8343 - $\quad-\quad$ - $0,4717 \mathrm{~g}$ neutrales Aetherextract 0,3067 - saures

$0,7784 \mathrm{~g}$ Rohfett, mithin im ganzen Trockenkoth $2,386 \mathrm{~g}$ Fett oder $0,577 \mathrm{~g}$ Kothfett pro Tag $=1,9$ pCt. der Fetteinfuhr. 
Im Ganzen sind an diesen 7 Tagen $29,87 \mathrm{~g} \mathrm{~N}$ oder im $\mathrm{Ta}$ gesmittel $4,26 \mathrm{~g} \mathrm{~N}$ durch den Harn ausgetreten, dazu $0,42 \mathrm{~g} \mathrm{~N}$ durch den Kotb, giebt 4,68 $\mathrm{g} \mathrm{N}$ als Gesammtausscheidung, so dass $0,2 \mathrm{~g} N$ pro Tag zum Ansatz gelangt sind. Das Körpergewicht hatte zuletzt zwischen 9,42 und $9,51 \mathrm{~kg}$ geschwankt.

Nunmehr wurden $16,6 \mathrm{~g}$ Eiweiss abgezogen und dafür $16,6 \mathrm{~g}$ Kohlehydrate gegeben, so dass die Ration nunmehr aus $14,5 \mathrm{~g}$ Eiweiss (mit 2,28 $\mathrm{g} \mathrm{N}$ ), $33 \mathrm{~g}$ Fett, $85 \mathrm{~g}$ Kohlehydrate bestand, die in Form von $36 \mathrm{~g}$ Fleisch, $32 \mathrm{~g}$ Schmalz und $110 \mathrm{~g}$ Reiss gegeben wurden. Die Kost, welche ebenfalls $143 \mathrm{~g}$ Trockensubstanz einschloss, konnte 716 Cal. liefern oder $76 \mathrm{Cal}$ pro Kilo Thier. Allein diese eiweissärmere Kost erwies sich wiederum ungeachtet des hohen Wärmewerthes als durchaus ungenügend.

\begin{tabular}{|c|c|c|c|c|}
\hline & Harn-N & \multirow[t]{6}{*}{ Koth-N } & Gewicht $\mathrm{kg}$ \\
\hline \multicolumn{2}{|r|}{ Dec. 18.} & 3,418 & & 9,38 \\
\hline \multirow{9}{*}{ (2. Woche) } & 19. & 2,839 & & 9,4 \\
\hline & 20. & 3,196 & & 9,34 \\
\hline & 21. & 2,689 & & 9,25 \\
\hline & 22 . & 2,864 & & 9,21 \\
\hline & 23. & 3,02 & \multirow{5}{*}{$1,525^{1}$} & 9,11 \\
\hline & 24. & 5.481 & & 8.95 \\
\hline & 25. & & & \\
\hline & 26. & 3,03 & & 8,9 \\
\hline & 27. & 2,889 & & 8,82 \\
\hline
\end{tabular}

Im Mittel dieser 10 Tage wurden 2,94 $\mathrm{g} \mathrm{N}$ durch den Harn, $0,51 \mathrm{~g} \mathrm{~N}$ durch den Koth entleert, im Ganzen $3,45 \mathrm{~g} \mathrm{~N}$ per Tag gegenüber $2,28 \mathrm{~g} \mathrm{~N}$ in der Einfuhr, so dass der tägliche Verlust $1,17 \mathrm{~g} N$ beträgt. Mithin hat in diesen 10 Tagen der Körper $11,7 \mathrm{~g} \mathrm{~N}=73,7 \mathrm{~g}$ Eiweiss oder $345 \mathrm{~g}$ Fleisch eingebüsst. Da nun das Körpergewicht von $9,45 \mathrm{~kg}$ am Schluss der eiweissreichen Periode bis auf $8,82 \mathrm{~kg}$, also um $630 \mathrm{~g}$ abgenommen hat, während der Hund nachweislich nur $345 \mathrm{~g}$ Fleisch eingebüsst hat, müssen ausserdem rund $300 \mathrm{~g}$ vom Wasser- und Fettbestande des Körpers geschwunden sein.

Es wurde daher die Ration, unter Belassung des Eiweissquantums, an Fett und Kohlehydraten erhöht, so dass sie nun

1) Koth von 3 Tagen $69,9 \mathrm{~g}$ feucht $=20,8 \mathrm{~g}$ trocken, entsprechend $5 \mathrm{pCt}$. der Einfuhr, $0,8923 \mathrm{~g}$ Trockenkotb geben $0,06542 \mathrm{~g} \mathrm{~N}$. 
in $33 \mathrm{~g}$ Fleisch, $45 \mathrm{~g}$ Schmalz und $120 \mathrm{~g}$ Reiss $14,5 \mathrm{~g}$ Eiweis (mit $2,28 \mathrm{~g} \mathrm{~N}$ ), 45,5 g Fett, $92 \mathrm{~g}$ Kohlehydrate bei $160 \mathrm{~g}$ Trockensubstanz und ein Nährstoffverhältniss von $1: 13,9$ bot und 852 verwerthbare Calorien, d. h. per Körperkilo $96 \mathrm{Cal}$. liefern konnte. Allein auch dies hohe Kostmaass genügte dem Bedarf noch nicht.

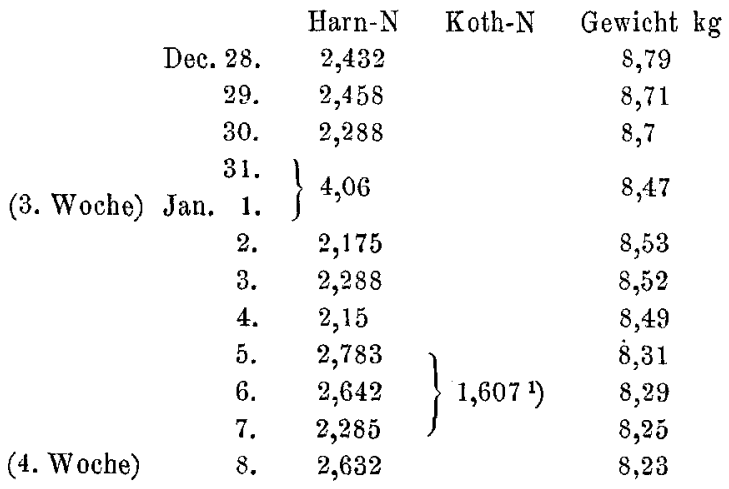

An diesen 12 Tagen sind durch den Harn ausgetreten insgesammt $29,556 \mathrm{~g} \mathrm{~N}$ oder im Tagesmittel $2,463 \mathrm{~g} \mathrm{~N}$, durch den Koth $0,536 \mathrm{~g} \mathrm{~N}$, somit beträgt die mittlere Ausfuhr rund $3 \mathrm{~g} \mathrm{~N}$ gegenüber $2,28 \mathrm{~g} \mathrm{~N}$ in der Einfuhr, so dass der Fehlbetrag sich pro Tag auf $0,72 \mathrm{~g} \mathrm{~N}$ beläuft. Mithin wurden trotz des hohen Kostmaasses und der vorzüglichen Ausnutzung des Futters, insofern nur 5,3 pCt. der Trockensubstanz und gar nur 2,1 pCt. vom Fett unverwerthet geblieben sind, in diesen Tagen $(12 \times 0,72 \Rightarrow)$ $8,64 \mathrm{~g} \mathrm{~N}$ oder 54,4 $\mathrm{g}$ Eiweiss bezw. $264 \mathrm{~g}$ Fleisch vom Körper des Hundes abgegeben. Da der Gewichtsverlust während dieser Periode sich zu $590 \mathrm{~g}$ beziffert und nur rund die Hälfte in Form von Körperfleisch zum Verlust gegangen ist, müssen noch ausserdem $240 \mathrm{~g}$ Wasser und Fett eingebüsst worden sein. Schon in

1) Koth von 3 Tagen $67,7 \mathrm{~g}$ feucht $=25,3 \mathrm{~g}$ trocken, entsprechend $5,3 \mathrm{pCt}$. der eingeführten Trockensubstanz.

$1,448 \mathrm{~g}$ Trockenkoth geben $0,536 \mathrm{~g} \mathrm{~N}$.

5,828 - - $\quad-0,3941 \mathrm{~g}$ neutrales Aetherextract $\frac{0,275 \text { - saures }}{0,6691 \mathrm{~g} \text { Rohfett, mithin im gesammten }}$

Koth 2,9 g Fettkörper oder $0,97 \mathrm{~g}$ Kothfett pro Tag $=2,1 \mathrm{pCt}$. der Fetteinfuhr. 
der letzten Woche dieser Reihe verlor der Hund auffallend viel Haare, so dass manche Körperstellen, im Umfange eines Markbis Thalerstückes, fast kahl aussahen. Auch fiel es auf, dass der Hund nicht mehr aus dem Käfig springen konnte.

Da offenbar mit einer so niedrigen. Eiweissgave trotz der grossen Mengen von Kohlehydraten und Fetten $\mathrm{N}$ - und Körpergleichgewicht nicht zu erzielen war, wurde die Eiweissration um $2 \mathrm{~g}$ erhöht, so dass er von nun ab $16,3 \mathrm{~g}$. Eiweiss in $40 \mathrm{~g}$ Fleisch und $130 \mathrm{~g}$ Reiss (mit 2,6 g N) und dazu $45 \mathrm{~g}$ Schmalz erhielt.

$\begin{array}{rrll} & \text { Jan. 9. } & 2,682 \mathrm{~g} \mathrm{~N} \text { im Harn } & 8,21 \mathrm{~kg} \\ & 10 . & 2,23 & 8,27 \\ & 11 . & 2,247 & 8,34 \\ & 12 . & 2,22 & 8,35 \\ & 13 . & 2,142 & 8,38 \\ \text { (5. Woche) } & 14 . & 2,079 & 8,31 \\ & 15 . & 2,054 & 8,28 \\ & 16 . & 2,045 & 8,26 \\ & 17 . & 2,022 & 8,24\end{array}$

In den letzten 5 Tagen wurde eben $\mathrm{N}$ - und Körpergleichgewicht erreicht. Durch den Harn sind an diesen 5 Tagen ausgeschieden worden $10,342 \mathrm{~g} N$ oder im täglichen Mittel $2,07 \mathrm{~g} \mathrm{~N}$, dazu $0,57 \mathrm{~g} \mathrm{~N}$ durch den Koth, giebt 2,64 g N. Am Morgen des 17. Januar wurden behufs Abgrenzung des Kothes, 6 Stunden vor dem Futter, Knochen gegeben. Am 18. Januar Vormittags frass er seine halbe Ration noch ohne Weiteres auf, desgleichen am Abend die andre Hälfte. Am 19. Januar Vormittags wurde er todt und schon in beginnender Starre im Käfig gefunden. Noch stärker, als in der ersten Woche des Januar, hatte er in der letzten Woche ausserordentlich reichlich Haare verloren, so dass er z. B. am Hintertheil fast ganz haarlos wurde. Ausserdem hatte sein Kräftezustand fortschreitend abgenommen, so dass, während er Anfangs Januar zwar nicht mehr springen, aber doch noch gut stehen konnte, nunmehr auch zum Stehen zu schwach war und daher beim Katheterisiren am Nacken und am Hintertheil gehalten rerden musste, sonst drohte er einzuknicken und auf die Seite za fallen.

Die Section ergab hochgradige Abmagerung, Körpermuskeln blassroth, zum Theil blassgelb; insbesondere schlaff und blass 
erscheint der Herzmuskel, zumal der linke Ventrikel nahe der Spitze; dabei sind die einzelnen Herzabtheilungen mit Blut gefüllt, das nur partiär gallertig, zum Theil speckhäutig geronnen ist. Da, wo es wie in der unteren Hohlvene nicht geronnen ist, enthält es lant Prüfung an Fleischl's Hämometer 60-63 pCt. Hämoglobin, den normalen Gehalt zu $100 \mathrm{pCt}$. gesetzt. Leber sehr blutreich, die Randpartien der Acini verfettet. Sonstiger Befund bietet von der Norm nicht Abweichendes. Bei der mikroskopischen Untersuchung fanden sich an den Muskelfasern des Herzens, zumeist am linken Ventrikel nahe der Spitze, ziemlich zahlreiche fettig entartete Fasern.

Ob dieser Befund des schlaffen und zum Theil verfetteten Herzfleisches neben der allgemeinen hochgradigen Abmagerung und Entkräftung als Todesursache genügt, dürfte schwer zu entscheiden sein. Näher liegt es offenbar an die Schädigung durch die eiweissarme Nahrung zu denken und eventuell auch diese für die Alteration der nicht genügend ernäbrten Muskelfasern verantwortlich zu machen, um so mehr als die grosse Ration der Kohlehydrate und Fette erst in den letzten 9 Tagen, als der $\mathrm{N}$-Gehalt des Futters um $0,3 \mathrm{~g}$ oder $13 \mathrm{pCt}$. gegen zuvor gesteigert wurde, im Stande war, N-Gleichgewicht herbeizuführen. Und zwar meine ich die Schädigung, die der Körper durch den thatsächlichen Verlust von Eiweiss oder Fleisch, und, wie die obigen Ableitungen schon wahrscheinlich gemacht haben und die Section mit Sicherheit erweist, auch durch den Verlust von Fett erlitten. Den Verlust von Körperfleisch anlangend, lassen sich dafür ziffermässige Angaben machen. In den ersten 30 Tagen der eiweissreichen Fütterung (17. Nov. - 16. Dec.) kann der $\mathrm{N}$-Verlust nicht nennenswerth gewesen sein, wurde doch in der letzten Woche dieser Periode sogar 0,2 g N täglich angesetzt. Dagegen ist die $\mathrm{N}$-Einbusse bei der eiweissarmen Nahrung (18. Dec. - 18. Jan.) zum Theil sehr beträchtlich. Er beziffert sich für die Zeit vom

18. - 27. Dec. auf $11,7 \mathrm{~g} \mathrm{~N}=73,7 \mathrm{~g}$ Eiweiss $=345 \mathrm{~g}$ Fleisch 28.Dec.-8.Jan. - $8,64--=54,4-\quad-\quad=254$ 9. - 12. Jan. -
insgesammt auf
$21,45 \mathrm{~g} \mathrm{~N}=135,1 \mathrm{~g}$ Eiweiss $=632 \mathrm{~g}$ Fleisch. 
Da zum Beginn der eiweissarmen Kost der Hund 9,4 kg wog und beim Hunde die Musculatur etwa $42 \mathrm{pCt}$. des Körpergewichtes in Anspruch nimmt, so besass er $(9,4 \mathrm{~kg} \times 0,42 \Rightarrow$ $3948 \mathrm{~g}$ Fleisch; von diesen hat er im Verlauf des letzten Monats $632 \mathrm{~g}$, d. h. knapp $\frac{1}{6}$ des Gesammtbestandes eingebüsst. Beim verhungerten Hunde beträgt die Einbusse an Muskelfleisch rund $\frac{1}{3}$, also das Doppelte des hier zu Stande gekommenen Verlustes. Nun hat aber der Hund vom Beginn der eiweissarmen Fütterung und einem Gewicht von $9,4 \mathrm{~kg}$ bis zum Tode, wo er nur noch $8,2 \mathrm{~kg}$ wog, $1,2 \mathrm{~kg}$ eingebüsst, wovon nur $630 \mathrm{~g}$ auf Fleisch entfallen. Also müssen $570 \mathrm{~g}$ in Form von Wasser und Fett, laut Ergebniss der Section wohl hauptsächlich Fett, eingebüsst worden sein.

Die eiweissarme Kost bot nicht einmal genügend Eiweiss zur Regeneration des nur spärlich zerfallenden stabileren Eiweisses der Gewebe, daher der Muskelschwund, daher der Haarausfall, daher das schlaffe Herz, vielleicht auch daher die Verfettungen der Muskelfasern. So vereinigt sich, wie es scheint, Alles, um den hier, gerade nach eben erreichtem N-Gleichgewicht, unerwartet eingetretenen Tod mit einem hohen Maass von Berechtigung zu der eiweissarmen Kost und den daraus für den Körper resultirenden Folgen in Beziehung zu bringen, insofern dieselbe nicht genügend Eiweissmaterial bot, um den Muskelschwund und den Haarausfall durch entsprechende Neubildung dieser Gewebe zu compensiren.

Obgleich ich daher auf diese Beobachtung keinen zu grossen Werth legen möchte, so bietet sie doch manches Interesse, insofern sie u. A. auch das lehrt, dass für einen Mittelhund von $10 \mathrm{~kg}$ bei einer Ration von $\left.0,255 \mathrm{~g} \mathrm{~N}^{1}\right)=1,6 \mathrm{~g}$ Eiweiss pro Körperkilo der Eiweissbestand nicht gewahrt wird, auch wenn der Brennwerth der Nahrung über $100 \mathrm{Ca}$ lorien pro Kilo beträgt; vielmehr müssen bei dem gleichen Wärmewerth des Futters mindestens $0,31 \mathrm{~g} \mathrm{~N}^{2}$ ) = $2 \mathrm{~g}$ Eiweiss pro Kilo geboten werden, soll N-und Körpergleichgewicht bestehen (vergl. auch S.118).

1) $2,3 \mathrm{~g} \mathrm{~N}$ pro Tag für einen Hund von $9,4 \mathrm{~kg}$.

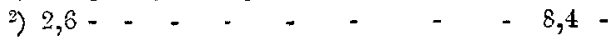


Allgemeine Ergebnisse der Versuche.

Die vorstehend geschilderten drei Versuchsreihen am Hunde - die vierte kann ihrer Besonderheiten halber für allgemein giltige Schlüsse nicht verwerthet werden - stimmen in Bezug auf den Ablauf und die bei ausreichender, aber eiweissarmer Ernährung weiterhin auftretenden Störungen qualitativ überein, nur dass sich quantitativ d. h. in Bezug auf die In- und Extensität der Störungen und den Zeitpunkt ihres ersten Auftretens Verschiedenheiten geltend machen, und zwar, wie bei pathologischen Störungen, je nach dem Körper- und Kräftezustand sowie nach der Widerstandsfähigkeit der betroffenen Individuen, also je nach der "individuellen Disposition“, wie die Pathologen sagen. Diese Störungen sind, wofern rechtzeitig die eiweissarme Kost aufgegeben und eine eiweissreichere and kohlehydratärmere eingeleitet wird, zumeist reparabel, wenn sie noch nicht zu lange bestanden und den Kräftezustand zu sehr untergraben haben. Gelegentlich kann es, zumal bei fettarmen schwächlichen Thieren oder bei intercurrenten Erkrankungen, überraschend schnell zu Ende gehen, wie in meiner 4. Reihe und in der oben (S. 117) angezogenen Beobachtung von Rosenheim.

Kommt es bei eiweissarmer $(1,8-2 \mathrm{~g}$ Eiweiss pro $\mathrm{kg}$ für Hunde von $10 \mathrm{~kg}$ ), an $\mathrm{N}$-freien Stoffen (Fett, Kohlehydrate) reicher Nahrung zum $\mathrm{N}$ - und Körpergleichgewicht, so bedarf es dazu ausnahmlos grösserer Nährstoffmengen als bei einer Kost von mittlerem Eiweissgehalt ( $3-5 \mathrm{~g}$ Eiweiss pro $\mathrm{kg}$ ), und zwar muss der Inhalt an potentieller Energie bei wenig Eiweiss mindestens um 24 pCt. (II) ${ }^{1}$ ), höchstens um 39 (IV) bis 41 pCt. (I) höher sein als bei einer Nahrung mit mittlerem Eiweissgehalt ${ }^{2}$ ). Auch bei dieser ausserordentlichen Höhe des calorischen Werthes der Nahrung darf für einen Hund von $10 \mathrm{~kg}$ die Tagesgabe an Eiweiss nicht unter $1,8-2 \mathrm{~g}$ pro $\mathrm{kg}$ heruntergehen, wenn überhaupt das $\mathbf{N}$ - und Körpergleichgewicht gewahrt werden soll (IV). Solch' eine eiweissarme Kost mit einem Nährstoffverhältniss von $1: 12$

1) Der Kürze halber werden beim Verweisen auf die vorstehenden 4 Versuchsreihen dieselben als I, II, IIT, IV bezeichnet.

2) Vergl. hierüber anch die Zusammenstellung analoger Erfahrungen (S. 100) beim Menschen. 
bis 15, wie es sonst nur das Futter der grossen Pflanzenfresser darbietet und an dessen Wärmewerth das Eiweiss nur mit 8 bis 6,3 pCt. betheiligt ist, wird im Darm des Hundes auffallend gut verwerthet, insofern von der Trockensubstanz nur 4-6 pCt., vom Fett (bei $4-6 \mathrm{~g}$ pro $\mathrm{kg}$ ) nur 1,7 (III), 1,8 (II), 1,9 (IV), böchstens 3,2 pCt. (I), von den Kohlehydraten, sogar bei $10 \mathrm{~g}$ pro kg, nur Spuren unbenützt mit dem Koth ausgestossen werden. Bei einer solchen Nahrung kann durch viele Wochen bindurch ein so niedriger Eiweissumsatz, entsprechend 2-2,2 $\mathrm{g} \mathrm{N}=13 \mathrm{~g}$ Eiweiss, bestehen, der noch unter dem Eiweissumsatz der späteren Hungertage steht.

Allein eine so eiweissarme, an N-freien Stoffen überreichliche Kost vermag, auch wenn sie zweckmässig aus Fleisch, Schmalz und Reiss zusammengesetzt, möglichst gut zubereitet wird und endlich auch einen entsprechenden Zusatz von Aschebestandtheilen erhält, auf die Dauer den Appetit nicht rege za halten; von der 8. (II, III) oder 9. Woche (I) ab wird zunächst die Aufnahme des Tagesfutters auf einmal verweigert. Zumeist hilft hier noch eine Theilung des Tagesfutters in zwei, mit einem Intervall von 6-8 Stunden gereichten Portionen, event. eine Dreitheilung des Kostmaasses; allein bald früher, bald später tritt absolute Verweigerung der Aufnahme solchen Futters, oder, bald nur über einen, bald über mehrere Tage sich erstreckend, Erbrechen im directen Anschluss an die Futteraufnahme, zuweilen auch bei nüchternem Magen (II) auf. Während unter diesen Verhältnissen alle kohlehydrat- und fettreichen Nahrungscombinationen verschmäht werden, gelingt höchstens die Beibringung von reinem Fleisch, mit Wasser abgekocht, event, mit Zusatz von etwas Fett. Unter diesem Fleisch- bezw. Fleischfettfutter kann sich der Hund, je nach seinem Körper- und Kräftezustand, schon innerhalb 2 Tagen (III) erholen, bald dauert es $5-7$ Tage (I, II), bis die Folgen der eiweissarmen Fütterung im Wesentlichen überwunden sind. Volle Erholung und restitutio ad integrum erfolgt erst, wenn mindestens noch eine Woche lang eine eiweissreiche Kost gegeben wird ${ }^{1}$ ).

1) Vergl. auch die oben (S. 118) citirte analoge Frfahrung von Zuntz beim Hunde. 
Der Kräfteverfall wird erkenubar, noch ehe der Appetit und die Nahrungsaufnahme Noth leiden. Als wesentliche Ursache dafür stellt sich die bemerkenswerthe Thatsache heraus, dass mit der Dauer der eiweissarmen Nahrung die Ausnützung der Nährstoffe im Darm, die Anfangs sehr gut oder geradezu vorzüglich gewesen war (S.122, 129, 135), sich progressiv verschlechtert, und zwar frühestens mit der 6 . Woche beginnend (I, III), zuweilen erst in der 8. Woche nachweisbar (II). Diese Schädigung in der Ausnützung des Futters im Darm trifft am stärksten das Fett, noch beträchtlich das Eiweiss, am wenigsten die Kohlehydrate. Der Grad dieser Herabsetzung der Resorptionsgrösse schwankt bei den verschiedenen Individuen, insbesondere in Bezug auf die Verwerthung der Fette, innerhalb weiter Grenzen, während die unbenützte Ausstossung des Nahrungseiweiss (im Verein mit reichlicherer Abstossung seitens der Darmschleimhaut) einen ziemlich constanten Werth erreicht, der in maximo $\frac{4}{5}$ bis doppelt so gross wird, als er in den ersten Versuchswochen gewesen. Der mit dem Koth ausgestossene Antheil des Nahrungsfettes stieg von $1,7 \mathrm{pCt}$. in der 4 . Woche (III) auf 3,2 pCt. in der 6., auf 8,7 pCt. in der 10 . Woche; in einem anderen Falle (II) von 1,8 pCt. noch in der 5 . Woche auf $8,5 \mathrm{pCt}$. in der 8 . und 9 . Woche; endlich am stärksten (I) von 3,2 pCt. in der 5 . Woche auf 4,9 pCt. in der 6 , auf 15,5 pCt. in der 7. und auf $28 \mathrm{pCt}$. in der 10. und 11. Woche! Die verdaulichen Kohlehydrate, welche Anfangs bis auf Spuren verwerthet worden sind, nahmen an dieser Verschlechterung kaum Theil oder für gewöhnlich so wenig, dass selbst bei ungünstiger Fettausnützung nur $\frac{1}{2} \mathrm{pCt}$. der gefütterten Kohlehydrate sich im Koth fanden; nur in einem Falle (I), in dem zugleich die Schädigung der Fettresorption am stärksten ausgeprägt war, sind in der 9.-11. Woche 2,1 pCt. Kohlehydrate unbenützt im Koth wieder erschienen.

Indem nun so weniger Eiweiss und weniger Fett in die Säftemasse übertraten, konnte das vorher bestandene $\mathrm{N}$ - und Körpergleichgewicht nicht gewahrt bleiben. Es begann nun eine N-Einbusse seitens des Körpers und eine langsam steigende Gewichtsabnahme. Durch diese N- und z. Th. auch FettverIuste seitens des Körpers erklärt sich der im Verhältniss zur Grösse 
dieser Einbussen stehende Kräfteverfall und musste schliesslich bedrohlich werden, wenn durch Sinken des Appetites die Nahrungsaufnahme und Nährstoffresorption noch mehr Noth litt und zuletzt ganz sistirte.

Die Schädigung der Verdauung und Resorption ist, von einer Nutritionsstörung der bei der Stoffaufsaugung activ betheiligten Epithelzellen des Dünndarms abgesehen, wohl zumeist auf eine Abnahme der Secretion der Verdauungssäfte zurückzuführen, welche sich für einen Saft, die Galle, ziffermässig nachweisen liess. Der Antheil der Gallenstoffe an den durch den Koth austretenden Substanzen ging auf $\frac{1}{2}-\frac{1}{3}$ der ursprünglichen Grösse herunter; Hand in Hand damit nahm auch der Koth eine mehr graugelbe, zuletzt fast rein graue, fast acholische Farbe an. Es ist höchst wahrscheinlich, dass in gleicher Weise auch die Abscheidung der anderen Verdauungssäfte geschädigt wird, nur dass sich dies nicht streng beweisen lässt. Die eiweissarme Nahrung bietet offenbar zu wenig Eiweiss zum stetigen Wiederauf bau des bei der Secretion z. Th. zerfallenden, bezw. in das Secret übergehenden Protoplasmas der Drïsenzellen, daher auch die Bildung der verdauungstïchtigen Secrete mit der Zeit immer mehr abnehmen muss.

Es ist von Interesse, dass diese Ergebnisse am Hunde eine frappante Aehnlichkeit zeigen mit denjenigen, die E. Wolff ${ }^{1}$ ) an den omnivoren Schweinen gewonnen hat. Wolff fand nehmlich, dass, wenn bei Fütterung mit Schrot und Stärkemehl das Nährstoffverhältniss ein ähnlich weites wurde, wie in vorstehenden Versuchen am Hunde, nehmlich $1: 12$, die Ausnützung des Fettes mit der Zeit immer schlechter wurde, ebenso die des Eiweiss, dagegen wurden auch dann noch die verdaulichen Kohlehydrate vorzüglich verwerthet.

Rückblick auf den Eiweissbedarf des Menschen.

Durch die Beobachtung und die Erfahrung ist festgestellt worden, dass für den Menschen eine gemischte, theils dem Thierreich, theils dem Pflanzenreich entlehnte Kost am geeignetsten ist, welche - neben den nöthigen Salzen (Aschebestandtheilen), Würz- und Genussstoffen - Eiweiss, Kohlehydrate und Fette

1) Die Ernährung der landwirthschaftlichen Nutzthiero. 1876. S. $145 \mathrm{ff}$. 
bietet. Bezüglich der absoluten Mengen der letztgenannten 3 organischen Nährstoffgruppen hat man theils durch den Versuch ${ }^{1}$ ), theils durch die statistische Ermittelung des Nährstoffverbrauches in öffentlichen Anstalten (Kasernen, Pflegeanstalten u. A.), endlich durch die Untersuchung der freigewählten Kost bei Individuen, welche dabei ihren Körperbestand wahrten, in's Reine zu kommen gesucht. Auf Grund directer Bestimmungen und statistischer Berechnungen hat $\mathrm{C}$. Voit geglaubt, als Kostmaass fordern zu müssen für den erwachsenen Mann von rund $70 \mathrm{~kg}$ Gewicht bei leichter Arbeit $118 \mathrm{~g}$ Eiweiss, $56 \mathrm{~g}$ Fett, $400 \mathrm{~g}$ Kohlehydrate - mässiger ${ }^{2}$ ) - - - - - $\quad$ - 500

Gegen die Höhe der von Voit aufgestellten Norm ist, insbesondere in Bezug auf das Eiweiss, wiederholt begründeter Einspruch erhoben worden. Da die Kohlehydrate und Fette der Nahrung einen eiweisssparenden Einfluss ausüben, insofern durch ihre Zerstörung im Körper der Eiweissumsatz seiner Intensität nach beschränkt wird, kann die Frage nach dem Eiweissbedarf nur unter gleichzeitiger Berücksichtigung der daneben gereichten $\mathrm{N}$-freien Stoffe erörtert werden. Vom Fett und von den Kohlehydraten muss so viel eingeführt werden, als erforderlich ist, um den Kohlenstoff- oder Fettverlust vom Körper zu verhüten, weil, wenn dies nicht geschiebt, jedesmal zugleich mit dem Fettverlust auch der Eiweissumsatz eine Steigerung erfährt. Der C-Bedarf des Menschen wird dureh die obigen Kostsätze von Voit zum Mindesten genügend gedeckt. Andererseits liegen bereits eine Reihe von Erfahrungen vor, denen zu Folge bei genügender Menge $\mathrm{N}$-freier Stoffe die tägliche Eiweissration kleiner sein kann, als die Voit'sche Norm. So konnte J. Ranke ${ }^{3}$ )

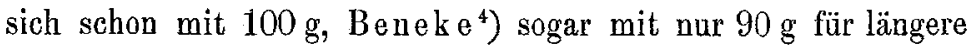
Zeit, bis zu 14 Tagen in's N-Gleichgewicht setzen. Auch hatten Pflüger und Bohland ${ }^{5}$ ) bei 8, nur leichte Arbeit ver-

1) wobei diejenige Nährstoffmischung genau ermittelt wird, bei welcher ein erwachsener Mann im N-, G- und Körpergleichgewicht verharrt.

2) nicht zu leichte, aber auch nicht übermässig angestrengte, sogenannte „mittlere" Arbeit.

3) Arch. f. Anat. u. Physiol. 1862. S. 311.

4) Schriften d. Marburg. naturwiss. Gesellsch. Bd. 11. S. 277.

5) Pflüger's Arch. Bd. 36. S. 165.

Archiv f. pathol. Anat. Bd.132. Hft. 1. 
richtenden jungen Menschen, welehe ihre Nahrung nach Belieben wählten, nur einen täglichen Umsatz von rund $90 \mathrm{~g}$ Eiweiss, durch die Grösse des Harn- $N$ gemessen, gefunden. Auch die Fortsetzung dieser Untersuchungen durch Bohland und Bleibtre $\mathbf{u}^{1}$ ) an 6 jungen und kräftigen Individuen hat für mittlere Arbeit einen Eiweissumsatz von $93 \mathrm{~g}$ und nur bei schwerer, angestrengter Arbeit einen solchen von $107 \mathrm{~g}$ ergeben. Endlich hat Uffelmann ${ }^{2}$ ) auf Grund von Beobachtungen und Erfahrungen wiederholentlich sich dahin geäussert, dass die Voit'sche Eiweissnorm als Mittelzahl entschieden zu hoch ist. Nach alledem dürfte, so schloss ich eine zusammenfassende Besprechung ${ }^{3}$ ), "eine Zufuhr von $100 \mathrm{~g}$ Eiweiss bei mittlerer Arbeit (und von $115 \mathrm{~g}$ bei angestrengter Arbeit) genügen, um einen kräftigen Mann von etwa $70 \mathrm{~kg}$ auf seinem Eiweissbestande zu erhalten“. Darauf hin wurde ich, nebst anderen Vertretern der etwas herabzusetzenden Eiweissration, von C. Voit ${ }^{4}$ ) apostrophirt, ob wir es wohl vertreten könnten, wenn den armen Gefangenen, denen auf seine (Voit's) Bemühungen hin endlich nach langem Kampf die höhere Eiweissration bewilligt wäre, das Nahrungseiweiss gekürzt würde? Ohne Voit's von mir stets anerkannten Competenz in Fragen des Stoffverbrauches und der Ernährung irgend wie zu. nahe treten za wollen, glaube ich von solchen sentimentalen Anwandlungen bei Erörterung rein wissenschaftlicher Fragen besser frei bleiben zu sollen. Im Uebrigen vertrete ich aus wissenschaftlicher Ueberzeugung und auf Grund der Erfahrungen der Ernährungspraxis die Herabsetzung der Eiweissration auf $100 \mathrm{~g}$ "auch für die armen Gefangenen“, vorausgesetzt, dass ihre Kost nicht ein Uebermaass von Kohlehydraten und dafür mehr Fettals bisher bietet, besser gewürzt und gekocht wird, als das gewöhnlich der Fall ist, und nicht das ewige Einerlei der breiigen Consistenz darbietet.

Aber auch aus dem eigenen Lager heraus hat die Voit'sche Eiweissnorm gewichtige Angriffe erfahren. Unter Fr. Hof-

1) Pflüg ger's Archiv. Bd. 38. S. 1.

2) in dem von ihm bearbeiteten "Jahresbericht über die Fortschritte und Leistungen auf dem Gebiete der Bygiene" für 1883-1888.

3) I. M u k , Deutsche med. Wochenschr. 1888. No. 5 .

4) Zeitschr. f. Biol. Bd. 25 . S. $232 \mathrm{ff}$. 
mann's Leitung hat Nakahama ${ }^{1}$ ) den Eiweissumsatz von 13 arbeitenden Individuen zu 65-113, im Mittel zu $85 \mathrm{~g}$ ermittelt, und zwar, um nur einige charakteristische Werthe herauszugreifen, bei einem Klempner von $78 \mathrm{~kg}$ einen Umsatz von $83 \mathrm{~g}$, bei einem täglich 12 Stunden lang angestrengt arbeitenden Erdbohrer von $68 \mathrm{~kg}$ sogar nur von $68 \mathrm{~g}$. Unter Uffelmann's Leitung hat $\mathrm{H}_{0 \mathrm{ch}}{ }^{2}$ ) in der Tagesration eines sehr thätigen Steinhauers von $86 \mathrm{~kg}$ im Durchschnitt nur $93 \mathrm{~g}$ Eiweiss, in der eines Schuhmachers $98 \mathrm{~g}$ Eiweiss ermittelt. Nunmehr sah sich Voit ${ }^{3}$ ) selbst gedrängt, zuzugeben, dass seine Norm, $118 \mathrm{~g}$ Eiweiss, nur für kräftige, stark arbeitende Individuen berechnet sei, dass weniger kräftige, zumal solche von geringerem Körpergewicht mit einem kleineren Eiweissquantum auskommen können.

Inzwischen hatte man auch auf experimentellem Wege versucht, der Frage nach dem Minimum des Eiweissbedarfes näher zu treten. F. Hirschfeld ${ }^{4}$ ) hatte aus Selbstversuchen, welche er eine bis mehrere Wochen durchführte, erschlossen, dass er bei sehr reichlichem Genuss von N-freien Stoffen schon bei Zufuhr von nur $39 \mathrm{~g}$ Eiweiss auf N-Gleichgewicht bleiben kann. Ich ${ }^{5}$ ) habe die Verdienstlichkeit seines Versuches anerkannt, zugleich aber hervorgehohen, dass hierbei Alles auf den Nachweis ankommt, dass das $\mathrm{N}$ - und Körpergleichgewicht thatsächlich gewahrt bleibt, wozu nicht nur die Kenntniss der N-Ausscheidung durch Harn und Koth, sondern auch die genaue Feststellung der Grösse der N-Einfuhr mit der Nahrung erforderlich ist. Letztere war aber in jenen Versuchen mit der Unsicherheit behaftet, dass der NGehalt der Nahrung nicht direct bestimmt, sondern nur nach Durchschnittstabellen berechnet war, während es doch bekannt ist, dass der thatsächliche Gehalt an Eiweiss schwankt so z. B. für Reiss zwischen 6,3-7,7 pCt., beim Weissbrod zwischen 7 and 8,1 pCt., bei den Kartoffeln zwischen 1 und 2 pCt. Eiweiss, so dass die wirkliche Aufnahme an Eiweiss bald grösser bald kleiner sein kann als der Rechnung zu Folge. Hirsch-

1) Arch. f. Hygiene. Bd. 8. S. 98.

2) Dissert. Rostock 1888.

3) Zeitschr. f. Biol. Bd. 25. S. 232.

4) Pflüger's Arch. Bd. 41. S. 533.

5) Centralbl. f. d. med. Wissensch. 1888. S. 358 u. 359 . 
feld ${ }^{\text {) }}$ hat, wohl von der Berechtigung dieser Einwände überzeugt, in E. Salkowski's Laboratorium den Selbstversuch wiederholt und durch die $\mathrm{N}$-Analyse der Nahrung auf eine einwurfsfreiere Grundlage gestellt. Von allen seinen neueren Versuchsreihen war für die vorliegende Frage nur eine einzige beweiskräftig, in welcher Hirschfeld, 24 Jahre alt, $73 \mathrm{~kg}$ schwer, fettarm, aber musculös, in Kartoffeln, Semmeln, Eiern, Zucker, Bier und Wein, im Mittel von 8 Tagen nur $43,5 \mathrm{~g} \mathrm{~N}$-haltige Stoffe (mit 7,2 bis $7,8 \mathrm{~g} \mathrm{~N}), 165 \mathrm{~g}$ Fett, $354 \mathrm{~g}$ Kohlehydrate und $43 \mathrm{~g}$ Alkohol zu sich nahm und dabei durch Harn und Koth noch etwas weniger als 7,2 bis $7,8 \mathrm{~g} N$ ausschied, so dass bei rund $43,5 \mathrm{~g}$ Eiweiss erst in den letzten beiden Tagen N-Gleichgewicht bestand, dagegen sank das Körpergewicht täglich um $50 \mathrm{~g}$. Ebenfalls unter Salkowski's Leitung hat Kumagawa ${ }^{2}$ ), nur $48 \mathrm{~kg}$ schwer (!), fettarm, Selbstversuche ausgeführt. In einer 9 tägigen Versuchsreihe mit rein vegetabilischer Kost (täglich $600 \mathrm{~g}$ Reiss, ferner Kohlrüben, Zucker u. A. nebst Thee und Bier) wurden täglich $55 \mathrm{~g}$ Eiweiss (mit $8,8 \mathrm{~g} \mathrm{~N}$ ), $3 \mathrm{~g}$ Fett und $570 \mathrm{~g}$ Kohlehydrate genossen. Von den $42 \mathrm{~g}$ Eiweiss, die aus der Nahrung resorbirt wurden, gelangten sogar noch $4 \mathrm{~g}$ zum Ansatz, so dass der tägliche Umsatz nur $38 \mathrm{~g}$ Eiweiss betrug. Nunmehr glaubte Hirschfeld ${ }^{3}$ ) in einer rein kritischen Studie den Satz aufstellen zu können, es wäre nur erforderlich, dem Körper eine solche Menge von Nährstoffen zuzuführen, welche einen den Bedarf deckenden Wärmewerth liefern; ist dies durch Darreichung grosser Mengen N-freier Stoffe der Fall, so könne man mit der Eiweissration, laut Zeugniss seiner (Hirschfeld's) Versuche, bis auf $50 \mathrm{~g}$ heruntergehen, wohl auch für die Dauer; wenigstens hat Hirschfeld in seinen, 1887-89 erschienenen Veröffentlichungen keine, die zeitliche Dauer einer so niedrigen Eiweisszufuhr einschränkende Bemerkung gemacht. Diesen Schluss habe ich wiederholentlich beanstandet ${ }^{4}$ ): einmal wäre erst zu

1) Dieses Archiv. Bd. 114, S. 350 .

2) Dieses Archiv. Bd.116. S. 370.

3) Pflüger's Arch. Bd. 44. S. 248.

$\left.{ }^{4}\right)$ I. Munk, Centralbl. f. d. med. Wiss. 1889. S. 837. - VirchowHirsch's Jahresber. für 1889. I. S. 162. - I. Munk und Uffelmann. Ernährung des gesunden und kranken Menschen. 2. Aufl. 1891. S. 49. 
ermitteln, ob dieses physiologische Bedarfsminimum mit dem hygienisch-vortheilhaften zusammenfalle, wofür die Erfahrung nicht zu sprechen scheine, zweitens sei durch einen einzigen Selbstversuch von Hirschfeld nur bewiesen, dass für eine kurze Zeit (2-8 Tage) bei einer Eiweissration von $40-50 \mathrm{~g}$ der Erwachsene auf N-Gleichgewicht bleiben könne. Daraus folge aber keineswegs, dass der Körper, auch für die Dauer mit einer so geringen Eiweissration auskommen könne, um so weniger, als es doch bekannt sei, dass der Körper, Dank einem ihm innewohnenden umfangreichen Anpassungsvermögen, sich, für eine Zeit lang wenigstens, mit den verschiedensten Mengen der einzelnen Nährstoffe in's Gleichgewicht setzen könne. Ob aber für die Dauer, das wäre erst durch neue, viele Wochen lang fortgesetzte Versuchsreihen zu erweisen. Weiter führte ich aus, wären die zur vorübergehenden Erhaltung von N- und Körpergleichgewicht erforderlichen Nährstoffmengen bei niedriger Eiweissration in summa erheblicher grösser, als bei einer Nahrung von mittlerem Eiweissgehalt, ein Moment, das ich gelegentlich der oben dargestellten 4 Versuchsreihen am Hunde wiederholt hervorgehoben und durch, wie mir scheint, stringente Erfahrungen belegt habe; ferner habe ich es höchst wahrscheinlich machen können, dass dasselbe auch für den Menschen zutrifft (S. 100). Wenn man daher, wie allgemein üblich, unter einer zweckmässigen Nahrung dasjenige Gemisch an Nährstoffen versteht, bei dem sich das Gleichgewicht zwischen stofflicher Aufnahme und Verbrauch mittelst der geringsten Menge von Nährs to ffen decken lässt, so wäre schon aus dem zuletzt angeführten Grunde die eiweissarme Kost als eine zweckmässige nicht zu erachten, selbst wenn sich beweisen liesse, was bislang nicht der Fall ist, dass man auch für die Dauer damit im Gleichgewicht bleiben kann. Endlich bliebe noch darzuthun, dass eine solche eiweissarme Nahrung weder die Leistungsfähigkeit des Körpers noch dessen Widerstandsfähigkeit gegen krankmachende Einflüsse beeinträchtigt. Uebrigens spreche $\mathrm{Kuma-}$ gawa's Versuch nicht für einen niedrigen Eiweissbedarf; denn wenn für diesen, nur $48 \mathrm{~kg}$ schweren Mann 55 bezw. $51 \mathrm{~g} \mathrm{Nah-}$ rungseiweiss genügten, so würde sich daraus für einen $70 \mathrm{~kg}$ schweren Mann 80 bezw. $77 \mathrm{~g}$ Eiweiss berechnen, oder unter 


\section{0}

Berücksichtigung der Thatsache, dass kleinere Individuen einen relativ höheren Eiweissverbrauch haben, als grössere, würde die daraus abzuleitende Eiweissration für den Erwachsenen von $70 \mathrm{~kg}$ auf mindestens $70 \mathrm{~g} \mathrm{zu}$ bemessen sein.

Von diesen eben dargelegten Einwänden ist bisher kein einziger beweiskräftig widerlegt worden. Nur wurde für die Unschädlichkeit einer eiweissarmen, aber kohlehydratreichen Nahrung von verschiedenen Seiten, neuerdings wiederum von Hirschfeld ${ }^{1}$ ), auf die ostasiatischen Völkerstämme exemplificirt, welche, wie die Japaner und die Chinesen, sich fast ausschliesslich von dem eiweissarmen Reiss nähren „animale Kost nur sehr selten geniessen". So allgemein gefasste Behauptungen können nur auf den Unkundigen den Eindruck eines Beweises machen, vielmehr k o m $\mathrm{mt}$ hier Alles auf die Mengen der Nahrung an, die genossen werden, und daräber schweigen sich die Verfechter der niedrigen Eiweissnorm beharrlich aus. Und doch liegen die zuverlässigsten Zeugnisse darüber vor, denen zu Folge selbst bei diesen, hauptsächlich von eiweissarmen Vegetabilien lebenden Volksstämmen die tägliche Eiweissration durchaus nicht klein ist. Solche Berichte liegen vor theils von deutschen Aerzten and Forschern, welche in Japan längere Zeit gelebt und gelehrt haben, theils von Japanern selbst, welche, an deutschen Hochschulen für wissenschaftliche Untersuchungen ausgebildet, die Kost der erwachsenen Japaner gerade in Rücksicht auf deren Gehalt an Nährstoffen und deren vermeintliche niedrige Eiweissration wiederholt geprüft haben. So hat Rintaro Mori ${ }^{2}$ ) in der aus Reiss, Zubereitungen der Sojabohne (Miso, Shoja) und etwas frischen oder getrockneten Fischen bestehenden Nahrung der niponischen Soldaten $80-90 \mathrm{~g}$ Eiweiss, $6-18 \mathrm{~g}$ Fett und $334-622 \mathrm{~g}$ Kohlehydrate ermittelt; er bemerkt dazu treffend, dass, da der Japaner im Durchschnitt ein um $\frac{1}{5}$ geringeres Körpergewicht besitzt als der Europäer, dies Kostmaass auch als völlig ausreichend zu erachten ist. Ejkmann ${ }^{3}$ ) fand in der Kost der Militärzöglinge in Tokio $83 \mathrm{~g}$ Eiweiss, $14 \mathrm{~g}$ - Fett und

1) Berl. klin. Wochenschr. 1891. No. 26. - Grundzüge der Krankenernäbrung. Berlin 1892. S. 49.

2) Arch. f. Hygiene. Bd. 5. S. 333 .

3) Bei Nakahama, Arch. f. Hygiene. Bd. 8, S. 78. 
$622 \mathrm{~g}$ Kohlehydrate; vom Eiweiss wurden $\frac{3}{5}$ in Form von Reiss aufgenommen. Scheube ${ }^{1}$ ) hat die Kost 3 Japaner zu $90 \mathrm{~g} \mathrm{Ei-}$ weiss, $12 \mathrm{~g}$ Fett und $552 \mathrm{~g}$. Kohlehydrate ermittelt. Ferner führen Kellner und $\mathrm{Y}$. Mori ${ }^{2}$ ) an, dass selbst die ärmste Klasse der Japaner, welche nur Reiss, Sojabohnen, Gerste, Kartoffeln, Rettig und grüne Gemüse geniessen, darin bis zu $750 \mathrm{~g}$ Trockensubstanz pro Tag aufnehmen und zwar bis zu $100 \mathrm{~g}$ Eiweiss (davon nach Mori's Selbstversuch $77 \mathrm{~g}$ resorbirbar), $17 \mathrm{~g}$ Fett, $570 \mathrm{~g}$ Kohlehydrate. Die Nahrung der weniger armen, auch Fische geniessenden Volksklasse enthält nach denselben Autoren sogar $109 \mathrm{~g}$ Eiweiss, $20 \mathrm{~g}$ Fett und $460 \mathrm{~g}$ Kohlehydrate. Und dabei sind die Japaner, was immer zu berücksichtigen ist, kleine und nur $42-58 \mathrm{~kg}$ schwere Leute! Nach Wernich ${ }^{3}$ ), der mehrere Jahre in Japan gelebt hat, nehmen die armen Japaner, welche zumeist von dürftigem Wuchs, geringem Brustumfang und schwacher Musculatur sind, als Kost in Wasser gequollenen Reiss auf, nur von Zeit zu Zeit mit einem Bissen Fleisch und in Salz präservirtem Gemüse, und zwar für je eine der drei Mahlzeiten $470 \mathrm{~g}$ Reiss, so dass sie mit rund $1400 \mathrm{~g}$ Reiss pro Tag $84 \mathrm{~g}$ Eiweiss und $1070 \mathrm{~g}$ Kohlehydrate geniessen.

Endlich ist so eben die neueste Untersuchung über die Kost der japanischen Soldaten von R. Mori, G. Oi und S. Ihisima ${ }^{4}$ ) veröffentlicht worden, der za Folge die Truppenreisskost nach genauer Bestimmung der von 6 Individuen (23-24 Jahre alt und im Mittel 58,2 kg schwer) an je 8 Tagen aufgenommenen, zubereiteten Nahrung pro Kopf $85 \mathrm{~g}$ Eiweiss (davon $71 \mathrm{~g}$ ausgenützt), $534 \mathrm{~g}$ Kohlehydrate und $15 \mathrm{~g}$ Fett bot; die Nahrung enthielt ausser Reiss auch andere pflanzliche Nahrungsmittel und Fische, zuweilen etwas Rindfleisch. Demnach müssen wir alle Angaben von einer sehr geringen Eiweissaufnahme

1) Bei Nakahama, Arch. f. Hyg. Bd. 8. S. 78.

2) Zeitschr. f. Biol. Bd. 25. S. 102.

3) Geographisch-medicinische Studien nach den Erlebnissen einer Reise um die Erde. 1878.

4) Arbeiten aus der K. jap. Militärärztlichen Lehranstalt. I. 1892. S. 1. Verff. haben auch die sog. Reissgerstenkost untersucht, die nur $78 \mathrm{~g}$ Eiweiss, $13 \mathrm{~g}$ Fett und $460 \mathrm{~g}$ Kohlehydrate liefert, bei der indess die 6 Versuchssoldaten nicht ihr N-Gleichgewicht behaupten konnten, vielmehr pro Tag 1,5 $\mathrm{g} \mathrm{N}=9,5 \mathrm{~g}$ Eiweiss (44 g Körperfleisch) einbüssten, 
der ostasiatischen Völkerstämme, welche hauptsächlich von eiweissarmen Vegetabilien leben, als unbegründet und irrthümlich zurückweisen.

Auf Grund dieses gesammten thatsächlichen Materials äusserte ich mich schon vor 2 Jahren über die Eiweissnorm folgendermaassen ${ }^{1}$ ): „Demgemäss erscheint es vollauf begründet, die Eiweissration des Erwachsenen von mittlerem Gewicht (70 kg) und bei mässiger Arbeit bis auf $100 \mathrm{~g}$ herabzusetzen; dass diese Ration für die Dauer genügt, ist durch die Erfahrung sichergestellt. Andererseits ist es noch nicht bewiesen, dass ein Erwachsener auf die Dauer mit 50-80g Eiweiss pro Tag ausreicht. Die bisherigen Versuche zeigen nur, dass der Körper eine kurze Zeit lang sich auch bei eíner so geringen Eiweisszufuhr auf dem stofflichen Gleichgewicht erhalten kann, nicht aber, dass die Gesundheit und Widerstandsfähigkeit sowie die Leistungsfähigkeit bei steter Zufuhr so geringer Eiweissmengen keinen Schaden leiden."

Wer diese Sätze erschüttern will, muss dagegen Thatsachen vorbringen, davon ist aber bei Keinem unter den Vertretern der niedrigen Eiweissnorm das Mindeste zu entdecken. Somit wird es bis auf Weiteres bei einem Satze von rund $100 \mathrm{~g} \mathrm{Ei}$. weiss sein Bewenden haben.

Seitdem ich diese Sätze formulirt habe, sind kurz nach einander zwei Mittheilungen erschienen, welche, allerdings nur auf den ersten Blick, dazu angethan scheinen, die von mir aufgestellte, mittlere Eiweissnorm zu erschüttern. Tsuboi und Murata ${ }^{2}$ ) haben die Kost der Studirenden an der Universität Tokio und zugleich den dabei stattfindenden N-Umsatz untersucht. Die allerdings über nur 3 Tage sich erstreckenden Versuche, betreffen Individuen von $40,1,41,3,50,8 \mathrm{~kg}$, deren analysirte Kost 53,5 bezw. 50,8 bezw. 57,8 g N-haltige Substanz (neben 19-22 $\mathrm{g}$ Fett und $440-495 \mathrm{~g}$ Kohlehydrate) enthielt; vom gereichten $\mathrm{N}$ wurden, nach Maassgabe der $\mathrm{N}$-Ausstossung durch den Koth, $80-90$ pCt. resorbirt. Dabei befanden sich

i) I. Munk und Uffelmann, Ernährung. 2. Aufl. 1891. S. 205. -- Was oben ausfübrlich erörtert ist, konnte in unserem Handbuch nur in knappen, auf das Thatsächliche beschränkten Zügen angedeutet werden.

2) Mitheil. aus d. med. Facultat d. k. Japan. Universität. 1891. I. S. 359. 
alle 3 Individuen annähernd oder vollständig in N-Gleichgewicht. Wenn auch die Kost nur an 3 Tagen analysirt worden ist, so war es doch die gewöhnliche, in der Anstalt (die japanischen Studirenden sind kasernirt) übliche Kost, und wenn nicht Zufälligkeiten im Spiele waren, welche gerade an den Versuchstagen den N-Gehalt der Kost unter das gewöhnliche Maass hatten sinken lassen, würde sich daraus ergeben, dass ein Eiweissgehalt der Nahrung von $51-58 \mathrm{~g}$ für die betreffenden Individuen auch für die Dauer dem Bedarf genügen könne. Allein dabei ist eben wiederum zu beachten, dass die Versuchspersonen, entsprechend dem allgemeinen Habitus der Japaner, von geringer Körpergrösse und nur $40-51 \mathrm{~kg}$ schwer waren. Rechnet man die Eiweissration auf Menschen von dem bei uns gewöhnlichen Körpergewicht um, so würde dieselbe für Erwachsene von $70 \mathrm{~kg}$ einem Werth von $80-93 \mathrm{~g}$ entsprechen. Darnit fügt sich auch diese Beobachtung in den Rahmen unserer Eiweissnorm.

Sodann hat Breisacher ${ }^{1}$ ), $52 \mathrm{~kg}$ schwer, 33 Tage lang eine gemischte Kost zu sich genommen, die nach der Berechnung (der N-Gehalt der Nahrungsmittel ist nicht bestimmt) $68 \mathrm{~g} \mathrm{Ei}$ weiss (neben $60 \mathrm{~g}$. Fett und $494 \mathrm{~g}$ Kohlhydrate) enthielt, ohne dass während dieser $4 \frac{1}{2}$ Wochen sein Körpergewicht sich wesentlich änderte. Die N-Ausscheidung durch den Harn betrug, vom 4. Tage ab bestimmt, in den ersten 10 Tagen im Mittel 8,6 , in den folgenden 10 Tagen 7,7, in den letzten 10 Tagen $8,4 \mathrm{~g}$. Leider ist die $\mathrm{N}$ - und Fettausstossung durch den Koth nicht bestimmt, daher auch nicht zu sagen ist, ob die Verwerthung der Nährstoffe bis zum Schluss des Versuches eine gute geblieben ist. Von den der Berechnung nach eingeführten $68 \mathrm{~g} \mathrm{Ei-}$ weiss wurden, nach Maassgabe der N-Ausfuhr durch den Harn, $52 \mathrm{~g}$ im Körper umgesetzt. Da Breisacher mit $68 \mathrm{~g}$ Eiweiss 30 Tage ausgekommen ist, hält er diese Menge für seinen Körper auch für die Dauer ausreichend. Aber er selbst leitet daraus $a b$, dass für den Durchschnittsmenschen von $70 \mathrm{~kg}$ erst 87 bis $88 \mathrm{~g}$ Eiweiss dem Bedarf genügen würden, selbstverständlich neben ausreichenden Mengen $\mathrm{N}$-freier Nährstoffe. Vorsichtiger und überlegter Weise möchte er selbst zu einer so niedrigen

1) Deutsche med. Wocbenschr. 1891. No. 48, 
Eiweissnorm nicht rathen, meint vielmehr, dass die Versuche an Hunden, von denen zur Zeit seiner Veröffentlichung nur die erste meiner Reihen und Rosenheim's Beobachtung vorgelegen haben, zur Vorsicht bezüglich so geringer Mengen von Nahrungseiweiss mahnen müssen. Diese Vorsicht erscheint um so begründeter, als bei seiner Versuchsreihe in der dritten 10tägigen Periode die zuvor nur $7,7 \mathrm{~g}$ betragende tägliche $\mathrm{N}$-Ausscheidung durch den Harn auf $8,4 \mathrm{~g}$ angestiegen ist und seiner eigenen Angabe nach in der letzten Woche sich Müdigkeitsgefühl eingestellt hat, das mit dem Ansteigen des Harn- $N$ oder wenigstens mit der eiweissarmen Nabrung zusammenbängen könnte. In Analogie meiner Thierversuche liegt es nahe, beide Erscheinungen als die ersten Anzeichen einer in Folge der fortgesetzten eiweissarmen Nahrung sich anbahnenden Störung anzuseben, die wahrscheinlich zunächst gleichfalls zu einer Verschlechterung in der Ausnützung der Nährstoffe im Darm und weiterhin zu weiteren, leichter erkennbaren Symptomen geführt hätte, wäre nicht gerade, als die ersten leichten Störungen auftraten, der Versuch abgebrochen worden.

Allmählich haben denn auch die radicalen Vorkämpfer für die niedrige Eiweissnorm begonnen, Wasser in ihren Wein zu schütten. Während in ihren früheren Darstellungen davon keine Rede gewesen ist, dass die durch ihre Versuche als ausreichend ermittelte niedrige Eiweissration nicht allgemein giltig oder zum Mindesten noch nicht als für die Dauer genügend erwiesen sei, fiuden wir neuerdings bei Hirschfeld ${ }^{1}$ ) "wenigstens ergaben meine Untersuchungen, dass ein kräftiger Mann im Stande jst ohne Schädigung seiner körperlichen Leistungsfähigkeit sich vorübergehend mit weniger Eiweiss zu erhalten". Nach diesem ersten Schritt werden, so lässt sich hoffen, die weiteren Schritte zur Näherung an die von uns vertretene Anschaunng nicht ausbleiben, um so weniger, als Hirschfeld neuestens ${ }^{2}$ ) erst $70 \mathrm{~g}$ Eiweiss als ausreichend hinstell $\mathrm{t}^{3}$ ).

1) Berl. klin. Wochenschr. 1891. No. 26.

2) Grundzüge der Krankenernährung. S. 48, 49.

3) Soeben geht mir noch eine Mittheilung von Demuth "über die bei der Ernäbrung des Menschen nötbige Eiweissmenge“ zu (Münch. med. Wochensehr. 1892. No.43-45). Ferf.'s Beobachtungen aus der Praxis, 
Ist somit durch die Beobachtung beim Menschen und die statistischen Erhebungen des Nährstoffverbrauches erwiesen, dass neben einer gewissen Menge, 60-100 g, Fett und Kohlehydraten, 300-400 g, jeder gesunde, mässig arbeitende Mensch von $70 \mathrm{~kg}$ täglich etwa $100 \mathrm{~g}$ Eiweiss geniesst, so fragt es sich, welchen Functionen die Zersetzung dieser relativ grossen Eiweissmenge dient? $\mathrm{Von}$ den $\mathrm{N}$-freien Stoffen wissen wir, dass sie die wesentlichste Quelle für Wärmebildung und Muskelkraft bilden (auch thermogene und dynamogene Nährstoffe genannt). Die Nothwendigkeit eines Verbrauches von $100 \mathrm{~g}$ Eiweiss ist, wie G. Bunge treffend hervorhebt, nicht verständlich „so lange uns keine Körperfunction bekannt ist, zu deren Verrichtung die chemischen Spannkräfte des zerfallenden Eiweisses verwerthet würden". Es ist nicht entfernt anzunehmen, dass der für das zu Grunde gehende Zelleiweiss erforderliche Bedarf behufs Ersatzes der zerstörten und behufs Wachsthums der zurückgebliebenen zelligen Elemente je einen so hohen Betrag erreichen könnte. Allenfalls dürfte man zum Verständniss für die Nothwendigkeit einer relativ hohen Zufuhr an Nahrungseiweiss gegenüber dem nur einen Bruchtheil davon betragenden thatsächlichen Zugrundegehen von Zelleiweiss sich auf die Erfahrungen berufen, die wir über den Eiweissansatz und über die Verhältnisse der Milchbildung kennen. Ebenso wenig wie ein Ueberschuss von $10 \mathrm{~g}$ Nah-

die sich über 12 Jahre erstrecken, bezweckten die Menge der Nährstoffe und die Mischung derselben bei zahlreichen Individuen in Stadt und Land zu ermitteln und mit dem Ernährungs- und Kräftezustand, dem Allgemeinbefinden und der körperlichen Leistungsfähigkeit der betreffenden Personen zu vergleichen. Ausserdem hat Verf. den Einfluss einer von ibm zusammengesetzten Kost auf Ernährungs- und Kräftezustand festzustellen sich bemüht. Als Resultat seiner Ermittelungen, die, wie wohl kanm zu bemerken nöthig, nicht die Schärfe physiologischer Experimente erreichen können, hebt Verf. herror, dass "jede Nahrung, deren Eiweissgehalt unter $90 \mathrm{~g}$ sinkt, auch wenn sie mehr als genügenden Wärmewerth besitzt, nicht geeignet ist, auf die Dauer Wohlbefinden und Leistungsfähigkeit eines sog. mittleren Arbeiters von $70 \mathrm{~kg}$ zu erbalten". Das Nahrungseiweiss soll nicht unter $1,3 \mathrm{~g}$, das resolbirte Eiweiss nicht unter $1,1 \mathrm{~g}$ pro Körperkg sinken. In der Mehrzahl der Fälle dürfte man gut thun, noch über diese Menge binauszugehen. Diese Thesen laufen im Wesentlichen auf das binaus, was ich schon fast 2 Jahre vor Demuth aufgestellt habe. 
rungseiweiss über den Bedarf wieder $10 \mathrm{~g}$ Eiweiss zum Ansatz am Körper bringt, sondern nur einen Bruchtheil davon, indem mit der grösseren Eiweisszufuhr auch der Eiweissumsatz steigt und somit nur eine bald kleinere, bald etwas grössere Quote des Eiweissüberschusses in der Nahrung für den Eiweissansatz verfügbar bleibt, ebenso wenig wird der Eiweissüberschuss der Nahrung bei dem milchenden Thier für die Zwecke der Milchsecretion verfügbar, sondern nur ein Bruchtheil davon. Analog wird nach Hagemann's ${ }^{1}$ ) Untersuchungen nur ein Bruchtheil des Eiweissüberschusses über den Bedarf während der Schwangerschaft zum Wachsthum des Uterus, zur Organbildung der Föten und zum Wachsthum der Milchdrüsen verwendet und als Organeiweiss angesetzt. Demnach scheint das todte Nahrungseiweiss nur unter einem mehr oder weniger grossen Verluste in lebendiges Zelleiweiss umgesetzt werden zu können. Hierin dürfte die Ursache dafür liegen, dass zum Ersatz für einen täglichen Verlust von, sagen wir, $30 \mathrm{~g}$ Zelleiweiss eine Zufuhr: von $90 \mathrm{~g}$ Nahrungseiweiss erforderlich ist.

Wissen wir somit nichts Sicheres darüber, weshalb sich jeder Mensch in seiner Nahrung rund $100 \mathrm{~g}$ Eiweiss zu verschaffen sucht, so war doch über die Bedeutung der relativ grossen Eiweisszufuhr ein Fingerzeig, za erhoffen, wenn sich feststellen liesse, ob die stetige Zufuhr einer niedrigen Eiweissration bei sonst ausreichender Nahrung nicht schliesslich gewisse Schädlichkeiten oder Störungen herbeiführt, welche bei einem der Norm entsprechenden Eiweissgenuss von $100 \mathrm{~g}$ nicht eintreten. Da nun, wie es scheint, Niemand den heroischen Versuch wagen will, am eigenen Leibe die Folgen Wochen und Monate lang fortgesetzter eiweissarmer Nahrung zu prüfen, so bleibt nur übrig an Thieren die Frage experimentell zur Entscheidung zu bringen. Vier solcher, mit allen Cautelen durchgeführter Versuchsreiben am Hunde sind in dieser Mittheilung beschrieben; sie haben alle zu in qualitativer Hinsicht übereinstimmenden Ergebnissen geführt, die in dem vorhergehenden Abschnitte summarisch zusammengefasst sind (S. 141). Ich brauche wohl nicht darauf hinzuweisen, dass die grundlegenden Versuche auf dem

1) Arch. f. (Anat. u.) Physiol. 1890. S. 577. - Landwirthsch. Jabrbücher. 1891. Heft 1. 
Gebiete des Stoffverbrauches und der Ernährung von Bischoff und C. Voit, später von Voit allein, zum Theil auch im Verein mit v. Pettenk ofer am Hunde durchgeführt worden 'sind und dass die beim Hunde gewonnenen Ergebnisse bei der Fortführung der Versuche am Menschen seitens Voit's und v. Pettenkofer's auch für den Menschen sich haben bestätigen lassen, nur dass in quantitativer Hinsicht sich einige Abweichungen herausgestellt haben. Es würde zu weit führen, hier darauf näher einzugehen. Methodisch und mit vollständiger Beherrschung der Experimentaltechnik ausgeführte Versuchsreihen am Hunde haben für die Lehre des Stoffverbrauches und der Ernährung die Grund. Jagen und den weiterén Ausbau geliefert, und so wird es auch für die Zukunft bleiben. Selbstverständlich ist es höchst wünschenswerth, die beim Hunde gewonnenen Erfahrungen der directen Prüfung am Menschen zu unterziehen; allein man darf dabei nicht vergessen; dass bei der grössten Sorgfalt und Exactheit in der Anordnung, Ausführung und Beobachtung die Versuche am Menschen nie so scharf und gleichmässig ausfallen als beim Hunde. Wenn nun noch, wie in der vorliegenden Frage, aus den Erfahrungen beim Hunde sich das nur allzu berechtigte Bedenken erhebt, es möchte die durch Wochen und Monate fortgesetzte eiweissarme Nahrung auch beim Menschen zu mehr oder minder schweren Schädigungen führen, dann wäre es ein sehr gewagtes Unternehmen, solche Versuche am Menscher anstellen zu wollen. Wenn irgendwo, so gilt für Fragen, wie die hier behandelte, der Grundsatz: fiat experimentum in anima vili! 